\title{
Age estimation in a sub-adult Western Australian population based on the analysis of the pelvic girdle and proximal femur
}

Siobhan Lee Sullivan (BSc, GDipForSci)


Centre for Forensic Anatomical and Biological Sciences

School of Anatomy, Physiology and Human Biology

University of Western Australia

This thesis is presented in fulfillment of the degree of Master of Forensic Science 


\section{Declaration}

I declare that the research presented in this thesis, for the Master of Forensic Science at the University of Western Australia, is my own work. The results of the work have not been submitted for assessment, in full or part, within any other tertiary institute, except where due acknowledgement has been made in the text.

Siobhan Lee Sullivan 


\section{Abstract}

The anthropological assessment of unidentified individual involves the creation of a biological profile. Age estimation is an essential component of the biological profile, thus is required to be accurate and precise. Skeletal age estimations should be based on the application of standards (statistical data), the recommended practice of the Scientific Working Group for Forensic Anthropology (SWGANTH).

The primary research aim is to develop age estimation models for a contemporary sub-adult Western Australian population based on the fusion of the os coxa, sacrum and proximal femur. The other research aims were to evaluate the reliability and accuracy of selected existing age estimation methods in a Western Australian sub-adult population and use novel statistical analyses of the timing of growth and development in a Western Australian sub-adult population.

The study sample comprised 562 MDCT scans (292 male, 270 female) of individuals between 0 and 25 years of age. The scans were assessed at nine morphological developmental attributes using a three stage scoring system. The iliac crest was also assessed using the Risser scoring systems (French and American).

Prior to the data collection, the intra-observer error was quantified using a precision test. The mean level of intra-observer agreement based on analysis of the total sample was: $x=0.79$. Bilateral asymmetry of the data was evaluated using a paired t-test. There was no significant difference $(p=<0.01)$ between the stages assigned to the left and right sides; all attributes examined had an almost perfect correlation $(r=\geq 0.99)$. An independent $t$-test was used to quantify the degree of sexual variation in the timing of fusion. Statistically significant sex differences were observed in the assignment of non-fusion in the proximal femur and os coxa. The mean age of commencement of fusion is significantly earlier (2-4 years) in females 


\section{ABSTRACT}

and there were no sex differences in the timing of fusion in the iliac crest. The inconsistent sexual variation of fusion timing supports the use of pooled sex standards for sub-adult age estimation.

Descriptive statistics showed the fusion of the os coxa and proximal femur occurs around the 14th and 15th year of age. Polynomial regression analysis was used to formulate the predictive age estimation models. The standard error of the estimate of the models ranged from \pm 3.59 to \pm 4.58 years. Transition analysis calculates the mean and standard error of the age of transition between defined stages. Transition analysis shows timing of fusion of iliac crest is delayed in comparison to other attributes of os coxa and proximal femur. Further investigation into the timing of fusion in the sacrum is required due to variable results.

The results have shown the three stage scoring system is preferential to the Risser scoring methods when assessing the iliac crest. Transition analysis provides anthropologists with an alternative approach to traditional statistical analysis. The study addressed the lack of Australian standards, the results of the present study demonstrate that the pelvic girdle and proximal femur can be used to accurately estimate chronological age. 


\section{ACKNOWLEDGEMENTS}

\section{Acknowledgements}

The undertaking of academic research has been a challenging and invaluable experience. I would not have been able to complete this project without the support of numerous people. I take this opportunity to acknowledge and show my appreciation for their support and contributions.

\section{Professional Acknowledgements}

Firstly I would like to thank my supervisors Associate Professor Daniel Franklin and Ambika Flavel. I am grateful for their editorial and intellectual input, patience, guidance and support for the duration of this project, especially in understanding the difficulties of being an external student. I would like to thank the Centre for Forensic Science, University of Western Australia for firstly providing the opportunity to undertake this project and the resources to complete it.

Thanks are due to Doctor Rob Hart for providing the MDCT scans utilized in this project. To Marty from the Centre for Applied Statistics, University of Western Australia for his advice.

\section{Personal Acknowledgements}

I would like to thank my parents, Kathleen and Michael, for their continued and unwavering support of my academic pursuits. They have supported me financially, emotionally and mentally throughout my entire life. I will never be able to express how lucky I feel to have such amazing parents.

I am extremely lucky to have a brilliant sister, Caitlin, who has provided relief and support throughout this process. My close friends, Cassie and Leith, for listening to my constant whinging and (almost) never complaining.

Lastly, to all the people currently and previously in my life that have encouraged and supported me, provided advice and relief, thank you. 


\section{List of Figures}

List of Tables

Chapter One:

1.1 Introduction to the present study

1.2 Aims and objectives

1.3 Sources of data

1.4 Thesis outline

1.5 Contributions of present research

Chapter Two: Anatomy of the pelvic girdle and proximal femur

2.1 Introduction

2.2 Anatomical position and directionality

2.3 Os coxa

2.3.1 Skeletal anatomy

2.3.2 Skeletal development

2.3.3 Musculature

2.4 Sacrum

2.4.1 Skeletal anatomy

2.4.2 Skeletal development

2.4.3 Musculature

2.5 Proximal femur

2.5.1 Skeletal anatomy

2.5.2 Skeletal development

2.5.3 Musculature $\mathbf{x}$

xiii

1

1

3

5

5

6

7

7

7

7

7

12

14

15

15

16

18

19

19

20

21 
TABLE OF CONTENTS

Chapter Three: Age estimation in forensic anthropology: a review of the literature relating to the pelvic girdle and proximal femur

3.1 Introduction

3.2 Applying skeletal development data to age estimation

3.3 Established methods of sub-adult age estimation

3.3.1 Dental development

3.3.2 Development of the bones in the hand-wrist complex

3.3.4 Spheno-occipital syncondrosis fusion

3.3.5 Long bone metrics

4.1 Introduction

4.2 Materials

4.2.1 Study sample

4.2.2 Inclusion and exclusion criteria 
4.5.2 Descriptive statistics

5.6 Polynomial regression analysis $\quad 75$

$\begin{array}{ll}5.7 \text { Transition analysis } & 77\end{array}$

$\begin{array}{ll}\text { Chapter Six: Discussion and Conclusions } & 81\end{array}$

$\begin{array}{lc}6.1 \text { Introduction } & 81\end{array}$

6.2 Aim One: to evaluate the reliability and accuracy of the selected age estimation methods in a Western Australian sub-adult population

6.2.1 Precision of scoring methods $\quad 82$

6.2.2 Bilateral asymmetry in fusion timing 83

6.2.3 Sex variation in the timing of epiphyseal fusion 84 
6.2.4 Timing of epiphyseal fusion $\quad 84$

6.3 Aim two: development of Australian standards 95

6.4 Aim three: novel statistical approaches 96

$\begin{array}{ll}\text { 6.5 . Forensic applications } & 97\end{array}$

$\begin{array}{ll}\text { 6.6 Limitations } & 98\end{array}$

$\begin{array}{ll}\text { 6.7 Future research } & 98\end{array}$

$\begin{array}{ll}\text { 6.8 Conclusion } & 99\end{array}$

$\begin{array}{ll}\text { References } & 100\end{array}$

$\begin{array}{ll}\text { Appendices } & 113\end{array}$

8.1 Appendix I - Human Ethics Approval 113

8.2 Appendix II - Descriptive statistics for individual sexes (left side only) 114

8.3 Appendix III - Polynomial regression models for males (left side only) 116

8.4 Appendix IV - Polynomial regression models for females (left side only) 121

8.5 Appendix V - Transition analysis results for individual sexes (left side only) 


\section{LIST OF FIGURES}

\section{List of Figures}

Figure 2.1. Terms of reference used to describe the human body displayed in situ.

Source: White et al. (2012).

Figure 2.2. Lateral view of the ilium, ischium and pubis of a one year old (left)

compared to a six year old (right). Source: White and Folkens (2005).

9

Figure 2.3. Anterior view of a MDCT scan of the pelvic girdle and proximal femur:

visualisation of the nine morphological developmental attributes investigated in

the present study. Source: author's own image.

Figure 2.4. Dorsal view of a MDCT scan of the left os coxa: visualisation of the six secondary ossification centres (highlighted in pink) investigated in the present study. See Table 4.3 for attribute descriptions. Source: author's own image.

Figure 2.5. Summary of the appearance $(A)$ and fusion $(F)$ of the ossification centres of the os coxa. Source: author's own image.

Figure 2.6. Anterior view of a MDCT scan of the sacrum: the five secondary ossification centres investigated in the present study are highlighted in pink.

Source: author's own image.

Figure 2.7. Anterior (top) and Superior (bottom) view of the sacrum with the

appearance (A) and fusion (F) timings. Source: Scheuer and Black (2004). 17

Figure 2.8. Posterior view of the superficial muscles of the back. Source: Netter (2014).

Figure 2.9. Anterior view of a MDCT scan of the right proximal femur. The three secondary ossification centres investigated in the present study are

highlighted in pink. Source: author's own image.

Figure 2.10. Summary of the timing of appearance $(A)$ and fusion $(F)$ of the secondary ossification centres of the proximal femur. Data taken from: (Flecker 1932; Francis et al. 1939; Lewis and Garn 1960; Scheuer et al. 2000b; White et al. 2012). Source: author's own image.

Figure 2.11. Dorsal view of the deep muscles in the gluteal region (posterior pelvis and femur). Source: Drake et al. (2010).

Figure 3.1. Stages of formation of female mandibular incisor roots as presented in Moorrees et al. (1963a) 


\section{LIST OF FIGURES}

Figure 3.2. Dental maturity percentiles for four teeth $\left(2^{\text {nd }}\right.$ molar, $1^{\text {st }}$ and $2^{\text {nd }}$

premolar and $1^{\text {st }}$ incisor) as presented in Demirjian and Goldstein (1976). 30

Figure 4.1. OsiriX visualisations showing contrasting slice thickness of lateral view

pelvic MDCT scans. A: 3D MPR view of PEL000832 (Female, 22 years) with

slice thickness of $1.5 \mathrm{~mm}$; B: 3D Multiplanar Reconstruction (MPR) view of

PEL000856 (Female, 22 years) with a slice thickness of $0.63 \mathrm{~mm}$.

Figure 4.2. Visualisation in OsiriX of a pelvic MDCT scan of a 10.70 year old male.

A: Maximum intensity projection (MIP) anterior view of PEL000535; B: 3D

Multi-planar reconstruction (MPR) anterior view of PEL000535; C: Individual slice coronal view of PEL000535; D: Anterior view of 3D volume rendering of PEL000535.

Figure 4.3. Anterior view of the femoral head, greater trochanter and lesser trochanter in various stages of fusion.

Figure 4.4. Anterior view of the bones of the os coxa (ilium, ischium and pubis) in various stages of fusion.

Figure 4.5. Anterior view of the anterior inferior iliac spine in various stages of fusion.

Figure 4.6. Superior view of the ischial tuberosity in various stages of fusion. $\quad 54$

Figure 4.7. Lateral view of the sacral vertebrae in various stages of fusion. $\quad 55$

Figure 4.8. Superolateral view of the iliac crest in various stages of fusion. 56

Figure 4.9. A) The American and B) French Risser scoring systems for the iliac

crest. Stages are defined in Table 4.4. Source: Bitan et al. (2005).

Figure 4.10. Shape of polynomial regression models up to the fourth degree.

Source: von Eye and Schuster (1998).

Figure 5.1. Mean age distribution of the Western Australian population according to the fusion stage of the proximal femur.

Figure 5.2. Mean age distribution of the Western Australian population according to the fusion stage of the acetabulum.

Figure 5.3. Mean age distribution of the Western Australian population according to the fusion stage of the anterior inferior iliac spine, and ischial tuberosity. 72

Figure 5.4. Mean age distribution of the Western Australian population according to the fusion stage of the iliac crest. 


\section{LIST OF FIGURES}

Figure 5.5. Mean age distribution of the Western Australian population according to the fusion stage of the sacral vertebrae.

Figure 5.6. Probability density plot: phase 2-3 transition distribution for pooled data (left side). 


\section{List of Tables}

Table 3.1. Timing of fusion (age in years) as reported by Coqueugniot and Weaver (2007).

Table 4.1. Age distribution (in years) for the total sample.

Table 4.2. Broad ancestral categories according to Australian State or Territory.

Source: Australian Bureau of Statistics (2012).

Table 4.3. Morphological developmental attributes evaluated in the present study.

Table 4.4. The French and American Risser lliac Crest Scoring Systems.

Table 4.5. Significance of the Kappa statistic. Source: Landis and Koch (1977b). 59

Table 5.1. Summary age statistics of the precision test data set.

Table 5.2. Intra-observer accordance for each morphological developmental attribute assessed.

Table 5.3. Analyses of bilateral asymmetry of the morphological developmental attributes.

Table 5.4. Analyses of sex variances of the morphological developmental attributes.

Table 5.5. Descriptive age statistics of the scored stages in the proximal femur (pooled sex data; age in years).

Table 5.6. Descriptive age statistics of the scored stages in the os coxa (pooled sex data; age in years)

Table 5.7. Descriptive age statistics of the scored stages in the iliac crest (pooled sex data; age in years).

Table 5.8. Descriptive age statistics of the scored stages in the sacrum (pooled sex data; age in years).

Table 5.9. Polynomial regression equations from fusion phase scores for age estimation (Pooled sex data).

Table 5.10. Transition analysis of the fusion phase scores of the proximal femur, os coxa and iliac crest (individual and pooled sex) [results in years].

Table 5.11. Transition analysis of the fusion phase scores of the sacrum (individual and pooled sex). 


\section{LIST OF FIGURES}

Table 6.1. Comparison of the fusion timing of the proximal femur based on morphological observations.

Table 6.2. Comparison of the fusion timing of the acetabulum, ilial and ischial based on morphological observations.

Table 6.3. Comparison of the fusion timing of the iliac crest based on morphological observations.

Table 6.4. Cross-tabulation agreement between the French and American Risser scoring methods.

Table 6.5. Cross-tabulation of agreement between the three-stage scoring method (ICE) and the Risser (FRE/USA) scoring methods.

Table 6.6. Comparisons of fusion timing in the iliac crest epiphysis based on morphological observations using the Risser scoring methods.

Table 8.1. Descriptive statistics for each stage at each morphological developmental attribute for female data (left side only).

Table 8.2. Descriptive statistics for each stage at each morphological developmental attribute for male data (left side only).

Table 8.3. Transition analysis of the fusion phase scores (right side) of the proximal femur, os coxa and iliac crest (individual and pooled sex). 


\section{CHAPTER ONE: INTRODUCTION}

\subsection{Introduction to the present study}

Forensic anthropology is the application of physical anthropological theory and methods in medico-legal investigations (Holobinko 2012). The analysis of skeletal remains is a part of the traditional role of the forensic anthropologist, although in recent times these methodologies have been applied to the assessment of age in the living. Physical and forensic anthropologists will assess skeletal remains and formulate biological profiles that include estimates of age, sex, stature and ancestry; additionally observations of trauma or pathology are often made (Dirkmaat et al. 2008; Franklin 2010; Garvin et al. 2012; Scheuer 2002). The latter assessment can then contribute towards the process of identifying an unknown individual, or aid in the resolution of other issues, such as age estimation in undocumented individuals (e.g. Illegal immigrants) (Cattaneo 2007; SWGANTH 2013).

The methodologies available to the forensic anthropologist for estimating the age of sub-adult individuals are numerous. These methods are based on the analysis of the multiple developmental indicators present during sub-adult growth (Scheuer 2002). In particular, the mineralisation, eruption and exfoliation of the deciduous dentition are the basis of numerous published methods of sub-adult age estimation (e.g. Demirjian et al. 1973; Hägg and Matsson 1985; Moorrees et al. 1963a; Moorrees et al. 1963b; Ubelaker 1999). Dental development is widely accepted as the most accurate proxy for estimating chronological age at death in sub-adults (Cardoso 2008; Coqueugniot and Weaver 2007; Coqueugniot et al. 2010; McKern and Stewart 1957; SWGANTH 2013). Amongst the most popular dental age estimation methods are those that utilize composite developmental atlases, such as Ubelaker (Ubelaker 1999) and Schour and Massler (Schour and Massler 1941).

Both of the aforementioned methods involve the visual assessment and stage assignation of the dentition: the quoted accuracy of such approaches generally ranges between \pm 2 to \pm 30 months (Scheuer et al. 2000a; Ubelaker 1999). The different methods of sub-adult age estimation available are critically evaluated in Chapter Two. 
Skeletal age assessments performed by a forensic anthropologist should be based on the application of standards (statistical data) that are both sex and population specific; this is a recommended practice of the Scientific Working Group for Forensic Anthropology, also known as SWGANTH (Cattaneo 2007; Dirkmaat et al. 2008; Franklin 2010; Garvin et al. 2012; SWGANTH 2013). The 'Best Practice', as recommended by the SWGANTH (2013), consolidates data collected using multiple different methods utilizing all available skeletal elements. The modern approach to age estimation typically evaluates numerous skeletal traits and elements, thus minimizing potential variability in any one single age indicator (Cattaneo 2007; SWGANTH 2013). The multifactorial approach to age estimation highlights the importance of developing contemporary Western Australian population specific standards for all methods of anthropological estimation.

The pelvic girdle (also referred to as the bony pelvis) is formed by the two os coxa, the sacrum and coccyx (Scheuer et al. 2000c). Each os coxa comprises three primary ossification centers - the pubis, ilium and ischium (Scheuer et al. 2000c); the timing and sequence of osteogenesis, and fusion of the respective primary and secondary centers of ossification, can be used to estimate skeletal age (e.g. Cardoso 2008; Coqueugniot and Weaver 2007; Jitt and Singh 1971; Schaefer 2008; Stevenson 1924; Webb and Suchey 1985). In the present study the timing of the ossification and fusion of the sacrum, proximal femur and ossa coxae are statistically quantified in a Western Australian population (Cardoso 2008; Coqueugniot and Weaver 2007). Such analysis of the pelvic girdle will contribute to the forensic estimation of age based on the assessment of multiple skeletal elements (multifactorial approach), which in turn will assist towards formulating a more accurate biological profile (Chritensen et al. 2014; Kemkes-Grottenthaler 2002).

Age estimation standards require statistical quantification of prediction error; the latter is especially important for the admissibility of anthropological evidence in the Page 2 


\section{CHAPTER ONE}

judicial system. To that end, the acquired morphological data will be analysed using robust multivariate statistical methods, including transition analysis (Boldsen et al. 2002; Milner et al. 2008) and Bayesian statistics (Braga et al. 2005; Lucy et al. 1996). Transition analysis is a method of estimating age that produces a transitional stage, rather than point estimates, based on a linear regression model (Boldsen et al. 2002; Milner et al. 2008; Sykes 2000). Bayes' theorem is then applied to develop likelihood ratios of the correct age estimate (Steadman et al. 2006). Bayesian statistics have been used in the analysis of age related metamorphosis in previous studies (e.g. Braga et al. 2005; Lucy et al. 1996; Schmitt et al. 2002) as has transition analysis (Alsup 2008; Shirley and Jantz 2011).

\subsection{Aims and objectives}

The primary objective of the present study is to formulate a set of Western Australian forensic age estimation standards based on the analysis of the growth and development of the pelvic girdle. The specific aims of the project are as follows:

\section{i) To evaluate the reliability and accuracy of selected existing age estimation methods in a Western Australian sub-adult population}

Risser (1958) developed a method of scoring epiphyseal fusion in the iliac crest (Risser sign) (Bitan et al. 2005; Little and Sussman 1994; Risser 1958; Wittschieber et al. 2013a). This method was subsequently adapted into two different versions: the US and French grading systems (Bitan et al. 2005). The method is based on the assumption that the iliac crest ossifies antero-laterally from a single ossification centre (Little and Sussman 1994; Risser 1958; Wittschieber et al. 2013a). This, however, is in contrast to Scheuer et al. (2000c) who describes the formation of the iliac crest from two separate ossification centres. Wittschieber et al. (2013a), who compared the US and French Risser sign grading systems, also did not commonly observe two ossification centres. This study will apply the US and French Risser grading systems a Western Australian population to 


\section{CHAPTER ONE}

investigate the accuracy and precision of the method for estimating age and further explore the ossification pattern of the iliac crest.

\section{ii) Development of age estimation standards based on a sample of sub-adult Western Australian population}

The Scientific Working Group for Forensic Anthropology (SWGANTH 2013) recommend the application of population specific standards for estimating the age of unidentified remains. The 'best practice' of using population specific standards is known to increase accuracy and reduce the effects of sex and ancestry-based variation (SWGANTH 2013). There is, however, a relative paucity of Western Australian standards for estimating sub-adult skeletal age. To that end, the present project will quantify the timing of the growth and development of the pelvic girdle and proximal femur using a four-stage morphoscopic classification system. This data will then be statistically analysed (see below) and used to develop age estimation standards for a Western Australian sub-adult population.

\section{iii) Novel application of statistical analyses of the timing of growth and development in a Western Australian sub-adult population}

Traditionally age estimation standards have lacked sophisticated statistical analyses and as a result are largely qualitative (Lucy et al. 1996). The requirements of forensic age estimations in medico-legal investigations are that it must demonstrate a minimum standard of accuracy and precision (Steadman et al. 2006). There are a variety of robust and sophisticated statistical methodologies available (e.g., Transition (Boldsen et al. 2002) and Bayesian analyses (Steadman et al. 2006)) that can be applied to quantify the accuracy and precision of anthropological data. This project will apply the latter analytical techniques to test the accuracy and reliability of the biological data acquired in this study. 


\subsection{Sources of data}

A total of 562 pelvic Multidetector Computer Tomographs (MDCT scans) of individuals between 0 to 25 years of age have been acquired from the Western Australian Department of Health (DoH) Picture Archiving and Communication System (PACS) database. The DoH PACS database contains medical scans from a number of Western Australian hospitals (e.g. Royal Perth Hospital, Sir Charles Gairdner Hospital). Equal numbers of male and female scans will be used, with a minimum of ten scans for each sex across groups encompassing a 12 month age range (where possible).

MDCT scans that show major abnormalities or considerable skeletal trauma in the bones of the pelvis, sacrum and proximal femur will not be used in this study. The majority of useable scans are those that were acquired for the clinical diagnosis of strains, sprains and soft tissue injuries. The MDCT scans are anonymous and only the sex and age of each individual is known. The project was granted human research ethics approval on $16^{\text {th }}$ May 2013 and has been added to Professor Franklin's existing HREC approved program (RA/4/1/4362) - 'Novel approaches to the forensic identification of human remains: bone morphometrics'.

\subsection{Thesis outline}

Chapter Two will present a summary of the anatomy and skeletal development of the ossa coxa, sacrum and proximal femur. In Chapter Three, the literature relevant to the present study is reviewed and a summary of current commonly applied sub-adult age estimation techniques is presented. In Chapter Four the materials and methods employed are described. The results of the study are presented in Chapter Five and discussed in Chapter Six; this chapter concludes with an exploration of the limitations of the study and suggestions for future research. 


\subsection{Contributions of present research}

Franklin (2010) discusses the increasing use of clinical scans, such as radiographs and computer tomographs, in forensic research. The development of standards for modern populations should improve the accuracy and precision of sub-adult age estimation. This project aims at producing population specific standards for subadult age estimation using the pelvic girdle and proximal femur. 


\section{CHAPTER TWO: ANATOMY OF THE PELVIC GIRDLE AND PROXIMAL FEMUR}

\subsection{Introduction}

The pelvic girdle is the bony structure that connects the spine and lower limbs while supporting and balancing the torso. The bony pelvis functionally provides protection for the pelvic and abdominal organs, and anchors muscles of the abdomen, pelvis and lower limb. The following chapter will review the anatomy of the pelvic girdle and proximal femur, with specific reference to the developmental attributes on which this study focuses.

\subsection{Anatomical position and directionality}

The anatomical position is the standard plane of reference used to describe the location of body structures. The human body is in anatomical position when standing upright, facing forward, hands by the side (palms facing forwards) and feet together (Figure 2.1). There are three planes passing through the human body in anatomical position; these are used to reference the locations of structures. The coronal plane vertically dissects the body into anterior and posterior parts. The sagittal plane vertically dissects the body into right and left parts. The transverse plane horizontally dissects the body into superior and inferior parts. The terms used to describe the location of structures in the body are: anterior (or ventral or palmar) refers to the front of the body while posterior (or dorsal) refers to the back of the body (Drake et al. 2010; White et al. 2012).

\subsection{Os coxa}

\subsubsection{Skeletal anatomy}

The os coxa (plural: os coxae) is formed by the fusion of the ilium, ischium and pubis (Figure 2.2) (Scheuer et al. 2000c). The two os coxa anteriorly articulate in the midline at the pubic symphysis. Posteriorly the os coxa articulates with the sacrum at the sacro-iliac joint (White and Folkens 2005). The os coxa and femur articulate infero-laterally at the acetabulum. The acetabulum is a ball and socket synovial joint formed by the fusion of the ilium, ischium and pubis (Moore et al. 2010). 


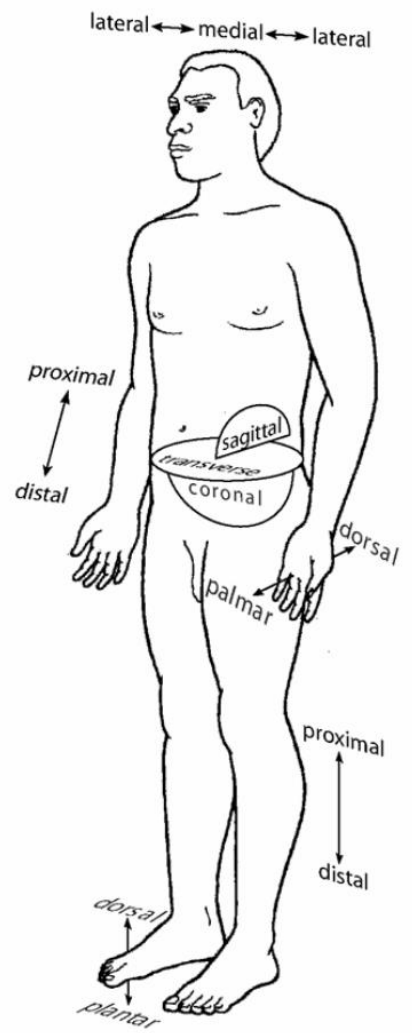

Figure 2.1. Terms of reference used to describe the human body displayed in situ.

Source: White et al. (2012).

The ilium, the most superior element of the os coxa, articulates with the sacrum at the auricular surface and provides attachments for ligaments that support the sacro-iliac joint (see Figure 2.3) (Scheuer et al. 2000c; White et al. 2012). The superior margin of the ilium is thickened and forms the prominent iliac crest (ICE), which is a site for the attachment of the muscles and fascia of the abdomen, back and lower limb (Scheuer et al. 2000c). The iliac crest terminates anteriorly at the anterior superior iliac spine (ASIS) and posteriorly at the posterior superior iliac spine (PSIS). Inferior to the anterior superior iliac spine on the anterior margin, is the anterior inferior iliac spine (AIIS), which lies directly above the acetabulum (Scheuer et al. 2000c). This protuberance is the point of attachment for the rectus femoris muscle and iliofemoral ligament (Drake et al. 2010). The posterior inferior iliac spine (PIIS) is a prominence occurring in the posterior sacral surface of the ilium, immediately inferior to the PSIS (Scheuer et al. 2000c; White and Folkens 
2005). The six ossification centres investigated in the present study are highlighted in Figure 2.4

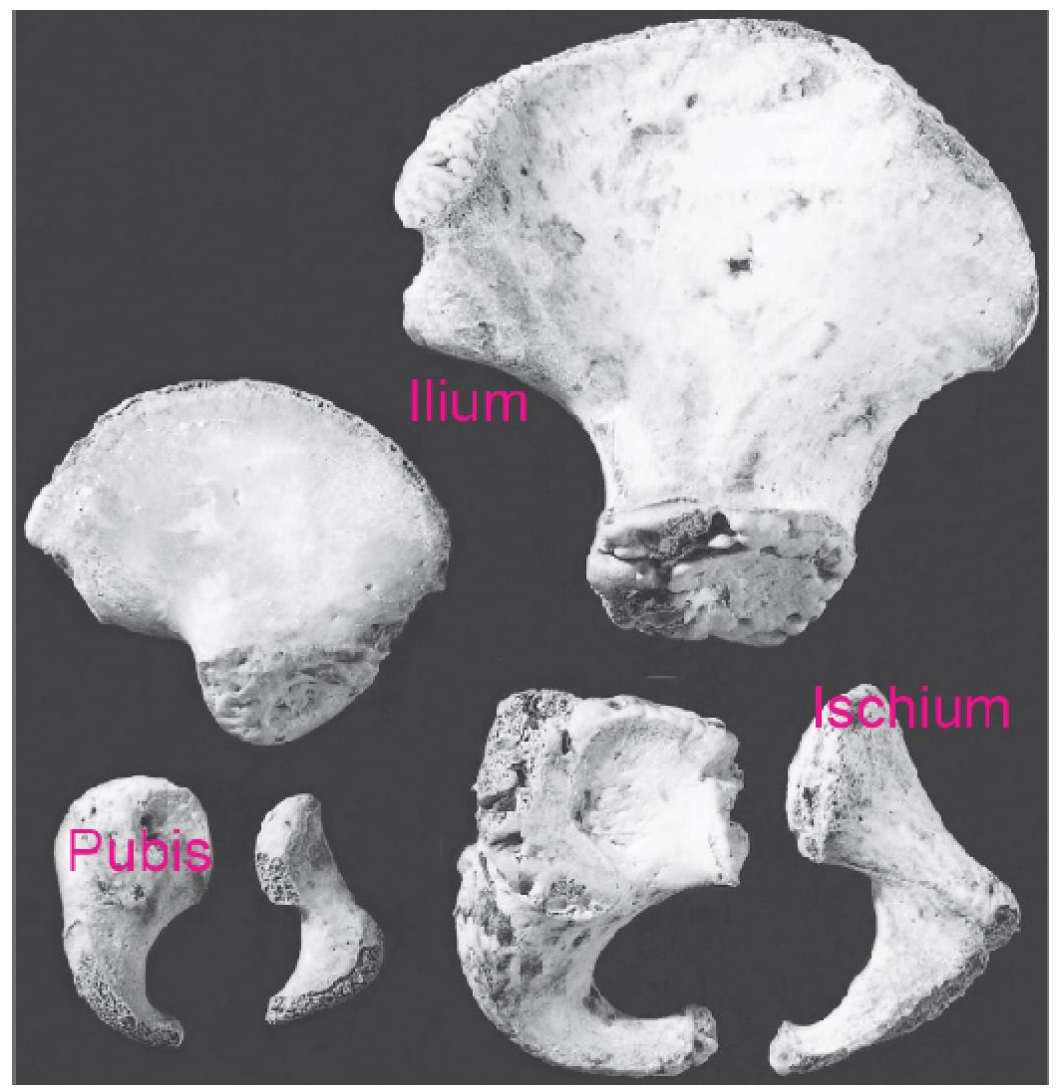

Figure 2.2. Lateral view of the ilium, ischium and pubis of a one year old (left) compared to a six year old (right). Source: White and Folkens (2005). 


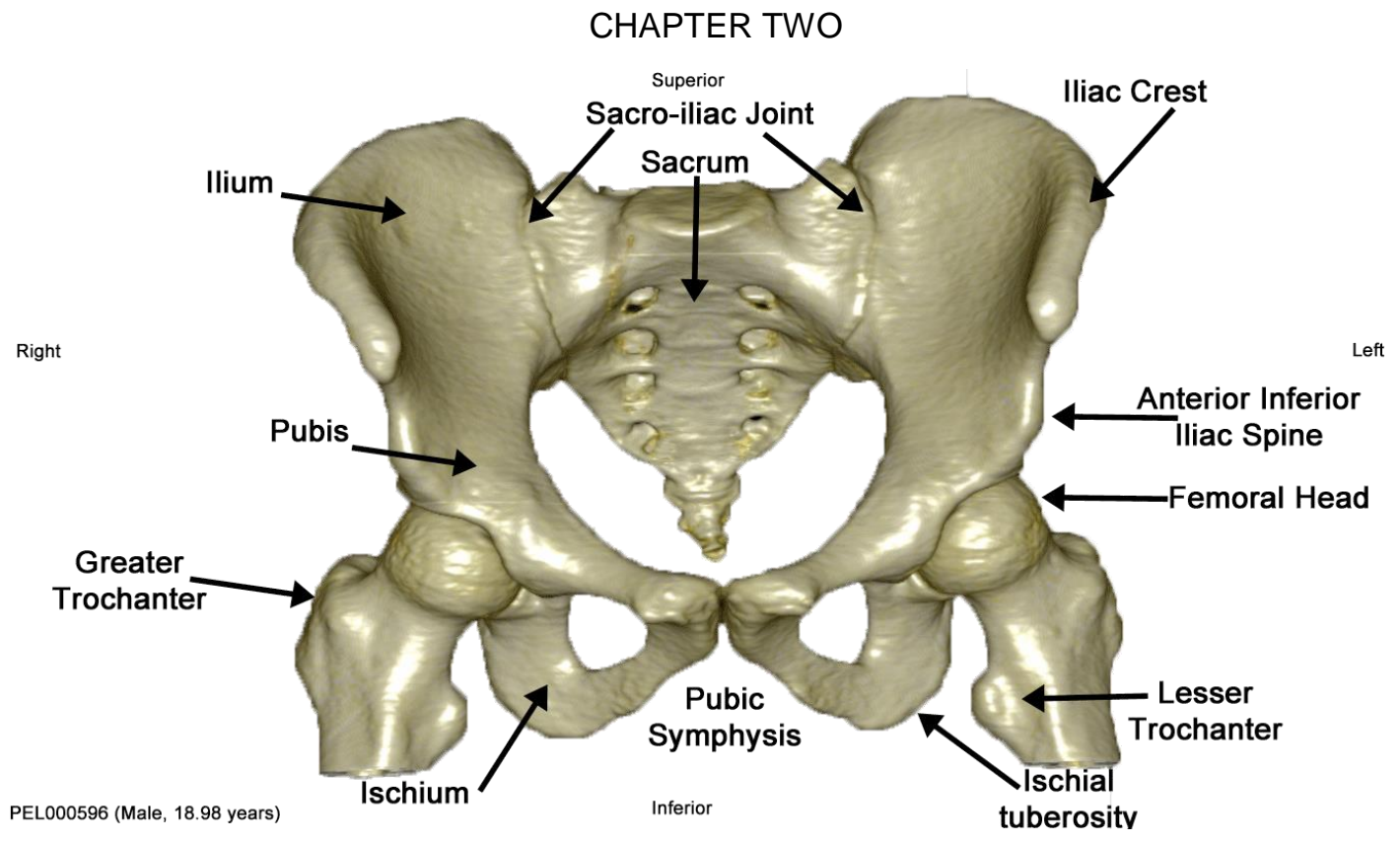

Figure 2.3. Anterior view of a MDCT scan of the pelvic girdle and proximal femur: visualisation of the nine morphological developmental attributes investigated in the present study. Source: author's own image.

The ischium is the postero-inferior part of the os coxa that is located infero-laterally to the ilium and pubis (Scheuer et al. 2000c). The ischium comprises a body and ramus; the body fuses with the ilium and the superior ramus to the pubis. The posterior margin is defined by the prominent ischial spine, which in addition to being a site for muscle attachment, separates the lesser and greater sciatic notches (Moore et al. 2010; White and Folkens 2005). The ischial tuberosity is the large prominence on the postero-inferior surface of the bone that provides attachment for the quadratis femoris, gemellus superior and gemellus inferior muscles (Moore et al. 2010). The ischial tuberosity tapers inferiorly, prior to turning anteriorly and forming the ischial ramus. The ischial ramus fuses with the inferior pubic ramus to form the ischiopubic ramus (White and Folkens 2005). 


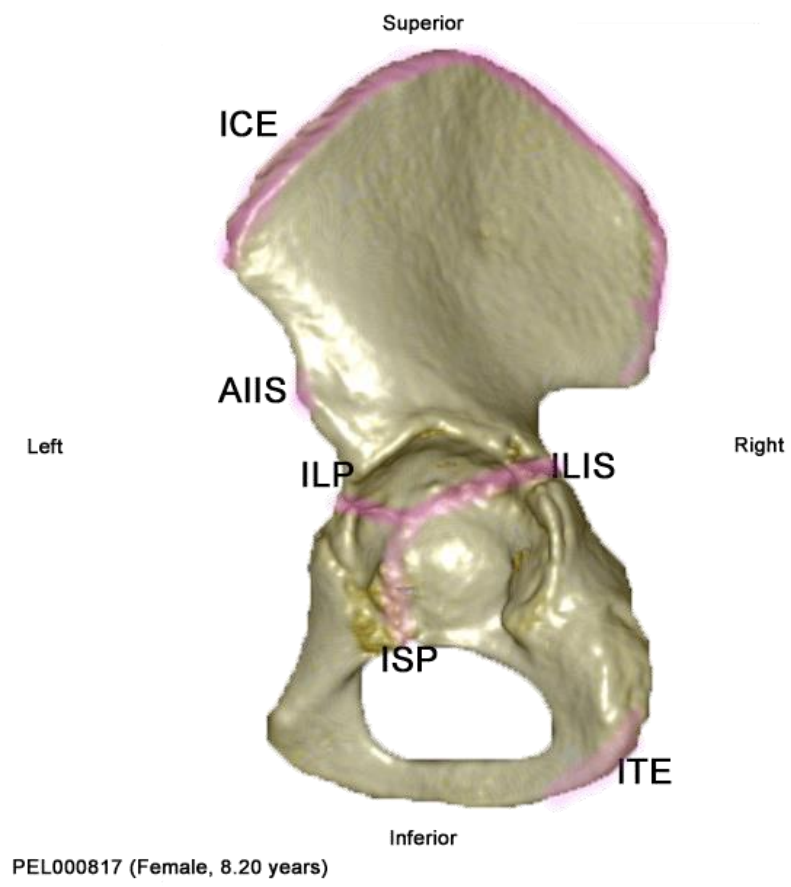

Figure 2.4. Dorsal view of a MDCT scan of the left os coxa: visualisation of the six secondary ossification centres (highlighted in pink) investigated in the present study. See Table 4.3 for attribute descriptions. Source: author's own image.

The pubis is the anterior inferior part of the os coxa and comprises the body and two rami (superior and inferior) (White et al. 2012; White and Folkens 2005). The body of the pubis is dorso-ventrally flat and articulates with the opposite os coxa in the midline at the pubic symphysis. The superior surface of the body is rounded, ending laterally at the pubic tubercle. Between the medial pubic symphysis and the lateral pubic tubercle is the superior border of the body the pubic crest. The pubis meets the ilium and ischium at the end of superior pubic ramus positioned towards the acetabulum (White and Folkens 2005). The lateral projection (inferior ramus) joins at the ramus of the ischium. The obturator foramen (formed by the pubis and ischium) is positioned anterior to the acetabulum; this acts a canal for the obturator nerve and vessels (Drake et al. 2010; White et al. 2012). 


\subsubsection{Skeletal development}

At birth the three primary pelvic growth centres (ilium, ischium and pubis) are present and identifiable (Scheuer and Black 2004; Scheuer et al. 2000c). The timing of appearance and fusion of the ossification centres of the os coxa is described below and illustrated in Figure 2.5. The ilium is the first element of the os coxa to ossify between 8-12 prenatal weeks (Laurenson 1964b). There are normally two epiphyses in the development of the ilium. The endochondral formation of the ischium is from one primary centre and ossification begins between the $3^{\text {rd }}$ and $5^{\text {th }}$ pre-natal month (Scheuer and Black 2004; Scheuer et al. 2000c). The endochondral formation of the pubis is commonly from one primary centre and is the last element of the os coxa to begin ossification between the $5^{\text {th }}$ and $6^{\text {th }}$ pre-natal month (Scheuer and Black 2004; Scheuer et al. 2000c).

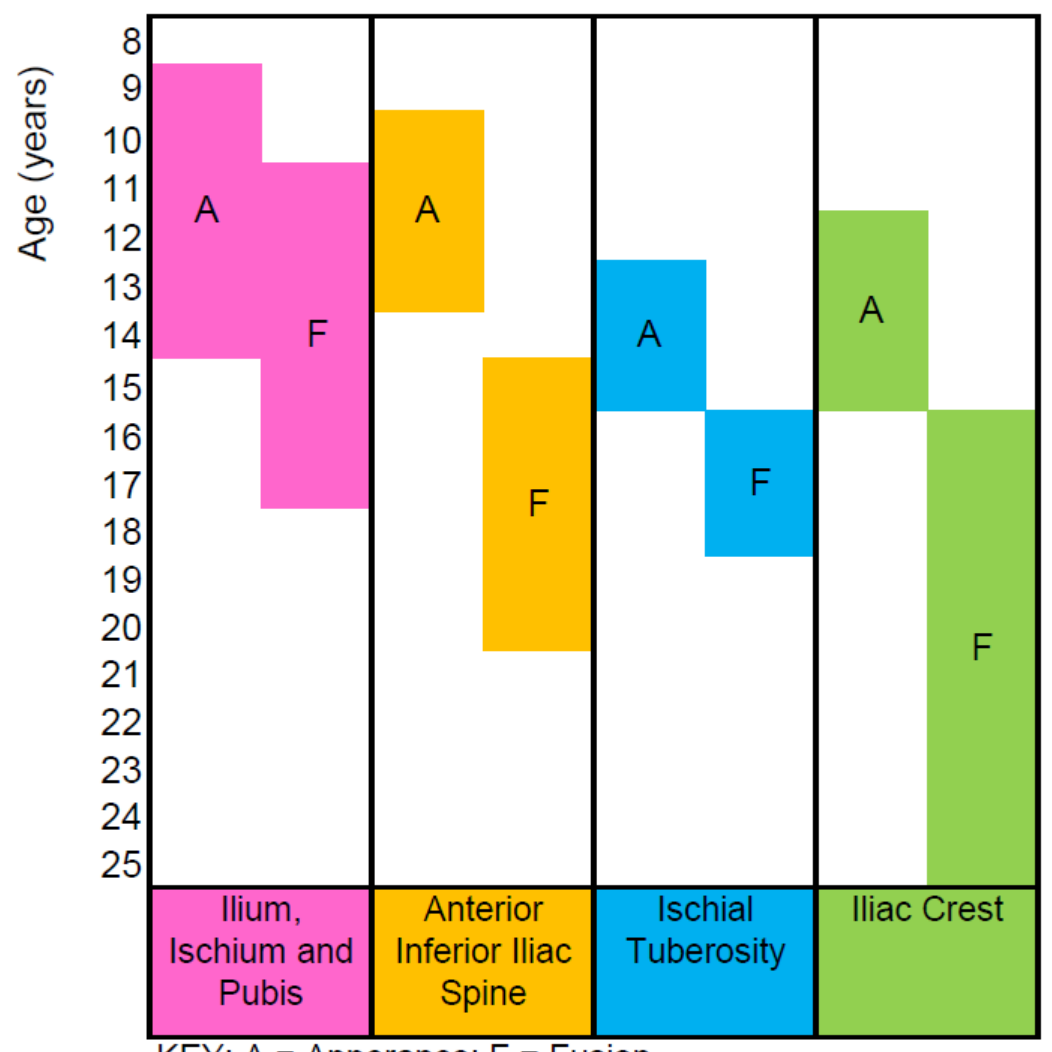

KEY: $A=$ Apperance; $F=$ Fusion

Figure 2.5. Summary of the appearance $(A)$ and fusion $(F)$ of the ossification centres of the os coxa. Source: author's own image. 
The secondary centres of ossification in the acetabulum develop in the cartilage separating the ilium, ischium and pubis. Os acetabuli is the first centre to appear anteriorly between the ilium and pubis (Scheuer et al. 2000c). The larger posterior epiphysis, between the ilium and ischium, appears between 9-10 years of age (Zander 1943). The superior epiphysis between the ischium and pubis appears between 12-14 years of age and is slightly inferior to the anterior inferior iliac spine (Scheuer and Black 2004). Small calcifications, called ossicles, commonly appear between the three acetabular secondary centres. Fusion of the acetabular centres occurs earlier in females (at 11 to 15 years of age) compared to males (14 to 17 years) (Scheuer and Black 2004).

The small cap epiphysis of the anterior inferior iliac spine begins to ossify between 10 to 13 years of age in both sexes (Scheuer and Black 2004). The anterior inferior iliac spine epiphysis fuses between 16 to 20 years of age in both sexes (Coqueugniot and Weaver 2007; Scheuer and Black 2004). The second iliac epiphysis is the iliac crest epiphysis, the sequence of epiphyseal fusion for which varies in the literature. One sequence states the iliac crest begins ossification from two separate centres that grow towards a midpoint that unite to form a single epiphysis. This epiphysis subsequently fuses to the iliac crest (Scheuer and Black 2004; Scheuer et al. 2000c). Stevenson (1924) and Laurenson (1964a; 1964b) noted that the iliac crest begins to ossify from two centres. Francis et al. (1939) disputed this theory, reporting that iliac crest epiphyseal fusion develops from a central epiphyses fusing laterally. It is now commonly accepted that there are two iliac crest epiphyses (anterior and posterior), with some dispute still continuing over the timing of fusion of the posterior epiphysis (Biondi et al. 1985; Bitan et al. 2005; Little and Sussman 1994; Risser 1958; Wittschieber et al. 2013a).

The iliac crest epiphysis generally appears between 12 to 13 years of age in females and 14 to 15 years of age in males (Wittschieber et al. 2013a; 2013b). The epiphyses then fuses to the iliac crest between 16 to 20 years of age (Wittschieber et al. 2013a; 2013b), with reports of complete fusion by 23 to 24 


\section{CHAPTER TWO}

years of age (McKern and Stewart 1957; Webb and Suchey 1985). Coqueugniot and Weaver (2007) investigated the timing of iliac crest apophyseal fusion, with complete fusion first appearing in females and males at 22 and 20 years of age respectively. The timing of fusion from commencement, until just before completion of fusion, ranged from 17 to 26 years of age in females and 16 to 24 years in males (Coqueugniot and Weaver 2007).

Scheuer and Black (2004) note that the secondary centre for the ischial tuberosity appears at 13 to 16 years, and fusion at 16 to 18 years of age. Coqueugniot and Weaver (2007) reported fusion of the ischial tuberosity at 14 to 26 years in females and 16 to 24 years in males, with complete fusion first appearing at 20 and 23 years of age in females and males respectively.

\subsubsection{Musculature}

The lateral walls of the pelvic cavity are formed by two muscles; obturator internus and piriformis (Drake et al. 2010; Moore et al. 2010). Obturator internus originates in the surface of the obturator membrane and associated bone. Piriformis originates in the anterior surface of the sacrum between the sacral foramen. Both muscles insert into the greater trochanter. Obturator internus and Piriformis are involved in the lateral rotation of the extended hip and abduction of the flexed hip (Drake et al. 2010; Moore et al. 2010).

The pelvic floor comprises the pelvic diaphragm, perineal membrane and muscles of the deep perineal pouch (Drake et al. 2010; Moore et al. 2010). The pelvic diaphragm is the muscular part of the pelvic floor that consists of levator ani and the coccygeus muscles. Levator ani consists of two muscles originating from each side of the pelvic wall and join together on the midline. At the midline the two muscles blend posteriorly to the vagina in women and around the anal aperture in both men and women (Drake et al. 2010; Moore et al. 2010). Posterior to the anal aperture the muscles come together to form a ligament called the anococcygeal 
ligament that attach as to the coccyx (Drake et al. 2010; Moore et al. 2010). Anteriorly these muscles are separated by the urogenital hiatus for the urethra in both sexes. The two coccygeus muscles complete the posterior part of the pelvic diaphragm (Drake et al. 2010; Moore et al. 2010) and insert at the tip of the ischial spine, and the base inserts to the lateral margins of the coccyx and adjacent margins of the sacral vertebrae.

\subsection{Sacrum}

\subsubsection{Skeletal anatomy}

The sacrum is formed from five sacral vertebrae comprising of 21 growth centres (White et al. 2012; White and Folkens 2005) (see Figure 2.6). The sacrum is located at the base of the vertebral column inferior to the lumbar vertebrae and superior to the coccyx (Scheuer et al. 2000d). The anterior surface of the sacrum is concave, while the posterior surface is convex (White and Folkens 2005). The superior surface of the sacrum is formed by the large body of the $\mathbf{S 1}$ vertebrae, flanked on either side by the transverse process called the ala (Scheuer et al. 2000d; White et al. 2012). Superiorly the apex articulates with the $5^{\text {th }}$ lumbar vertebrae. Inferiorly the base articulates with the coccyx. The lateral surface of the sacrum resembles an L-shape facet and provides an articulation site for the ilium at the sacro-iliac joint (Scheuer et al. 2000d; White and Folkens 2005). Posterior to the facet is an attachment site for ligaments that support the sacro-iliac joint (Scheuer et al. 2000d; White et al. 2012; White and Folkens 2005).

Each sacral vertebrae has six joints with adjacent vertebrae; four synovial (two above and below) and two symphyses (one above and below) (Drake et al. 2010; Moore et al. 2010). The symphyses between the intervertebral bodies are intervertebral discs comprised of hyaline cartilage. The synovial joints are formed by the articulation of superior and inferior articular processes of adjacent vertebrae (zygapophysial joints) (Drake et al. 2010). 


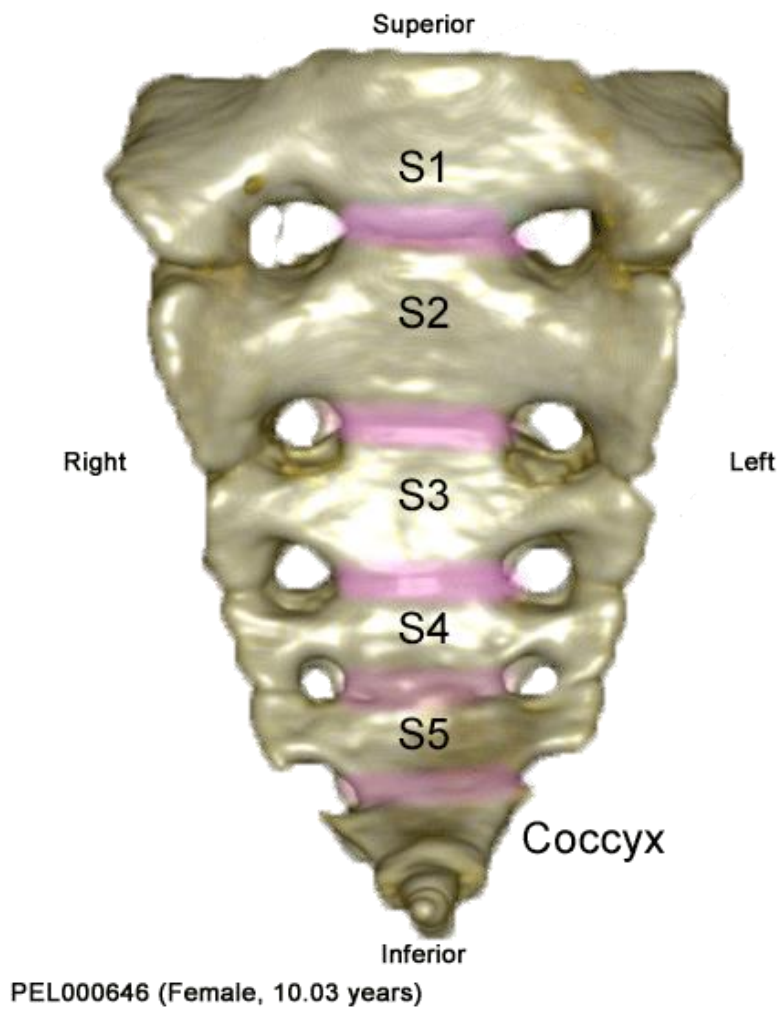

Figure 2.6. Anterior view of a MDCT scan of the sacrum: the five secondary ossification centres investigated in the present study are highlighted in pink.

Source: author's own image.

\subsubsection{Skeletal development}

The five sacral vertebrae ossify to form the immobile sacrum in a complex process involving approximately 21 primary and 14 secondary ossification centres (Scheuer and Black 2004; Scheuer et al. 2000b). The timing of appearance and fusion of the ossification centres of the sacrum are detailed below and illustrated in Figure 2.7. Typically the $S 1, S 2$ and S3 (occasionally also S4) sacral vertebrae form from five ossification centres: central body (1) and ala (4) (Scheuer and Black 2004; Scheuer et al. 2000d). The front of the ala (or costal elements) are formed from two anterolateral centres, while the posterior part of ala are formed by the neural arch (Scheuer and Black 2004; Scheuer et al. 2000d). The reported timing of the appearance of the ossification centres of the sacrum varies - generally the central body begins ossification in the $3^{\text {rd }}$ fetal month, neural arches appear at the $4^{\text {th }}$ to $6^{\text {th }}$ fetal month, with the centres forming the ala appear at the $6^{\text {th }}$ to $8^{\text {th }}$ fetal month 
(Scheuer and Black 2004; Scheuer et al. 2000d). The sacral vertebrae 4 and 5 are formed from three ossification centres for the central body (1) and neural arches (2). The central bodies appear in the $4^{\text {th }}(\mathrm{S} 4)$ and $5^{\text {th }}$ (S5) fetal month, while the neural arches appear in the $6^{\text {th }}$ to $8^{\text {th }}$ fetal months, along with the neural arches of S1, S2 and S3 (Scheuer and Black 2004; Scheuer et al. 2000d).
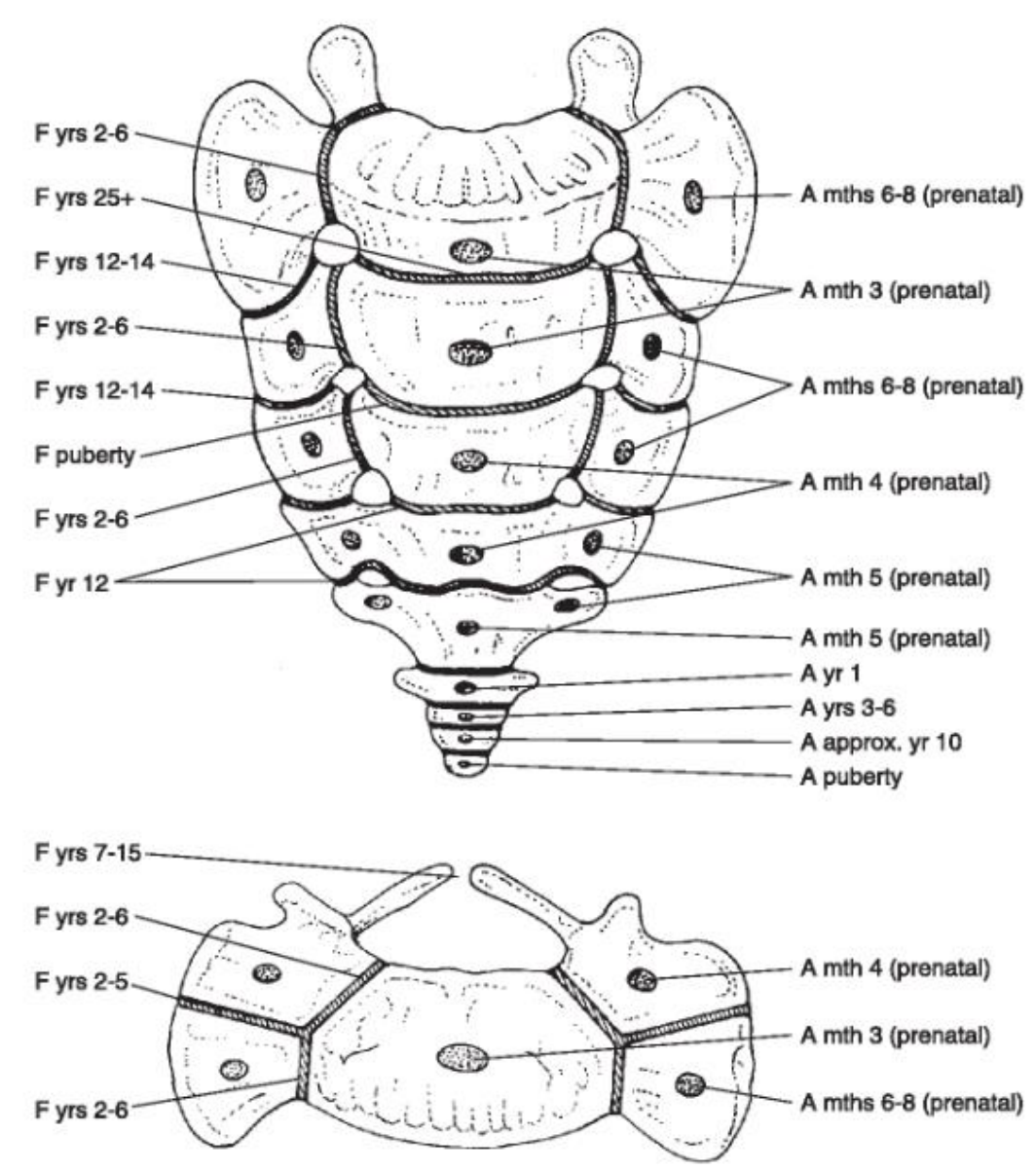

Figure 2.7. Anterior (top) and Superior (bottom) view of the sacrum with the appearance (A) and fusion (F) timings. Source: Scheuer and Black (2004).

At birth the sacrum generally consists of 21 sacral elements (Scheuer and Black 2004; Scheuer et al. 2000d). The central bodies, neural arches and alae (S1, S2 and S3 only) increase in size from S5 (smallest) to S1 (largest). Cardoso et al. (2014b) reported that the neural arch and central body of S1 fuse at 2 to 7 years of 


\section{CHAPTER TWO}

age, while the neural arch and ala, along with the ala and central body, fuse at 3 to 7 and 3 to 8 years of age respectively. The central body and neural arch of S2 to S5 all fuse between 1 to 5 years of age (Cardoso et al. 2014b). Cardoso et al. (2014b) also noted that the five sacral segments are unfused and morphologically recognizable complete vertebrae at 8 years of age, while Scheuer et al. (2000d) notes that this process is complete by the $7^{\text {th }}$ year of life.

At puberty the secondary centres appear, with the number of epiphyses varying (Scheuer and Black 2004; Scheuer et al. 2000d). The epiphyses are normally located on the superior and inferior sides of the central body (annular rings). There are two lateral auricular surfaces (location of sacro-iliac joint) and two lateral margins below the auricular surface (Scheuer and Black 2004; Scheuer et al. 2000d). It is also common for small epiphyses to form for the tips of the spinous and transverse processes (Scheuer and Black 2004; Scheuer et al. 2000d). Cardoso et al. (2014b) reported complete fusion of the secondary centres of ossification (annular rings, auricular surfaces and lateral margins) by 21 years of age and also observed fusion of the auricular surfaces at 16-21 years of age. Fusion of the annular rings was noted to occur at 15-21 years of age and the fusion of the lateral margin at 16-20 years of age (Cardoso et al. 2014c). Ríos et al. (2008) noted that the mean age-at-transition of complete fusion of the central bodies of S1-2 was $37.0 \pm 12.7$ years of age for males and $35.0 \pm 14.1$ years of age for females. McKern and Stewart (1957) reported that the fusion of the S1-2 was complete by 33 years of age, S2-3 was complete by 24 years of age, S3-4 was complete by 23 years of age and $\$ 4-5$ was complete by 23 years of age.

\subsubsection{Musculature}

The muscles of the back are separated based on embryological origin into extrinsic and intrinsic groups (Drake et al. 2010; Moore et al. 2010). The extrinsic muscles, involved in the movement of the upper limb and thoracic wall, are not relevant in the present study. The intrinsic muscles support and move the vertebral column (Drake et al. 2010; Moore et al. 2010). The intrinsic muscles of the back that insert 
into the sacrum are: longissimus, iliocostalis, and spinalis (which are conjointly referred to as erector spinae) (Figure 2.8) (Drake et al. 2010; Moore et al. 2010).

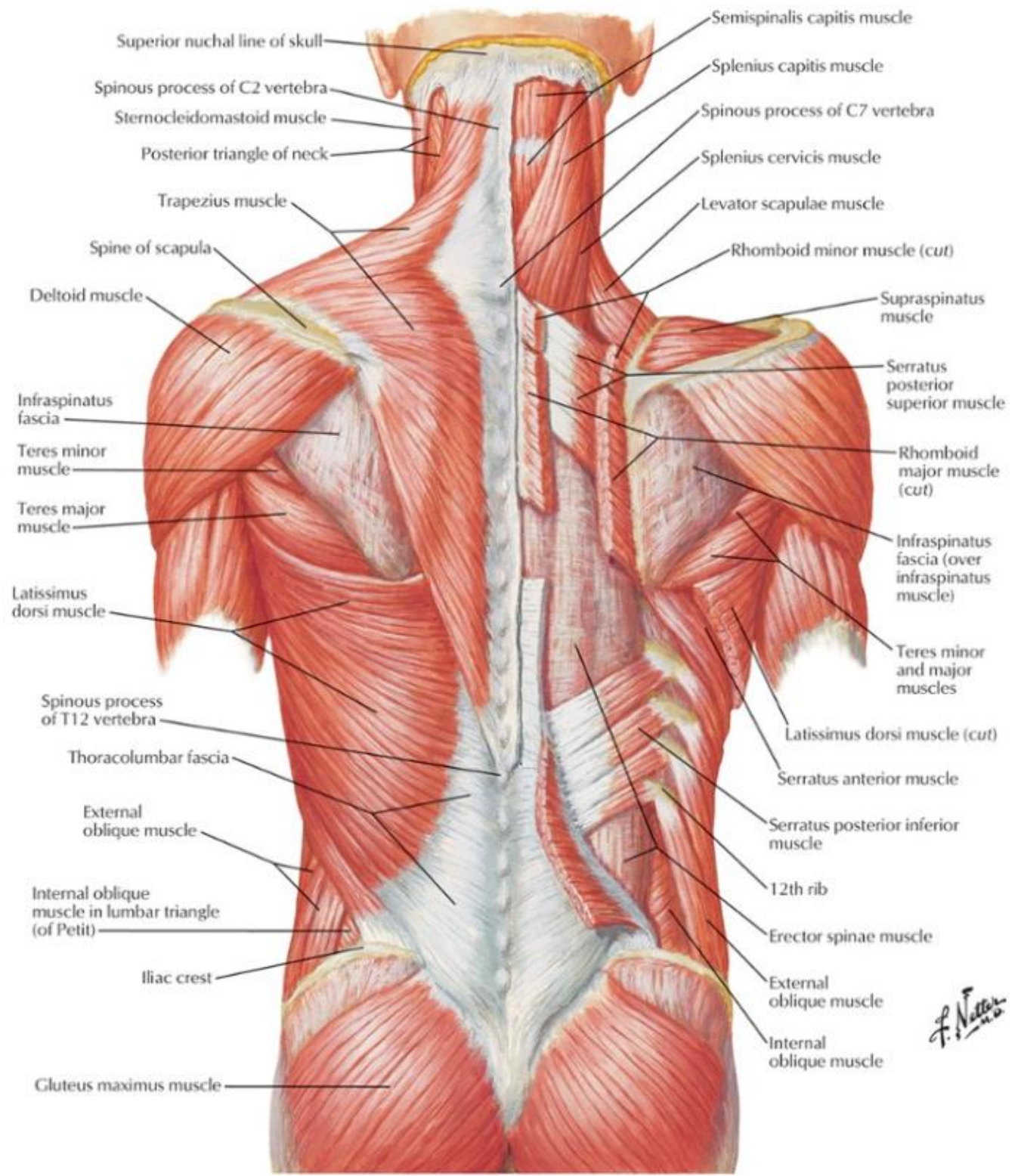

Figure 2.8. Posterior view of the superficial muscles of the back. Source: Netter (2014).

\subsection{Proximal femur}

\subsubsection{Skeletal anatomy}

The proximal femur comprises the head, neck and two trochanters (White and Folkens 2005) (see Figure 2.9). The proximal femur articulates with the 
acetabulum in a synovial joint allowing a large range of movements. The head of the femur is the spherical part of the bone that articulates with the acetabulum (White et al. 2012). It is the most proximal part of the femur and is fixed anterosuperiorly medially towards the acetabulum. The greater trochanter is the large non-articular prominence lateral to the head of the femur that provides insertion for the tendons of gluteus minimus and medius (Scheuer et al. 2000b; White et al. 2012). The lesser trochanter is the tubercle posterior and inferior to the head of the femur; providing an insertion site for the iliopsoas tendon (Drake et al. 2010; White and Folkens 2005).

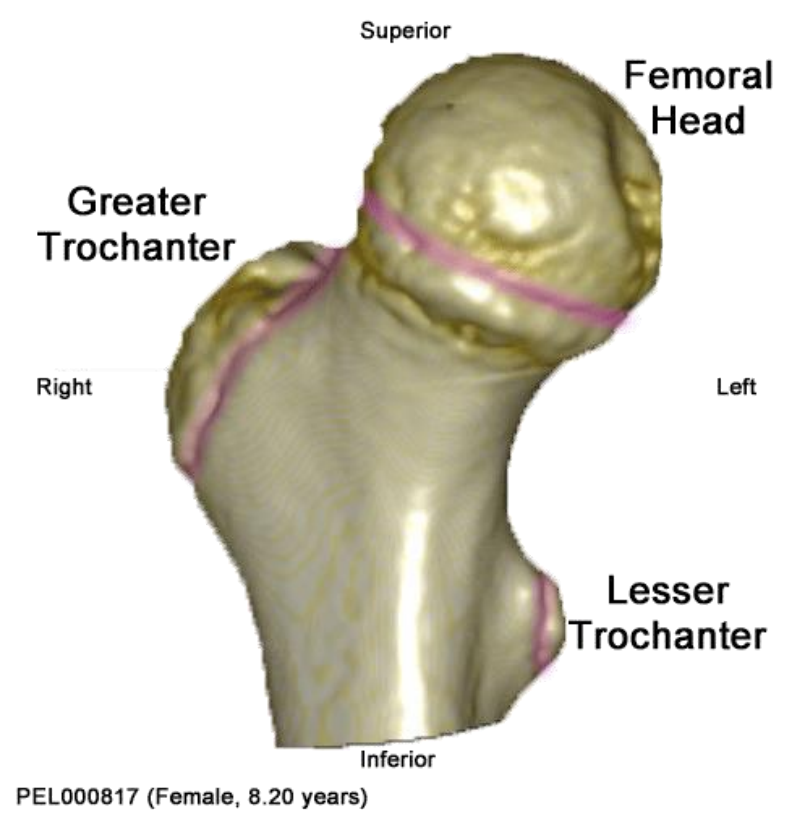

Figure 2.9. Anterior view of a MDCT scan of the right proximal femur. The three secondary ossification centres investigated in the present study are highlighted in pink. Source: author's own image.

\subsubsection{Skeletal development}

The proximal femur has three secondary ossification centres that form the femoral head and the greater and lesser trochanters (Scheuer and Black 2004; Scheuer et al. 2000b). Figure 2.10 summarises the appearance and fusion of the ossification centres at the proximal femur (Flecker 1932; Francis et al. 1939; Hansman 1962a). The ossification centre for the femoral head is already present at birth. This 
epiphysis fuses between 12 to 16 years of age in females and 14 to 19 years of age in males (Acheson 1957; Flecker 1932; McKern and Stewart 1957; Stevenson 1924). The ossification centre forming greater trochanter usually appears between the ages of 2 to 5 years of age (females earlier than males) (Flecker 1932; Francis et al. 1939; Lewis and Garn 1960). Fusion of the greater trochanter epiphysis generally occurs earlier in females at 14-16 years compared to 16-18 years of age in males (McKern and Stewart 1957; Scheuer et al. 2000b). The lesser trochanter ossification centre usually appears at 7-11 years of age (Scheuer and Black 2004; Scheuer et al. 2000b). The fusion of the epiphysis generally occurs between 16 and 17 years of age (Scheuer and Black 2004; Scheuer et al. 2000b), although McKern and Stewart (1957) noting that complete fusion does not occur until 20 years of age.

\subsubsection{Musculature}

The muscles of the gluteal region can be divided into two groups: a deep group of small muscles and a superficial group of larger muscles (Drake et al. 2010). The deep muscle group (Figure 2.11) includes the piriformis, obturator internus, quadratus femoris, gemellus superior and inferior. The superior muscle group comprises the gluteus minimus, gluteus medius, gluteus maximus and tensor fasciae latae.

Quadratis femoris is the most inferior muscle of the deep muscle group and originates just anterior to the ischial tuberosity. Quadratis femoris inserts in the quadrate tubercle of the proximal femur and laterally rotates the femur at the hip joint (Drake et al. 2010; Moore et al. 2010). Gemellus superior originates in the ischial spine and gemellus inferior originates at the ischial tuberosity. Both gemellus superior and inferior attach along the length of the obturnus tendon and then insert in the greater trochanter with the obturator internus tendon (Drake et al. 2010; Moore et al. 2010). Gemellus superior and inferior abduct and laterally rotate the femur at the hip. 


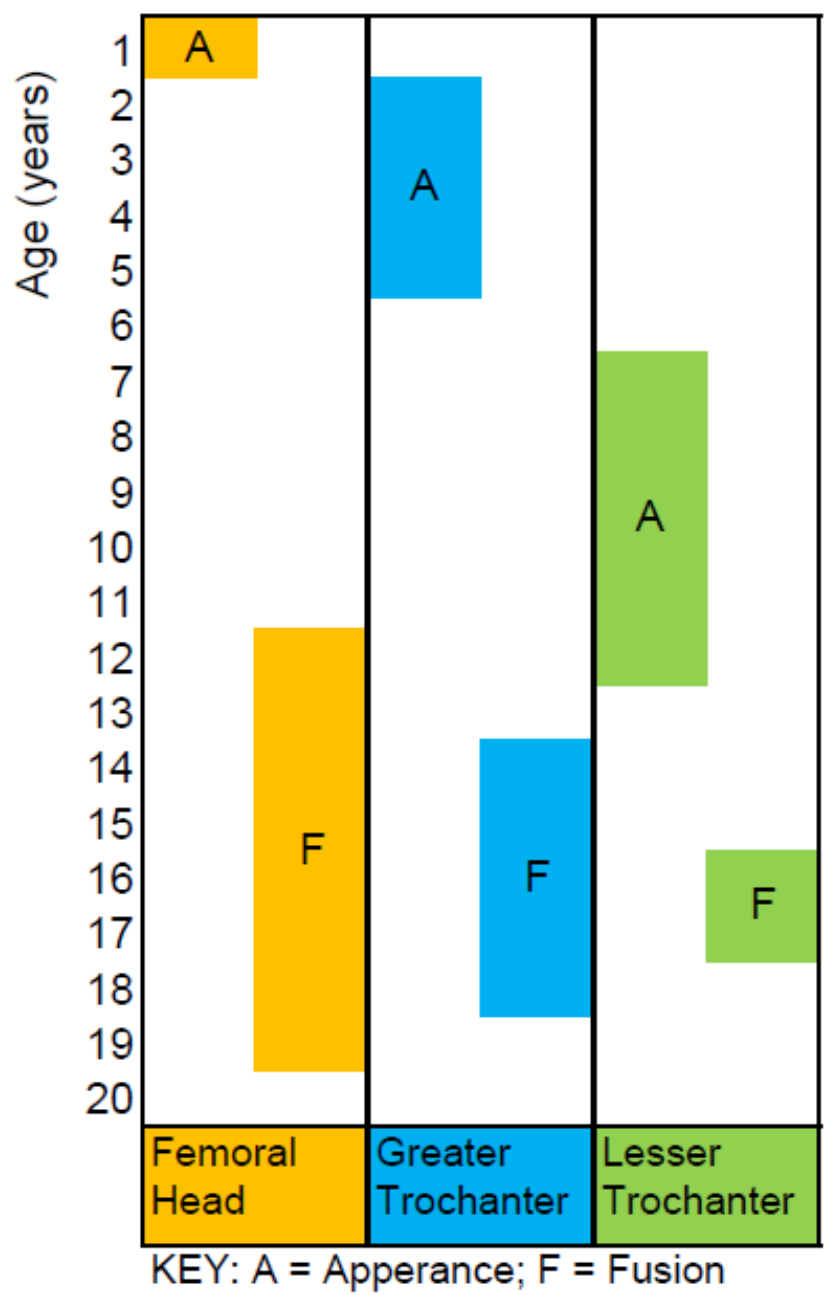

Figure 2.10. Summary of the timing of appearance $(A)$ and fusion $(F)$ of the secondary ossification centres of the proximal femur. Data taken from: (Flecker 1932; Francis et al. 1939; Lewis and Garn 1960; Scheuer et al. 2000b; White et al. 2012). Source: author's own image.

The Gluteus minimus and medius muscles originate from the external surface of the ilium, and abduct and medially rotate the femur (Drake et al. 2010; Moore et al. 2010). Gluteus minimus and medius insert in the greater trochanter. Gluteus maximus is the largest muscle in the pelvis region and originates from the ilium, dorsal surface of the sacrum and lateral surface of the coccyx then inserts onto the gluteal tuberosity of the proximal femur. The gluteus maximus extends the flexed femur, laterally rotates and abducts the femur and is a lateral stabilizer of the hip joint. Tensor fasciae latae originates from the lateral part of the iliac crest and 
inserts onto the fascia lata (Drake et al. 2010; Moore et al. 2010). Tensor fasciae latae stabilizes the extended knee.

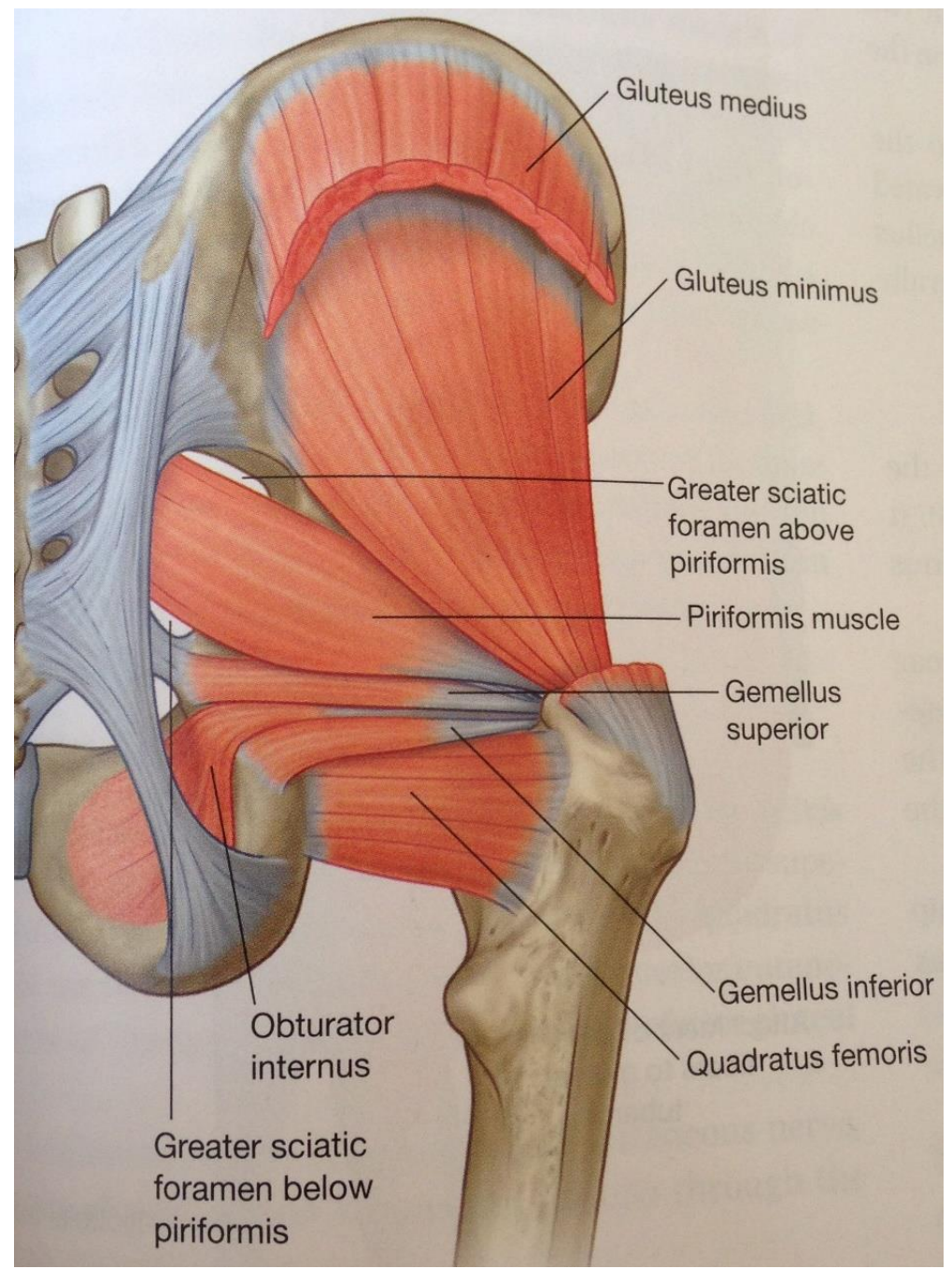

Figure 2.11. Dorsal view of the deep muscles in the gluteal region (posterior pelvis and femur). Source: Drake et al. (2010). 


\section{THIS PAGE HAS INTENTIONALLY BEEN LEFT BLANK}




\section{CHAPTER THREE: AGE ESTIMATION IN FORENSIC ANTHROPOLOGY: A REVIEW OF THE LITERATURE RELATING TO THE PELVIC GIRDLE AND PROXIMAL FEMUR}

\subsection{Introduction}

Age estimation is a central part of a forensic anthropologist's role in medico-legal investigation (Cunha et al. 2009; Franklin 2010). The usefulness of many skeletal elements in the context of forensic age estimation has been extensively researched (e.g. Franklin and Flavel 2014; Lottering et al. 2013; O'Connor et al. 2014; Villa et al. 2013; Wittschieber et al. 2013a)). Sub-adult age estimation methodologies commonly employed are based on the analysis of characteristics of dental and/or skeletal development (AIQahtani et al. 2010; Demirjian and Goldstein 1976; Demirjian et al. 1973; Fanning 1961; Moorrees et al. 1963a; Moorrees et al. 1963b; Schour and Massler 1941). The timing of skeletal development generally follows a predictable and well-documented pattern that correlates to chronological age - this is the basis for age estimation in sub-adult skeletal remains. The derived age estimate assumes that every individual conforms to the standard growth and developmental pattern. Although this assumption relies on predictable and documented growth trajectories, there will always be a degree of inaccuracy, as growth is not standardized nor linear (Blenkin and Taylor 2010; Cunha et al. 2009; Hackman et al. 2010; Ritz-Timme et al. 2000). The methodologies employed should thus attempt to minimize the degree of prediction error and therefore maximize the accuracy of an estimation of age. The purpose of the present chapter is to review a selection of established methods of sub-adult age estimation and thereafter focus on these methods that specifically involve the analysis of the pelvic girdle and proximal femur.

\subsection{Applying skeletal development data to age estimation}

A forensic age estimate needs to be both precise and accurate. Accuracy refers to the size of the confidence interval, while precision refers to the "absolute mean age estimate versus the actual age error" (Passalacqua 2010: pp.102). A modern approach to age estimation, as recommended by the SWGANTH (2013), involves analysing all available skeletal elements using population specific standards and 


\section{CHAPTER THREE}

relevant methodologies. This multifactorial approach allows for a consolidated age estimate that (in theory) should minimize error.

There are several factors to consider when selecting a technique for estimating age in the sub-adult skeleton, which include: sample size; geographical and ancestral composition of the reference sample; and sex frequencies (Cattaneo 2007; Franklin 2010; Ritz-Timme et al. 2000; SWGANTH 2013). Another consideration is the applicability of non-contemporary data where the effects of secular variation are known (Eveleth and Tanner 1990; Klepinger 2001; Roche 1979). Many skeletal collections (e.g. the Terry Collection at the Washington University School of Medicine; the Todd Collection at the Western Reserve University School of Medicine) contain a disproportionate number of sub-adults that are not necessarily representative of contemporary populations. Medical images provide forensic anthropologists an alternative modality for the investigation of skeletal maturity. Medical imaging provides a non-destructive, high-resolution model for studying the skeletal biology of contemporary individuals (Cunha et al. 2009; Dirkmaat et al. 2008; Franklin 2010).

\subsection{Established methods of sub-adult age estimation}

Two main parts of the skeletal system are generally assessed during the estimation of sub-adult age: the development of the dentition and the degree of bone growth/development relative to full maturity. The present chapter reviews a selection of established methods of sub-adult skeletal age estimation according to the specific element assessed.

\subsubsection{Dental development}

The assessment of dental development is widely considered the most accurate method for estimating age in sub-adults (Cardoso 2007; Franklin 2010; Wood and Cunningham 2011). The formation and eruption of the deciduous and permanent dentition is less affected by environmental factors (e.g. malnutrition) thereby 
reducing the risk of divergence from the standard maturation pattern (Cardoso 2007; Demirjian et al. 1985; Franklin 2010; Wood and Cunningham 2011). The estimation of sub-adult dental age assumes all teeth will develop and erupt in a predictable sequence that has a strong correlation to chronological age (Wood and Cunningham 2011). Dental development methods involve the macroscopic and/or radiographic examination of the stage of tooth development relative to full maturity. The emergence (or eruption) of the teeth into the oral cavity is assessed separately from tooth formation. Emergence is applicable up to the age of 30 months where the deciduous teeth have erupted and after approximately 6 years of age when the first permanent teeth emerge (Demirjian et al. 1973). The following considers a selection of commonly applied dental age estimation methods.

\section{i) Moorrees et al. (1963a; 1963b)}

The aim of the studies by Moorrees et al. were to produce an atlas of standardised stages of tooth formation, eruption and resorption of the deciduous and permanent teeth for application to age identification. The first study assessed intraoral radiographs of 134 Bostonian children, and 'lateral-jaw' radiographs of 246 Northern American Caucasian children, all described as being from 'middlesocioeconomic' backgrounds. The stages of deciduous and permanent tooth formation were categorized into crown, root or apex stages for single rooted (13 stages total) and molar teeth (14). The mean age and two standard deviations for all teeth and stages were presented for both sexes separately.

Intra-observer agreement was tested using 874 intraoral radiographs at 3 month age intervals, and was calculated to be 0.90 for the mandibular teeth (excluding incisors) and 0.75 for the incisors (Moorrees et al. 1963a). The completion of crown formation of all teeth (with the exception of the third molars) occurs by 6.5 years of age and by 12 years of age the mature root length of all permanent teeth (with the exception of the third molars) was attained. Root formation of the maxillary lateral incisor occurred 0.6 years earlier in females, whereas there was 
no significant sex difference in the timing of crown of formation. The data is presented chart form (see Figure 3.1) with no tabular data available.

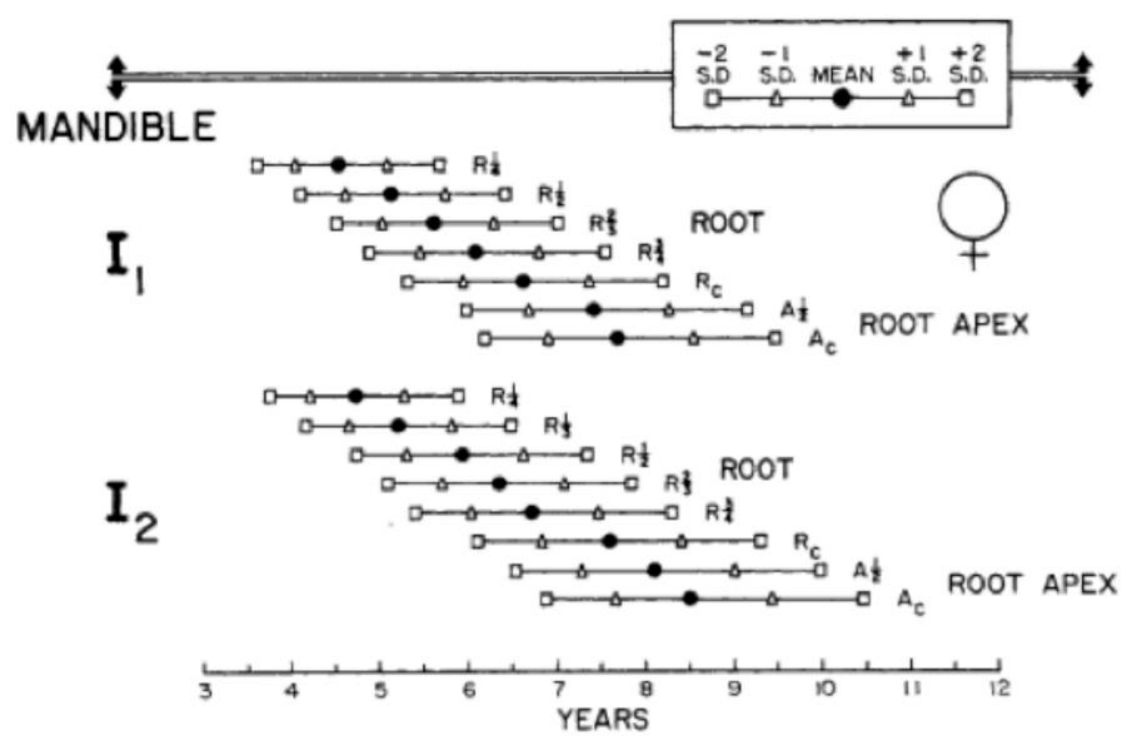

Figure 3.1. Stages of formation of female mandibular incisor roots as presented in Moorrees et al. (1963a)

The aim of the second study was to quantify the formation and resorption of the deciduous mandibular canines, and the first and second molars, based on the analysis of intraoral radiographs of 136 Bostonian children obtained serially from birth to 15 years of age. The tooth formation methodology followed the previous study (except for the quantification of resorption), which was assessed using an arbitrarily defined four-stage system: i) $25 \%$ root resorbed; ii) 50\% root resorbed; iii) $75 \%$ root resorbed; and iv) exfoliation. The mean age and two standard deviations for all teeth and stages are presented for each sex separately. This study does not state the level of intra-observer agreement. The data is presented chart form with no tabular data available. 


\section{ii) Demirjian et al. $(1973 ; 1976)$}

The 1973 study aimed to formulate a novel method of assessing the formation of seven left mandibular teeth to estimate dental age. Panoramic radiographs of 1146 male and 1482 female French-Canadian individuals, from 2 to 20 years of age, were assessed by four examiners. The subjects, all of French-Canadian ancestry, were examined and scanned in the Ste-Justine Hospital and Growth Centre, Montreal. All of the subjects had a complete permanent mandibular dentition and were screened for growth disorders. A nine-stage scoring system (A through $\mathrm{H}$ ) is used and the scores for each tooth are converted to a numeric standard value and summed to produce a maturity score. The sex specific maturity scores $(0-100)$ can then be compared to a sex-specific plot where the maturity score will correspond to dental age. The scores and percentile standards for both sexes are outlined separately (covering a 3 to 17 year age range).

Demirjian and Goldstein (1976) published an updated version of the 1973 method based on the analysis of a larger sample (2407 male; 2349 female). This study aimed to address the "two main shortcomings" of the previous study, which include insufficient sample size across specific ages and the requirement for all seven teeth (Demirjian and Goldstein 1976). The original nine-stage scoring system was employed. The maturity scores and percentile standards for both sexes were published and cover a 2.5 to 17 year age range (see Figure 3.2). The results were "smoothed" to reflect the continuous nature of increasing age, although the specific methods employed to do this are not described.

When applied to other populations, this technique has been shown to generally overestimate age. Moananui et al. (2008) applied Demirjian's (1994) method to a New Zealand population comprising individuals 2.5 to 14 years of age. The sample was split into three ethnic groups: Maori; Pacific Islander; and European. The method was shown to overestimate age, with the mean difference between chronological and dental age varying by $0.19 \pm 0.78$ years to $-1.88 \pm 1.08$ years for 
Maori females, and $-2.78 \pm 0.55$ years to $-0.18 \pm 0.86$ years for Pacific Island females.

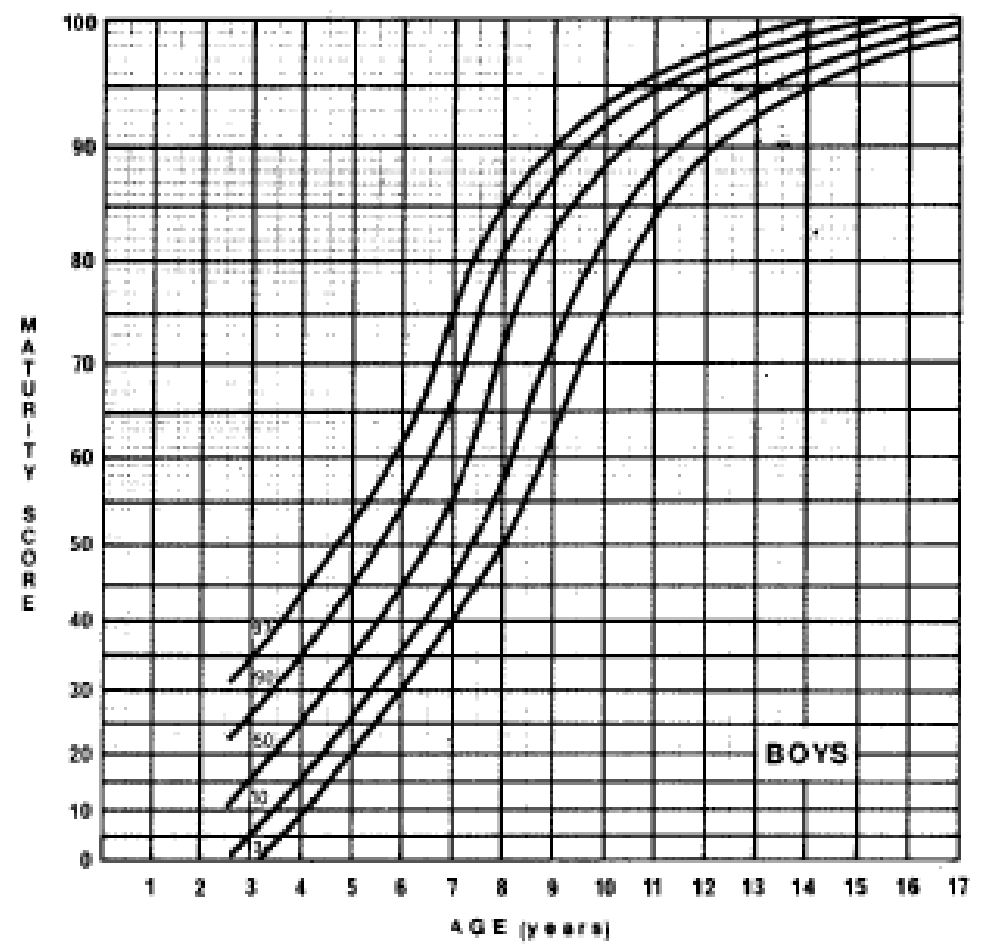

Figure 3.2. Dental maturity percentiles for four teeth $\left(2^{\text {nd }}\right.$ molar, $1^{\text {st }}$ and $2^{\text {nd }}$ premolar and $1^{\text {st }}$ incisor) as presented in Demirjian and Goldstein (1976).

Rózyło-Kalinowska et al. (2008) applied Demijian's 1973 and 1976 methods to a Polish sample of individuals 6 to 16 years of age. There was a significant statistical overestimation of age in $81.7 \%$ of females and $77.5 \%$ of males. Tunc and Koyuturk (2008) applied both Demijian methods to a Turkish population comprising individuals between 4 to 12 years of age. Their results demonstrated a mean under estimation of age of 0.50 to 1.44 years in males, and 0.50 to 1.43 years in females. It was concluded that Demirjian's standards were not sutiable for application in a northern Turkish population. 
iii) AIQahtani et al. (2010)

This study aim to produce a comprehensive validated atlas of dental age estimation standards (AlQahtani et al. 2010). The timing of tooth development was analysed in radiographs of 176 neonates (from 28 weeks in utero to 2 years) and 528 subjects (from 2-23 years) of Bangladeshi or Caucasian ancestry. The neonate sample was drawn from two archaeological collections: Spitalfields $(n=50)$; and Maurice Stack ( $n=136)$. The Spitalfields Coffin Plate Collection, located at the Natural History Museum of London, contains subjects with birth and death years from 1729 to 1859 AD. The Maurice Stack collection is part of the Odontological Collection at England's Royal College of Surgeons. All other radiographs $(n=528)$ examined were from the Institute of Dentistry, Barts and the London School of Medicine and Dentistry.

Dental development was assessed following the methodology of Moorrees et al. (1963a,b). Tooth eruption was assessed using a modification of the stages outlined in Bengston (1935). The level of intra-observer error (Kappa) in stage assignment was 0.90 for the sample containing individuals younger than 2 years, and 0.81 for those individuals older than 2 years of age. The minimum, median and maximum for each tooth (maxilla and mandible) in all age categories was calculated; the median age of alveolar eruption, clinical emergence and complete eruption of the permanent teeth was also calculated for each tooth (maxilla and mandible). The atlas does not provide error ranges, only the median age for each particular image. The results showed the most variability in tooth formation post 16 years of age. The authors claimed the least variability in "infancy", although less than $6 \%(n=41)$ of subjects were aged between 6 months and 2 years of age.

\subsubsection{Development of the bones in the hand-wrist complex}

A radiograph of the hand-wrist can be analysed and compared to one of the many atlases available to derive an age estimate (Greulich and Pyle 1959; Tanner et al. 2001). Age estimation using hand-wrist assessment is more commonly applied to situations involving identification in the living (Hackman et al. 2010; Serinelli et al. 
2011). Along with the Greulich and Pyle (1959) method, the Tanner-Whitehouse (1975) approach is commonly used in clinical situations and with partially or complete cadavers (Lewis and Flavel 2007). Hand-wrist methods are commonly employed due to the following factors: minimal radiation exposure; cheap and easy scanning technique; and multiple ossification centres in the one location (Lewis and Flavel 2007). A selection of hand-wrist methods are accordingly reviewed below.

\section{i) Greulich and Pyle (1959)}

The aim of this study was to produce a reference atlas of hand-wrist radiographs for assessing skeletal age as an indication of growth and development. This atlas has become one of the most extensively used methods for age estimation in the living (Anderson 1971; Bull et al. 1999; Hackman and Black 2013; Lampl and Johnston 1996; Santos et al. 2011). The radiographs were taken from the Brush Foundation Study of Human Growth and Development (conducted between 1930 and 1942); the sample includes middle class Caucasian children from Cleveland, Ohio. The atlas presents standard sex specific reference images that are deemed most representative of each stage of skeletal maturity, based on the central tendency of data collected from 100 subjects of that chronological age. The method involves a visual comparison of the maturity indicators displayed in the reference images to the subject being assessed. The atlas includes 31 male and 29 female radiographic standards at intervals of 3 months between 0 and 2 years; intervals vary from 6 to 12 months between the ages of 2 and 18 years. The atlas has two radiographic standards for males at 19 years and females at 28 and 50 years of age.

The accuracy of age estimation using the Greulich and Pyle atlas has been investigated in contemporary populations. Hackman and Black (2013) quantified the accuracy of age estimation in a modern Scottish population and found the mean difference between chronological and estimated age varied by \pm 1.95 months in females and \pm 1.63 months in males. Santoro et al. (2012) investigated the 
accuracy of the atlas in an Italian population and found the mean difference between chronological and estimated skeletal age was $0.4 \pm 1.0$ years and -0.1 \pm 1.3 years for females and males respectively. These studies highlight the inaccuracy of age estimation using the Greulich and Pyle atlas method.

The estimation of age of unidentified individuals in Australian criminal proceeding had relied on the assessment of hand-wrist radiographs since 2001. The Australian Human Rights Commission's Inquiry (Australian Human Rights Commission 2012) questioned the applicability of this methodology. The Inquiry concluded that the Greulich and Pyle atlas was designed to assess the skeletal maturity of an individual of known chronological age and should not be used for age estimation.

\section{ii) Tanner et al. (1962; 1975; 2001)}

The aim of Tanner et al (1962) was to produce an atlas of growth and development (similar to Greulich and Pyle (1959)) based on an absolute scale of maturity first utilised by Acheson (1954). The study examined 3000 hand-wrist radiographs of British subjects from birth to 18 years of age. The scans were taken between 1946 and 1970, with the socioeconomic background of the sample reported as lower to middle class. The Tanner-Whitehouse (1962) method involves scoring the maturity of the bones of the hand and assumes every bone undergoes a series of stages that constitute developing maturity (Tanner 1971). Each bone in the hand and wrist are separately assessed macroscopically using an anterior-posterior radiograph and scored into one of nine stages. The scores are then summed to provide an estimate of skeletal maturity. The system was revised in (1975) to address perceived shortfalls by updating the stage descriptions, scoring and reference sample. The TW2 system utilises the same sample as TW1 and did not reassess the sample. TW2 was revised in (2001) as TW3 with only the reference population changing not the stage descriptions or scoring. 


\section{CHAPTER THREE}

The applicability of the TW approach has been analysed in various populations (Andersen 1971; Beunen 1990; Bull et al. 1999; Schmidt et al. 2008). Schmidt et al. (2008) analysed radiographs of German individuals between 12 to 16 years of age; the mean difference between skeletal and chronological age was -0.1 and +1.4 years for TW2, and for TW3 it was -0.4 to +0.2 years. Bull et al. (1999) assessed radiographs of 362 British individuals between 2 and 18 years of age. The authors compared Greulich and Pyle's method with the TW2 method and found a mean age disparity of $0.38 \pm 0.71$ years. Intra-observer variation was larger for the Greulich and Pyle compared to the TW2 method, with 95\% confidence intervals of -2.46 years to 2.18 years compared to -1.41 years to 1.43 years respectively.

\subsubsection{Mandibular morphology}

Mandibular morphology, in particular ramus height, has been shown to correlate with cranial growth (Franklin and Cardini 2007; Norris 2002) and can be used to predict age in a forensic context. Two relevant studies are considered below.

\section{i) Norris (2002)}

Norris (2002) aimed to investigate whether age could be accurately estimated using a single mandibular measurement. The study analysed 53 individuals from the skeletal collection at the National Museum of Natural History, Washington D.C. The Native American subjects ranged from birth to 2 years of age. A sliding calliper (or mandibulometer) was used to take seven measurements as follows: length of the body, full length of half of the mandible, height of the body, minimum ramus breadth, maximum ramus breadth, maximum ramus height and gonial angle. The use of ramus height to estimate age was accurate to within \pm 6 months in individuals under 2 years of age. 


\section{ii) Franklin and Cardini (2007)}

Franklin and Cardini (2007) investigated the potential applicability of mandibular morphology to estimate sub-adult age. Ramus height of the mandible was measured in 79 individuals (43 male; 39 female) between 1 to 17 years of age from two skeletal collections: South African Bantu from the R.A Dart Collection of Human Skeletons; and African American subjects from the Hamann-Todd Osteological Collection. The study formulated linear regression models for forensic application with standard error rates of \pm 1.4 years for individuals $>10$ years of age and \pm 1.2 for individuals $\leq 10$ years. The SEE for the entire sample (1-17 years) was higher at \pm 2.4 years.

\subsubsection{Spheno-occipital syncondrosis fusion}

The timing of the closure of the spheno-occipital syncondrosis has been shown to be highly varied between populations; published fusion ages range from 10.5 to 17 years in females and 12.5 to 19 years in males (Scheuer et al. 2000a). A selection of relevant studies are considered below.

\section{i) Franklin and Flavel (2014)}

Franklin and Flavel (2014) aimed to quantify the timing of spheno-occipital closure in a modern Western Australian sample. The study assessed 312 (169 male, 143 female) cranial multi-detector computer tomographs (MDCT scans). The PACS database accessed comprised scans from individuals presenting for clinical cranial evaluation at various Western Australian hospitals between 2010 and 2011. The scans had a slice thickness of less than $1.5 \mathrm{~mm}$ and were pre-screened according to strict selection criteria (e.g. exclusions made based on trauma, pathology). A four-stage scoring system was used to assess the degree of fusion: Stage 0 unfused; Stage 1 fusing endocranially; Stage 2 fusing ectocranially; Stage 3 complete fusion. Intra-observer agreement was $94 \%(\mathrm{~K}=0.907)$, while interobserver agreement was $90 \%(K=0.867)$. The mean age for complete fusion in females was $18.62 \pm 3.55$ years and $19.83 \pm 2.94$ years in males (Franklin and 


\section{CHAPTER THREE}

Flavel 2014). Complete fusion occurred prior to 25 years of age in all individuals. Fusion began earlier in females by approximately two years.

\section{ii) Bassed et al. (2010)}

Bassed et al. (2010) aimed to quantify the timing of spheno-occipital syncondrosis fusion for an Australian population and its applications in discriminating juveniles and adults around 18 years of age. The sample comprised 666 high resolution $(1 \mathrm{~mm})$ multi-slice CT scans, taken at the Victorian Institute of Forensic Medicine (VIFM). The sample ranged in age from 15 to 25 years. A five-stage scoring system was used: Stage 1 unfused; Stage 2 superior border closed; Stage 3 superior half closed; Stage 4 complete fusion scar present; Stage 5 complete fusion scar obliterated. The level of intra-observer agreement was 93.5\% ( $\mathrm{K}=$ $0.907)$, while inter-observer agreement was $86.6 \%(K=0.780)$. There was no significant difference in fusion timing between males and females after 16 years ( $p$ $<0.01$ ). All individuals were shown to have completed fusion by 17 years of age. The timing of complete fusion reported in this study is markedly earlier than other published literature, which generally report latest complete fusion by 25 years of age (Drake et al. 2010; Scheuer et al. 2000a).

\subsubsection{Long bone metrics}

Metric methods of age estimation utilise measurements taken from long bones and address some of the subjective error associated with observational assessment.

\section{i) Cardoso et al. (2014a)}

Cardoso aimed to formulate sub-adult age estimation models using diaphyseal long bone length. The study involved two samples: a $19^{\text {th }}$ to $20^{\text {th }}$ Century Portuguese population from the skeletal collection at the Natural Museum of Natural History and Science in Lisbon; and an $18^{\text {th }}$ to $19^{\text {th }}$ Century English population from the Spitalfields and St. Bride's skeletal collections in London. The study sample comprised 184 subjects (72 female, 112 male) from birth to 12 years 
of age, with 109 from the Portuguese collection, 11 from St. Bride's and 64 from the Spitalfields collection. Maximum diaphyseal length (humerus, radius, ulna, femur, tibia and fibular) was measured using an osteometric board (or sliding calliper) and recorded to the nearest whole millimetre. Intra- and inter-observer error was calculated as the relative technical error or measurement (\%TEM) and coefficient of reliability $(\mathrm{R})$, with TEM under 0.77 and 0.72 respectively and $R$ values consistent at 1.00 .

There was no significant size or sex differences between the Portuguese and English samples for individuals $<2$ years of age, but for individuals $>2$ years of age there was a significant difference; as a result two subgroups were created $(<2$ years and $>2$ years). Classic calibration models were calculated for the female, male and pooled sex groups. The mean standard error (MSE) of the models were also calculated; the most accurate model was based on the length of the femur in all three groups (total sample): \pm 1.21 years; \pm 0.92 years; and \pm 1.06 years for females, males and pooled sexes respectively. The largest MSE based on the female data was for the fibula at \pm 1.39 years; for males it was the ulna at \pm 1.10 years; and in the pooled sex sample it was \pm 1.21 years for both the radius and ulna. The calibration models were also created for the two subgroups. The authors note that the formulae would be difficult to apply in a forensic context as the growth rates of the sample is not representative of modern populations.

\section{ii) Rissech et al. (2013)}

Rissech et al. (2013) aimed to investigate the correlation between humeral development and chronological age. The sample included 181 individuals (91 female, 90 male) from birth to 25 years of age. The sample was drawn from three skeletal collections: St. Bride's, London ( $18^{\text {th }}$ and $19^{\text {th }}$ Century); Bocage Museum, Lisbon (19 ${ }^{\text {th }}$ and $20^{\text {th }}$ Century); and the Coimbra University Anthropological Collection, Portugal ( $19^{\text {th }}$ and $20^{\text {th }}$ Century). Four measurements were taken: diaphyseal length; transversal diameter of the proximal end; epicondylar breadth of the distal epiphysis; and the vertical diameter of the head. Age estimation models 


\section{CHAPTER THREE}

were then formulated for all measurements. The standard error of the estimate (SEE) was calculated for all models; the most accurate was \pm 1.336 years (vertical diameter of humeral head). The least accurate model was for the transversal diameter of the proximal humerus ( \pm 2.360 years).

\subsubsection{Epiphyseal fusion of the Pelvic Girdle and Proximal Femur}

The timing of epiphyseal fusion of the pelvic girdle and proximal femur have been studied for potential forensic age applications. The investigations have been primarily focused on the sequence of fusion, albeit with minimal statistical analyses. The following reviews a selection of relevant macroscopic and morphometric methods.

\section{Macroscopic Approaches}

\section{i) Coqueugniot et al. $(2007 ; 2010)$}

The first study aimed to formulate new age estimation standards based on infracranial skeletal elements. The study sample was obtained from a skeletal collection at Coimbra University in Portugal, and comprised individuals born 1826 to 1922 , with associated date of deaths of 1904 and 1938 . The study sample consisted of 137 individuals (69 females, 68 male) with an age-at-death ranging from 7 to 29 years. There were a total of 64 infra-cranial centres of ossification analysed (scapula; clavicle; humerus; radius; ulna; os coxa; femur; tibia; calcaneus; and sacrum) according to a three-stage scoring system: (a) no fusion; (b) partial fusion; and (c) complete fusion. Sample assessment was undertaken by two observers (each scored half of the sample) with any unusual cases reviewed collaboratively.

Inter-observer correlation was calculated based on the assessment of 15 skeletons and was reported as 'minor differences in coding'. Bilateral asymmetry in the timing of the fusion of ossification centres was calculated, with $8 / 26(30.1 \%)$ paired centres found to be significantly different: ilium-pubis; ischium-ilium; iliac crest; 
sternal-end of the clavicle; distal radius; femoral head; proximal tibia; and the distal fibula. Results were presented as a series of figures displaying the age range for each stage in each morphological attribute. In addition, the results are compared to the epiphyseal standards of Buikstra and Ubelaker (1994). Their results demonstrated a large variation in the timing of fusion in the distal and medial humerus.

Table 3.1. Timing of fusion (age in years) as reported by Coqueugniot and Weaver (2007).

\begin{tabular}{lcccccc}
\hline \multirow{2}{*}{ Morphological Attribute } & \multicolumn{2}{c}{$\begin{array}{c}\text { Oldest subject } \\
\text { unfused }\end{array}$} & \multicolumn{2}{c}{ Fusing } & \multicolumn{2}{c}{$\begin{array}{c}\text { Youngest to } \\
\text { complete fusion }\end{array}$} \\
\cline { 2 - 7 } & Female & Male & Female & Male & Female & Male \\
\hline Anterior inferior iliac spine & 12 & 16 & $14-19$ & $16-20$ & 17 & 16 \\
Ischial tuberosity & 12 & 20 & $14-26$ & $16-24$ & 20 & 23 \\
Iliac crest & 19 & 20 & $17-26$ & $16-24$ & 22 & 20 \\
Ilium-Ischium & 19 & 16 & $11-29$ & $15-20$ & 12 & 17 \\
Ilium-Pubis & 19 & 16 & $12-21$ & $16-26$ & 12 & 17 \\
Lesser trochanter & 12 & 20 & $14-19$ & $16-21$ & 17 & 19 \\
Greater trochanter & 12 & 20 & $17-19$ & $16-20$ & 14 & 16 \\
Femoral head & 17 & 20 & $12-22$ & $16-24$ & 17 & 19 \\
\hline
\end{tabular}

The follow-up study of Coqueugniot et al. (2010) aimed to formulate an "alternative probabilistic approach" to age estimation using infra-cranial skeletal elements. The study evaluated the accuracy of epiphyseal fusion age assessment, whilst attempting to overcome the 'shortcomings' of the small reference sample. Data were analysed using kernel smoothing to produce likelihood distributions for all morphological attributes and ages. The authors chose a $15 \%$ margin of error as this correlates to a \pm 1 year error margin for the 7 year old group and a \pm 4 year error margin for the 29 year old subjects. The point estimates of age (based on the availability of the entire skeleton) had an accuracy value of up to $82 \%$, whilst single 


\section{CHAPTER THREE}

site estimates ranged from $41 \%$ to $78 \%$. Overall the age of females tended to be overestimated, whereas it was underestimated in males.

\section{ii) Schaefer (2008)}

The aim of this study was to quantify the timing of epiphyseal fusion in a sample of Bosnian males to assist the identification of commingled remains (e.g. identification of victims of conflicts in the former Yugoslavia). The identity of all subjects was confirmed through DNA and anthropological assessment prior to the commencement of the study. The sample included 258 male Bosniak individuals (Bosnian Muslim) ranging from 14 to 30 years of age. A total of 21 epiphyses were analysed: medial clavicle; acromion process; coracoid process; humerus (proximal and distal); ulna (proximal and distal); iliac crest; acetabulum; ischial tuberosity; proximal femur; greater and lesser trochanter; distal femur; tibia (proximal and distal); and fibula (proximal and distal). The degree of fusion was scored using a three-phase system as follows: Stage 0 no fusion; Stage 1 fusion commenced but not yet complete; and Stage 2 fusion completed and epiphyseal scar may (or may not) be present. The sequence for the commencement and completion of union was established according to the majority of individuals. The oldest individual found to present non-fusion (Stage 0) at the lesser trochanter, greater trochanter and ischial tuberosity was 18 years, with active fusion (Stage 1) occurring between 16 to 20 years of age.

\section{iii) Ríos et al. (2008)}

The aim of this study was to verify that the timing of sacral fusion could be used to estimate forensic age. The study investigated the degree of fusion in the central bodies of the sacral vertebrae. The study sample consisted of 242 subjects (142 male; 100 female) from the skeletal collection at the National Museum of Natural History in Lisbon, Portugal. The subjects ranged from 16 to 59 years of age and were assessed using a five-stage scoring system. The scoring system, first described by McKern and Stewart (1957), is: (0) no fusion; (1) fusion started, less than $1 / 3$ fused; (2) more than $1 / 3$ but less than $2 / 3$ fused; (3) more than $2 / 3$ fused, 
not yet completely fused; and (4) complete fusion. The mean age-at-transition from no fusion (stage 0) to the start of fusion (stage 1) at S1-2 was $25.6 \pm 8.7$ and $21.1 \pm 3.7$ years for males and females respectively. The oldest subjects found to present non-fusion (Stage 0) were 29 (female) and 35 years of age (male). Subjects under 20 years of age were scored as unfused at $\mathrm{S} 1-2$ in $90 \%$ of males and $100 \%$ of females. Thus Ríos et al. (2008) concluded that the scoring of nonfusion at S1-2 was useful for assigning unidentified remains to broad age categories (e.g. under or over 18 years; juvenile or adult).

\section{iv) Cardoso et al. (2014b)}

Cardoso and Pereira investigated fusion timing in the primary and secondary ossification centres of the sacrum and discussed their potential application for age estimation. The study sample consisted of 191 documented skeletons (101 male; 90 female) from the National Museum of Natural History in Lisbon, Portugal. The $20^{\text {th }}$ Century subjects were from low to middle socioeconomic backgrounds (Cardoso et al. 2014b). A three-stage scoring system (1: no fusion; 2: partial fusion; 3: complete fusion) was used to score the degree of fusion of nine primary centres and three secondary centres of ossification. The primary centres of ossification assessed were between the neural arches and central body for all five sacral vertebrae, and for S1 and S2 the fusion between the neural arches and costal element and the fusion between the costal element and central body. The secondary centres of ossification assessed in the sacral vertebrae (S1, S2, S3, S4, S5) were the sacro-iliac joint, lateral margin and annular ring.

Intra-observer agreement was reported to be $100 \%(k=1.00)$, while inter-observer agreement was reported as $96 \%$ and $87 \%$ between assessors. The primary centres were shown to commence fusion from 1 year of age, with complete fusion achieved by 8 years of age. The secondary centres commenced fusion from 15 years, with complete fusion observed from 21 years of age. The neural arch and central body of S5 were the first primary centre to complete fusion, while the costal 


\section{CHAPTER THREE}

element and central body of S1 were the last to fuse. The annular rings and sacroiliac epiphyses complete fusion prior to the lateral margin.

\section{Radiographic Approaches}

\section{v) Risser (1958)}

An American orthopaedic surgeon (Joseph C Risser) developed a method of grading the ossification of the iliac apophysis (Risser sign) whilst investigating the treatment of idiopathic scoliosis. This method (commonly known as the "Risser method") is popular in the clinical analysis of radiographs (e.g. Biondi et al. 1985; Izumi 1995; Little and Sussman 1994). Risser conducted a 10 year study at the Los Angeles Orthopaedic Hospital quantifying physiological signs of the completion of vertebral growth. Risser proposed that the termination of spinal growth coincided with the complete fusion of the iliac apophysis. The method is based on the assumption that the iliac crest ossifies antero-laterally from a single ossification centre. This is in contrast to Scheuer et al. (2000c) who described the formation of iliac crest from two separate ossification centres (see Chapter Four).

The Risser method has over time developed into two different commonly applied versions: the US and French grading systems (Bitan et al. 2005; Wittschieber et al. 2013a). The American Risser grading system has six stages in which the iliac crest apophysis is divided into quarters. The French grading system has six stages in which the iliac crest apophysis is divided into thirds (see page 56 for a more detailed explanation). Both the French and American versions assume that the iliac crest ossifies from two apophysis (anterior and posterior).

\section{vi) Wittschieber et al. (2013a)}

Wittschieber et al. (2013a) investigated the forensic applicability of the Risser scoring system for the iliac crest apophysis. The study examined 566 anteroposterior pelvic radiographs of subjects between 10 to 30 years of age. The scans were taken between 2008 and 2010 at Germany's Münster University Hospital 
Institute of Clinical Radiology. The observers were blind to the age of the subjects and bilateral assessments were performed.

The scans were assessed using the French (FRE) and American (USA) versions of the six-stage Risser scoring system for the iliac crest apophysis. The American Risser scoring system divides the iliac crest into quarters as follows: Stage 0 no ossification; Stage 1 ossification within the first quarter commencing anterolaterally; Stage 2 ossification within the first half; Stage 3 ossification extending into the third quarter; Stage 4 ossification extending into the fourth quarter until complete ossification of the anterior apophysis; Stage 5 ossification posteromedially until complete fusion.

The French Risser scoring system divides the iliac crest into thirds, with the stages as follows: Stage 0 no ossification; Stage 1 ossification within the first third commencing antero-laterally; Stage 2 ossification within the second third; Stage 3 ossification extending into the third quarter; Stage 4 postero-medial fusion of the posterior apophysis begins; Stage 5 complete fusion of the apophysis to the ilium.

The mean age for assignment as non-fusion (Stage 0; left side) using both methods was $11.31 \pm 1.22$ and $12.38 \pm 1.41$ years in females and males respectively. There were no female subjects assigned using the USA method to Stage 3 (right side) and Stage 1 or 3 for the left side. The mean age for assignment as fused (Stage 5; left side) using the FRE method was $24.14 \pm 3.29$ and $24.87 \pm 3.50$ years in females and males respectively. The mean age for assignment as fused (Stage 5; left side) using the USA method was $22.77 \pm 4.10$ and $23.84 \pm 4.14$ years in females and males respectively. The authors noted that the Risser methods inadequately address the fusion of the posterior apophysis. Wittschieber et al. (2013a) concluded that both the USA and FRE Risser scoring systems "appear suitable for forensic age estimation in living individuals", but note 


\section{CHAPTER THREE}

the exposure of the gonads to high doses $(\sim 1350 \mu \mathrm{Sv})$ of radiation decrease the feasibility of the forensic applications for this method.

\section{vii) Bitan et al. (2005)}

Bitan et al. (2005) aimed to quantify disagreement between the American and French Risser scoring systems. The study examined 301 proximal pelvic radiographs from 167 subjects aged between 10 to 19.5 years of age. The scans were taken between 1975 to 2000, and are of subjects clinically diagnosed with adolescent idiopathic scoliosis in America. Two observers independently assessed 301 (24 male; 143 female) subjects according to either the American or French Risser grading method. The observers were blind to the age and sex of the subjects and assessed both the right and left sides.

Cross-tabulation calculations indicated that the agreement between the two versions ( $\mathrm{K}>0.4$ ) was "good to excellent" (pp.192), with $50.8 \%$ of observations in agreement (Bitan et al. 2005). Of the 148 cases of disagreement, 147 had a higher American Risser score higher than the French score by one $(88.5 \%)$ or two grades $(11.5 \%)$. This showed that the French Risser system underestimated the degree of ossification compared to the US Risser system. The study highlighted consistency in Stage 0, which showed perfect agreement between the two methods. The inconsistency in agreement between Stages 1-5 was highlighted, as agreement between the two methods ranged between 0.12 to 1.0 .

\subsection{Summary}

This chapter reviewed a selection of literature investigating age estimation methods both generally and those that use the bones of the sacrum, os coxa, proximal femur. The papers reviewed highlight the lack of Australian standards and thus the requirement for population specific studies. 


\section{CHAPTER FOUR: MATERIALS AND METHODS}

\subsection{Introduction}

This chapter outlines the sources of data for the study, including a description of the sample and the methods used to assess the MDCT scans. The statistical methodology used to analyse and interpret the data is also explained, including the rationale for selecting the specific methods applied; these include the precision test (intra-observer accordance), test for bilateral asymmetry (significance of the difference between left and right sides), regression (age estimation models) and transition analyses (mean age of transition between stages).

\subsection{Materials}

\subsubsection{Study sample}

The sample comprises 562 pelvic Multi-Detector Computed Tomograph (MDCT) (292 male; 270 female) scans acquired from the Western Australian Department of Health (DoH) Picture Archiving and Communication System (PACS) database. This database contains medical scans from a number of Western Australian hospitals (e.g. Royal Perth; Sir Charles Gairdner Hospital) and collectively represent individuals presenting for pelvic clinical evaluation. The scans are diagnostic from both clinical and trauma assessments. The age range of the sample studied is 1 day through to 30 years of age (Table 4.1). The date of birth and date of scan is known thus age at time of scan is known to two decimal places.

Table 4.1. Age distribution (in years) for the total sample.

\begin{tabular}{cccccc}
\hline & $\mathbf{n}$ & Mean & SD & Min & Max \\
\hline Male & 292 & 14.29 & 8.08 & 0.01 & 30.00 \\
& & & & & \\
Female & 270 & 13.42 & 7.82 & 0.17 & 30.00
\end{tabular}




\section{CHAPTER FOUR}

\subsubsection{Inclusion and exclusion criteria}

MDCT scans presenting evidence of major abnormalities or considerable skeletal trauma of the pelvis, sacrum and proximal femur were not included in the present study. The main skeletal abnormalities observed include: skeletal trauma (e.g. fractures; dislocations; vascular disruptions resulting in osteonecrosis), congenital disorders (e.g. spina bifida, scoliosis, hydrocephaly), or dysplasias and neoplastic conditions. The majority of useable scans were thus those acquired for the clinical diagnosis of strains, sprains and soft tissue injuries. The MDCT scans are anonymous and only the sex and age of the individual is known. Image resolution is another important consideration for sample inclusion; scans with a slice thickness over $1.5 \mathrm{~mm}$ were excluded. Image quality beyond the latter threshold does not have the resolution for the accurate assessment of the required morphological features. Figure 4.1 illustrates the resolution (range of slice thickness: $0.63-1.5 \mathrm{~mm}$ ) deemed suitable for the present study.

\subsubsection{Demographic profile of the Western Australian population}

The Western Australian population (of approximately 2.2 million) varies slightly to the general Australian population of 21.5 million (Office of Multicultural Interests 2013). Data from the 2011 Census shows that $31 \%$ of the Western Australian population were born overseas, compared to $26 \%$ of the Australian population (Australian Bureau of Statistics 2012; Office of Multicultural Interests 2013). The Aboriginal and/or Torres Strait Islander population of Western Australia is 3\%, slightly above the average frequency across Australia (2.5\%). The breakdown of the Australian population into four primary ancestry categories is shown in Table 4.2. It is evident that the Australian population is primarily of Caucasian ancestry. 


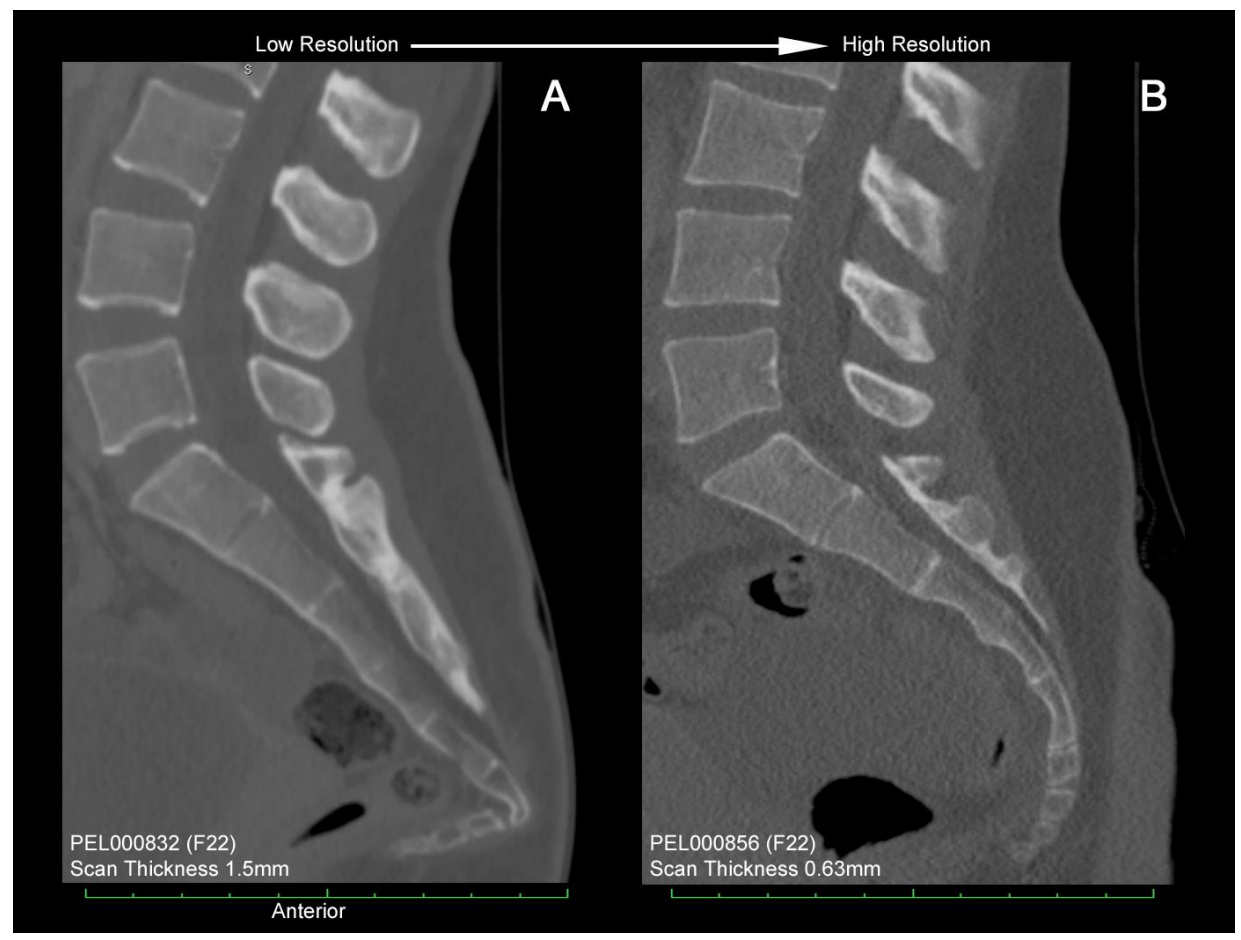

Figure 4.1. OsiriX visualisations showing contrasting slice thickness of lateral view pelvic MDCT scans. A: 3D MPR view of PEL000832 (Female, 22 years) with slice thickness of 1.5mm; B: 3D Multiplanar Reconstruction (MPR) view of PEL000856 (Female, 22 years) with a slice thickness of $0.63 \mathrm{~mm}$.

The ancestry of the subjects included in the present study is unknown, thus limiting the comparison to the Australian Bureau of Statistics data presented in Table 4.2. As it stands it can only be assumed that the ancestry of the sample mimics the general population demographics as reported in the 2011 census. The ancestry of the subject is not recorded at the time of scanning as it is not deemed to be medically relevant. The ancestral variation within the Australian population is apparent in the data presented in Table 4.2 but this level of variation would be less than the variation between the Australian population and other countries. Thus the Western Australian specific age estimation standards for the pelvic girdle and proximal femur would be more applicable to the general Australian population than the standards of other countries. 


\section{CHAPTER FOUR}

Table 4.2. Broad ancestral categories according to Australian State or Territory.

Source: Australian Bureau of Statistics (2012).

\begin{tabular}{llllll}
\hline Ancestry* & $\begin{array}{l}\text { Indigenous } \\
\text { Australian }\end{array}$ & Caucasian & Asian & African & $\begin{array}{l}\text { Other } / \\
\text { Unknown }\end{array}$ \\
\hline NSW & 0.025 & 0.740 & 0.134 & 0.005 & 0.096 \\
VIC & 0.007 & 0.777 & 0.124 & 0.008 & 0.084 \\
QLD & 0.036 & 0.791 & 0.060 & 0.006 & 0.107 \\
SA & 0.019 & 0.826 & 0.069 & 0.005 & 0.081 \\
WA & 0.031 & 0.763 & 0.089 & 0.015 & 0.102 \\
TAS & 0.040 & 0.823 & 0.025 & 0.003 & 0.109 \\
NT & 0.268 & 0.354 & 0.074 & 0.006 & 0.298 \\
ACT & 0.014 & 0.777 & 0.121 & 0.006 & 0.082 \\
OT ${ }^{* *}$ & 0.290 & 0.222 & 0.290 & 0.003 & 0.195 \\
\hline Total & 0.025 & 0.784 & 0.104 & 0.007 & 0.080 \\
\hline
\end{tabular}

${ }^{*}$ Ancestry categories taken from primary self-reported responses in the 2011 national census.

${ }^{* *}$ Other territories: Christmas Island, the Cocos (Keeling) Islands, and the Jervis Bay Territory.

\subsection{Human research ethics}

The ethical conduct and implications of any research involving human subjects in Australia is regulated by legislation established in the National Health and Medical Research Council's (NHMRC) National Statement on Ethical Conduct in Human Research (2007). The University of Western Australia requires staff and student researchers to comply with the policy listed in the National Statement. This project was granted approval from the Human Research Ethics Office (HREO) at the University of Western Australia prior to commencement; on the $16^{\text {th }}$ of May 2013, it was added to Professor Franklin's existing HREC approved program (RA/4/1/4362) - 'Novel approaches to the forensic identification of human remains: bone morphometrics' (see Appendix I). 


\subsection{Methods}

The following sections outline the methods used to visualize and assess the MDCT scans and the statistical approaches used to analyse the data and formulate the predictive models.

\subsubsection{Visualisation}

The MDCT scans are visualised using the OsiriX 64-bit software. OsiriX enables the visualization and magnification of Digital Imaging and Communications in Medicine (DICOM) images without the need to scale or alter image resolution. The software allows navigation of large multidimensional image data sets. The scans can be visualized in different displays as individual cross-sectional slices, thick-slab maximum intensity projections (MIP), orthogonal and oblique multiplanar reformatting (MPR) and 3D volume reconstruction (Rosset et al. 2004). OsiriX enables the manipulation of the images (zoom, pan, filtering, and intensity adjustment) as well as the additional functionality of multiplanar projection, convolution filter, variable slice thickness adjustment, volume rendering, intensity projection adjustment and surface rendering (Rosset et al. 2004). The different rendering options available for scan assessment in OsiriX are illustrated in Figure 4.2 . 


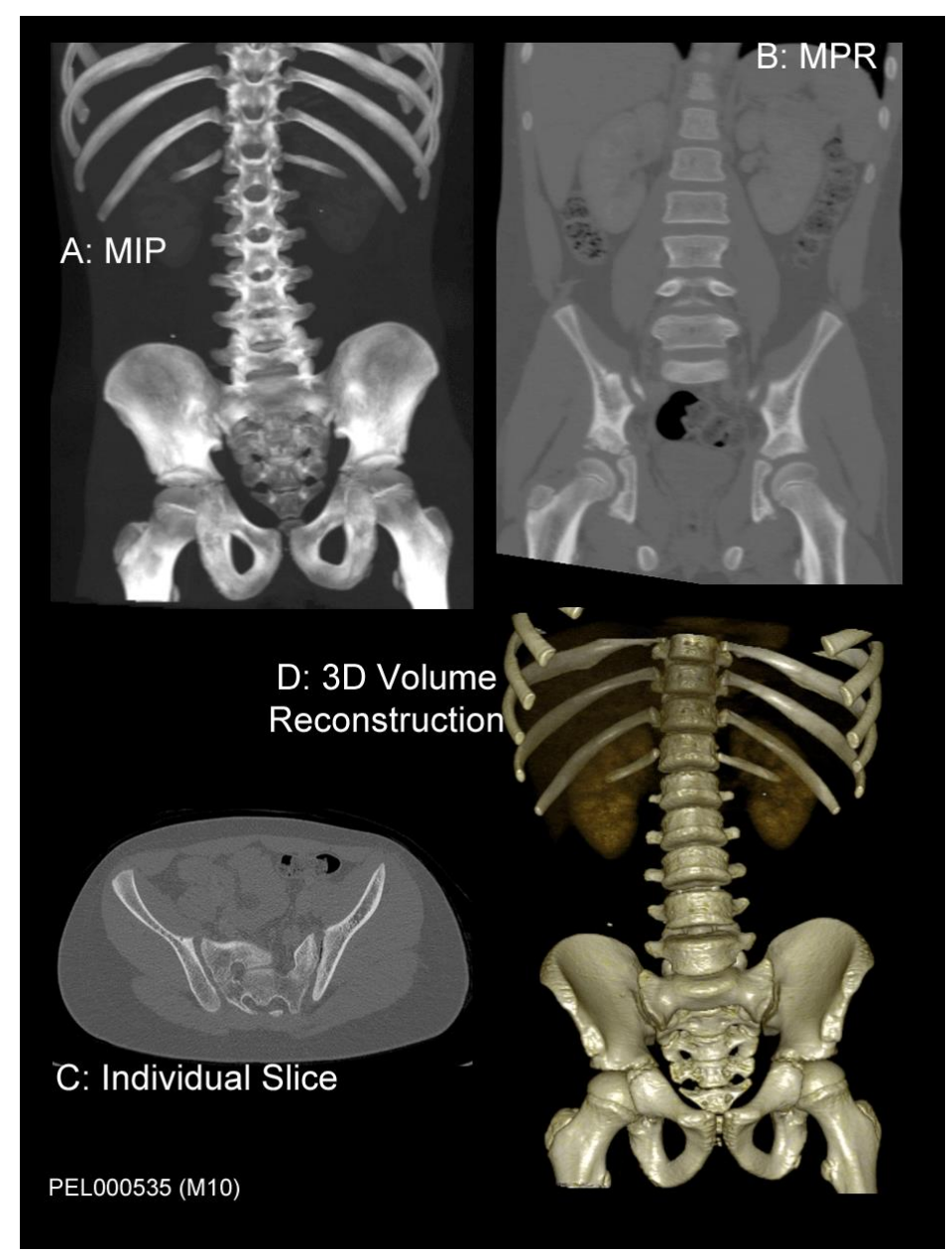

Figure 4.2. Visualisation in OsiriX of a pelvic MDCT scan of a 10.70 year old male.

A: Maximum intensity projection (MIP) anterior view of PEL000535; B: 3D Multiplanar reconstruction (MPR) anterior view of PEL000535; C: Individual slice coronal view of PEL000535; D: Anterior view of 3D volume rendering of PEL000535.

\subsubsection{Data acquisition}

The morphological developmental attributes assessed in the os coxa, sacrum and proximal femur are outlined in Table 4.3. The morphological developmental attributes are assessed using a three stage system commonly applied to score the fusion of secondary epiphyses in the os coxa and femur (Cardoso 2008; Johnston 1961). The degree of epiphyseal fusion relative to full maturity is scored as follows: 1) no fusion between the epiphyses (may not be present) and primary site; 2) partial fusion between the epiphysis and primary site; or 3) complete fusion of 


\section{CHAPTER FOUR}

the epiphysis, fusion scar may be present. As this system is simple to apply and familiar to most practitioners, it is accordingly used to assess all of the morphological developmental attributes in the present study. The individual regions assessed are described below. The scoring was completed using the four visualization techniques presented in Figure 4.2 using whichever technique provided the clearest assessment visualization for the scan and attribute being assessed.

Table 4.3. Morphological developmental attributes evaluated in the present study.

\begin{tabular}{ll}
\hline Skeletal Element & Code \\
\hline Femoral Head & FH \\
Greater Trochanter & GT \\
Lesser Trochanter & LT \\
Sacral Vertebrae 1-2 & S12 \\
Sacral Vertebrae 2-3 & S23 \\
Sacral Vertebrae 3-4 & S34 \\
Sacral Vertebrae 4-5 & S45 \\
Ilium-Ischium & ILIS \\
Ilium-Pubis & ILP \\
Ischium-Pubis & ISP \\
Anterior Inferior Iliac Spine & AlIS \\
\hline Ischial Tuberosity & ITE \\
Iliac Crest & ICE \\
\hline
\end{tabular}

\section{i) Proximal femur}

Three regions in the proximal femur are assessed: femoral head, greater trochanter; and the lesser trochanter (Figure 4.3) using a three stage scoring system. Stage 1 is classified as no fusion occurring between the epiphysis and diaphysis, with or without the epiphysis present. Stage 2 is classified as the fusion of the epiphysis. Stage 3 is assigned once fusion is complete and a scar may (or may not) be present. A fusion scar (also known as an epiphyseal scar) appears on 
a digital scan as dense band (called a scar) highlighting the point of epiphyseal fusion.

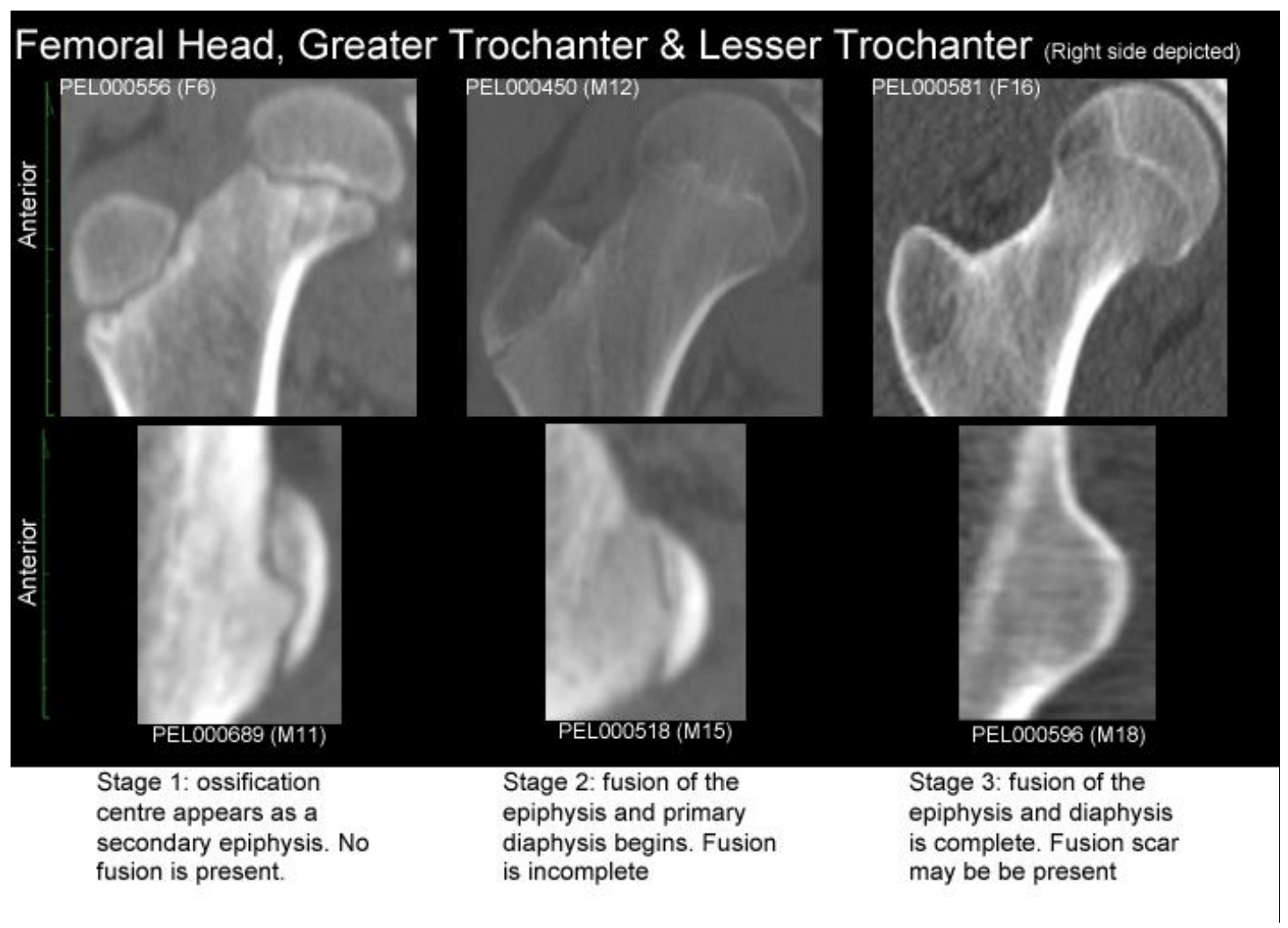

Figure 4.3. Anterior view of the femoral head, greater trochanter and lesser trochanter in various stages of fusion.

\section{ii) Os coxa}

The fusion of the three bones of the os coxa (ilium, ischium and pubis) is assessed using the three stage scoring system illustrated in Figure 4.4. At Stage 1 there is no fusion between the three bones and epiphyseal flakes may (or may not) be present. At Stage 2 fusion of the three bones and the epiphyseal flakes commences, but fusion is not yet complete. Stage 3 is assigned once fusion is complete and a fusion scar may (or may not) be present. 


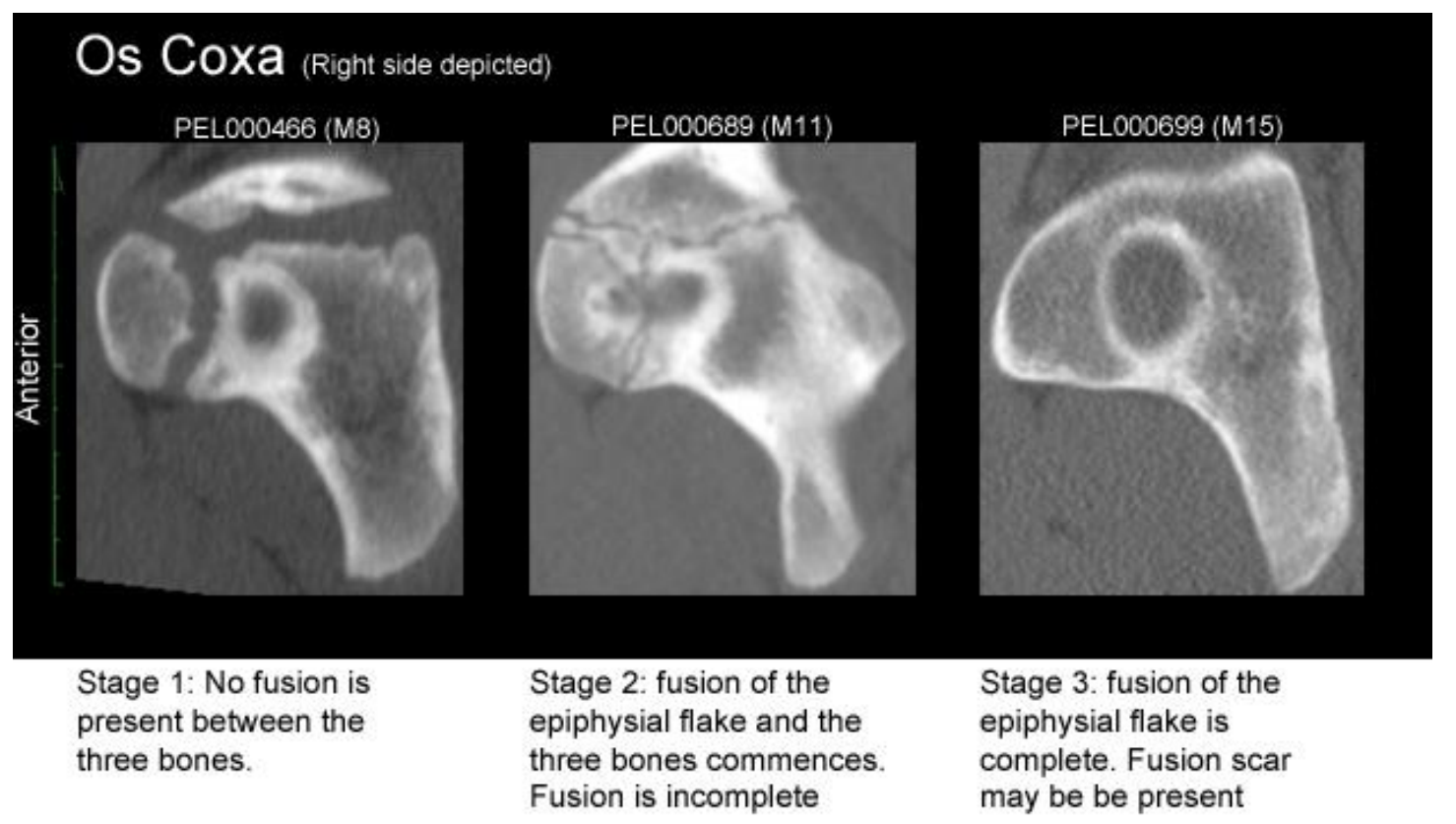

Figure 4.4. Anterior view of the bones of the os coxa (ilium, ischium and pubis) in various stages of fusion.

\section{iii) Anterior inferior iliac spine}

The anterior inferior iliac spine is scored as shown in Figure 4.5. In Stage 1 fusion has not commenced and the epiphysis may (or may not) be present. At Stage 2 fusion between the epiphysis and ilium has commenced at any point along the crest, but is not yet complete. Stage 3 is assigned once fusion is complete and a fusion scar may (or may not) be present.

\section{iv) Ischial tuberosity}

The ischial tuberosity is scored as shown in Figure 4.6. In Stage 1 fusion has not yet commenced and the epiphysis may (or may not) be present. In Stage 2 fusion has commenced between the epiphysis and the ischium and fusion is not yet complete. Stage 3 is assigned once fusion is complete and a fusion scar may (or may not) be present. 


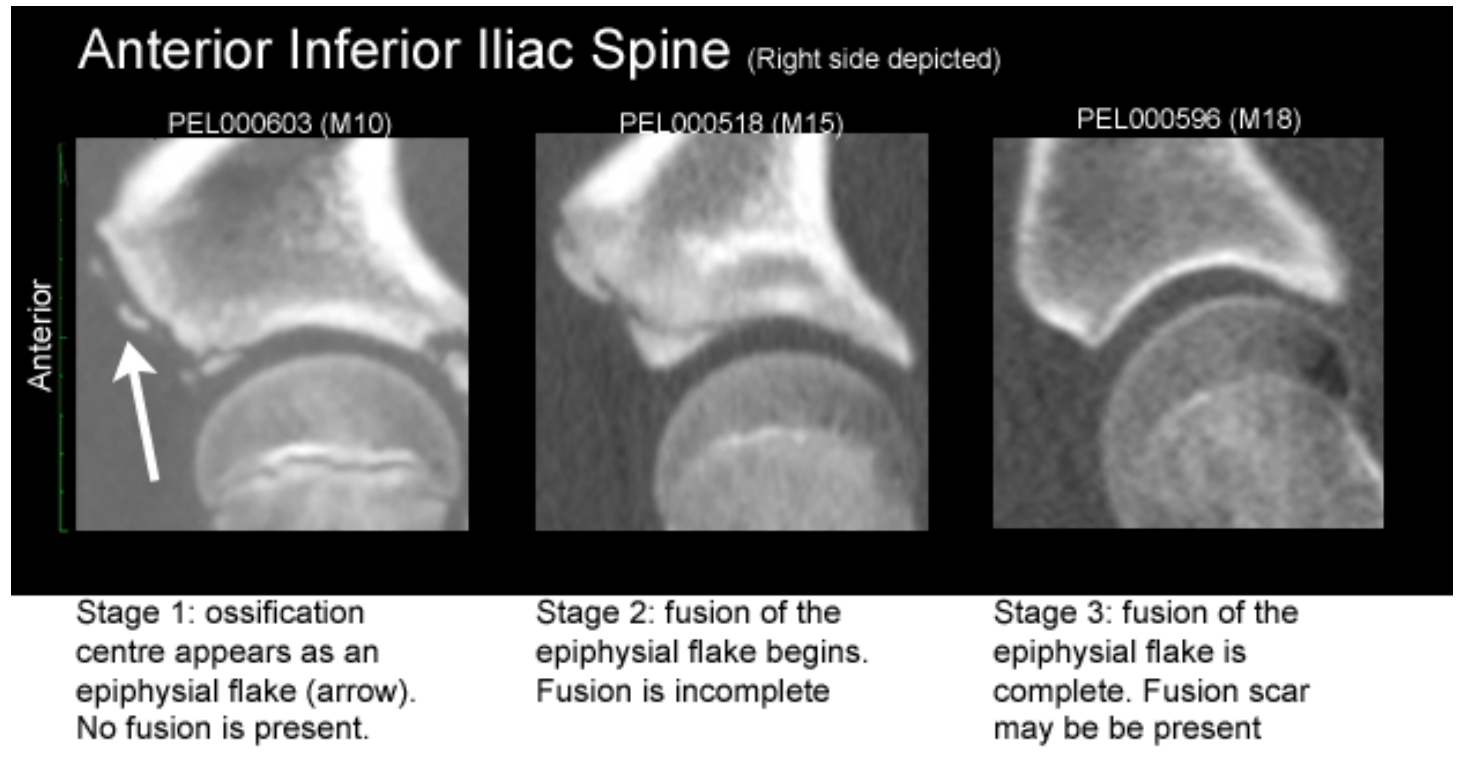

Figure 4.5. Anterior view of the anterior inferior iliac spine in various stages of fusion.

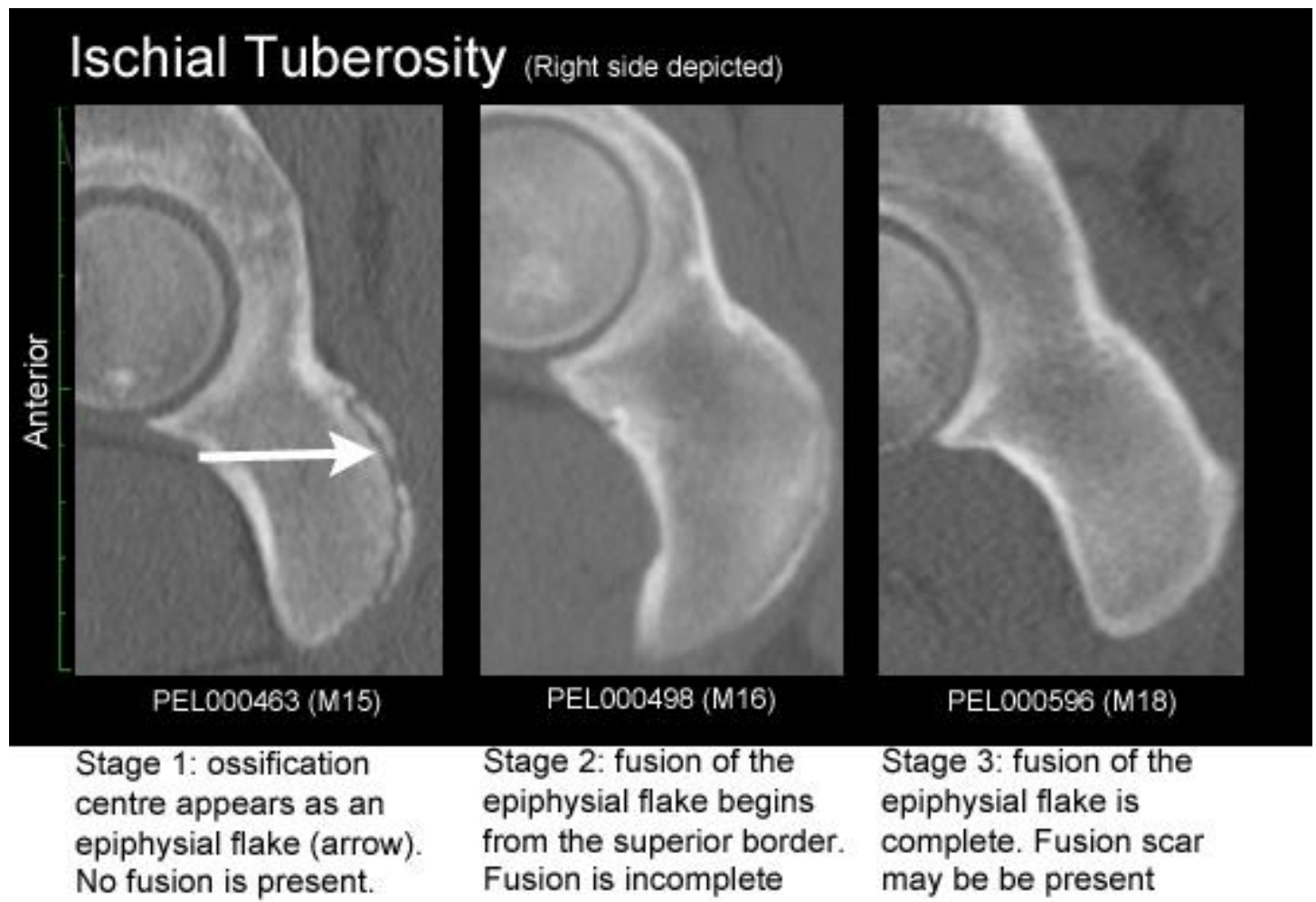

Figure 4.6. Superior view of the ischial tuberosity in various stages of fusion. 


\section{v) Sacral vertebrae}

The sacral vertebrae are scored as shown in Figure 4.7. At Stage 1 no fusion has commenced between the vertebrae. In Stage 2 fusion has commenced between the vertebrae, but is not yet complete. Stage 3 is assigned once fusion is complete and a fusion scar may (or may not) be present.

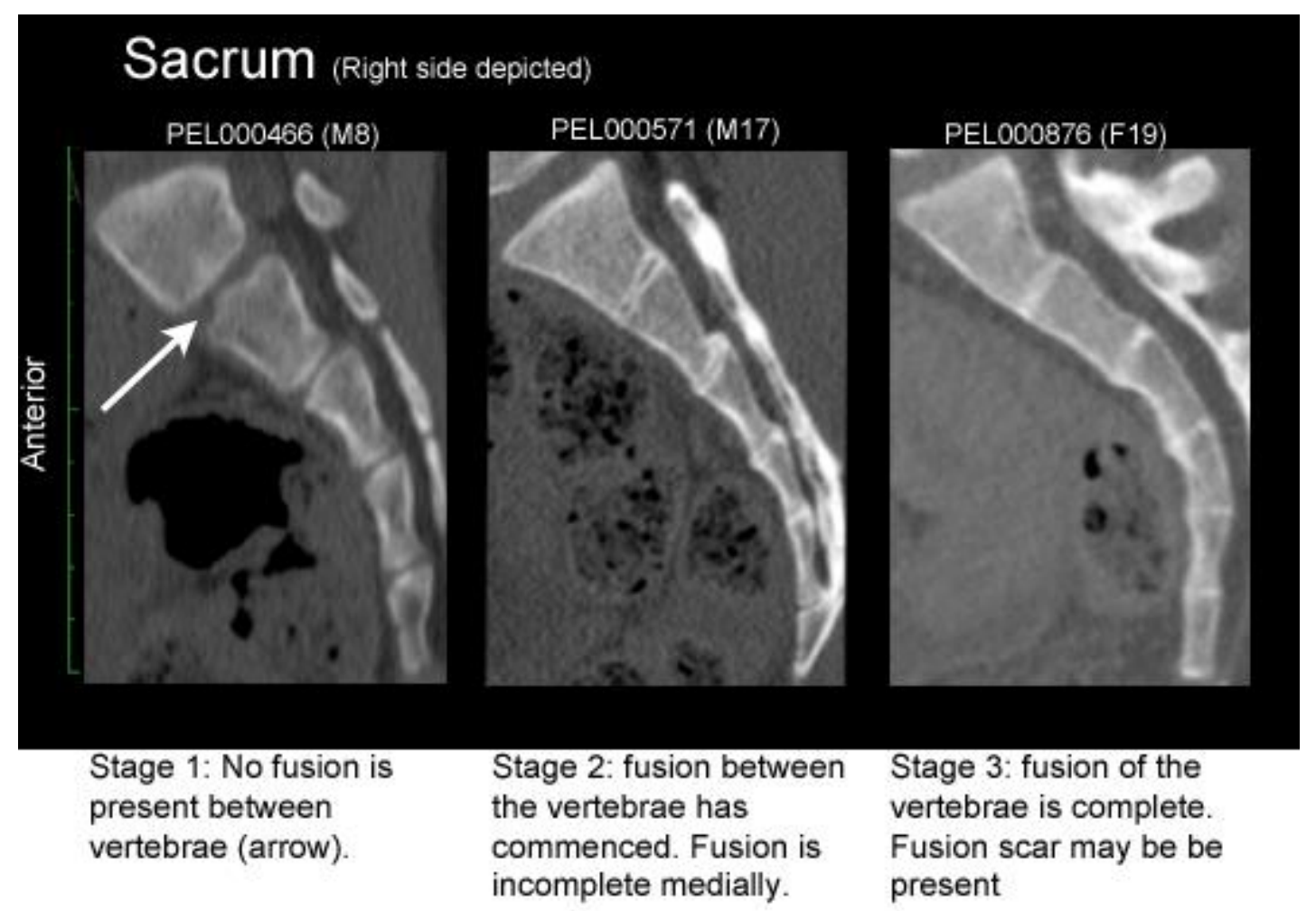

Figure 4.7. Lateral view of the sacral vertebrae in various stages of fusion.

\section{vi) Iliac crest - 3 phase system}

The iliac crest is scored as shown in Figure 4.8. In Stage 1 fusion has not commenced and the epiphysis may (or may not) be present. In Stage 2 fusion between the epiphysis and the ilium has commenced, but it is not yet complete. Stage 3 is assigned once fusion is complete, and a fusion scar may (or may not) be present. 


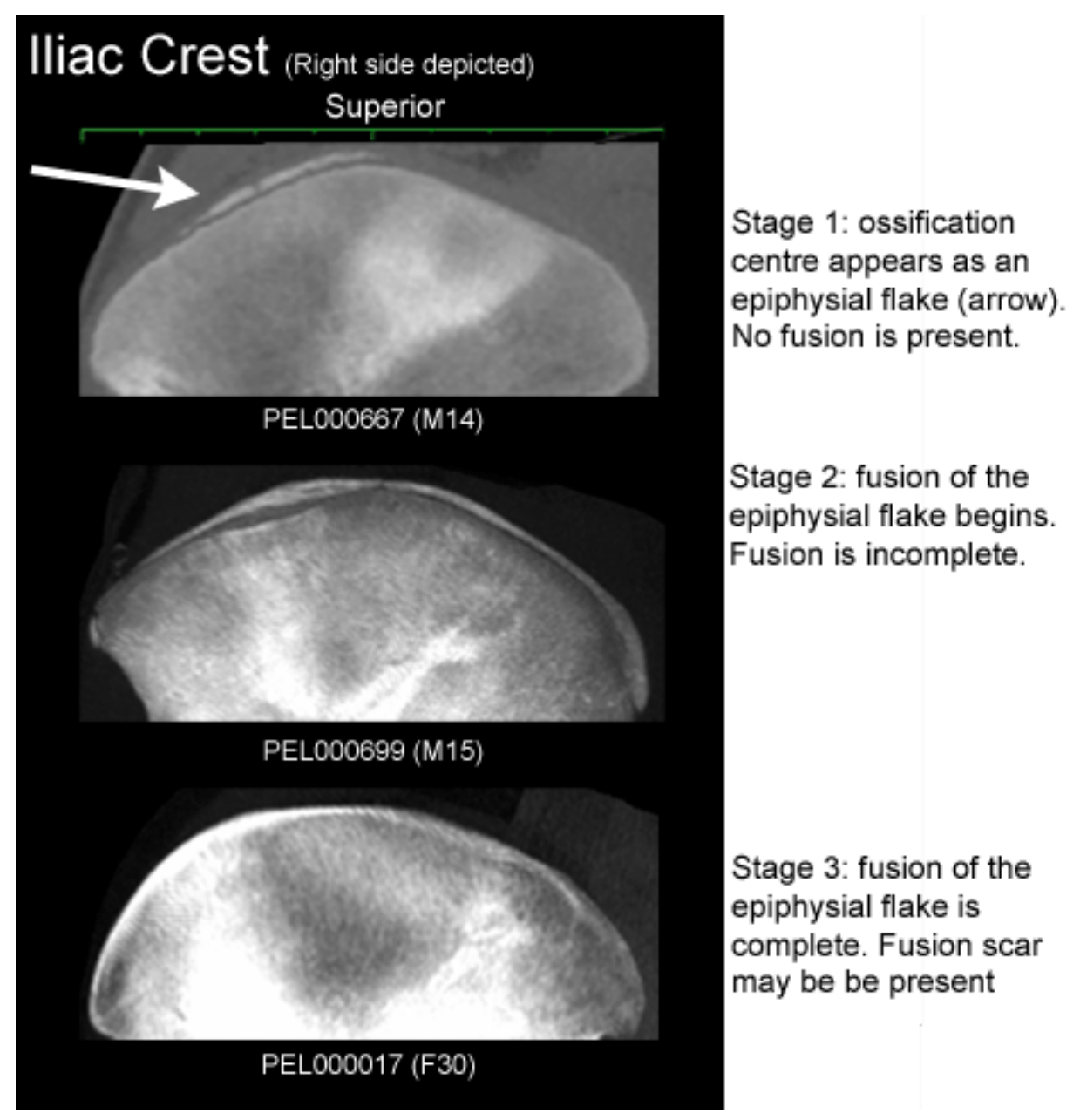

Figure 4.8. Superolateral view of the iliac crest in various stages of fusion.

\section{vii) Iliac crest - Risser scoring system}

The Risser (1958) scoring system is also used to assess the iliac crest in the present study. This system was designed as a clinical method of assessing radiographs and is being evaluated for its forensic applicability to MDCT scans. The Risser scoring system has been developed into two slightly different versions; the French (FRE) and American (USA) Risser scoring methods, which are described in Table 4.4 and illustrated in Figure 4.9.

The French Risser scoring system divides the anterior apophysis into thirds and has an individual stage for scoring the posterior apophysis (Bitan et al. 2005; Wittschieber et al. 2013a). The American Risser scoring system divides the 


\section{CHAPTER FOUR}

anterior apophysis into quarters and includes the fusion of the posterior apophysis into the final stage with complete fusion (Bitan et al. 2005; Wittschieber et al. 2013a).

Table 4.4. The French and American Risser lliac Crest Scoring Systems.

\begin{tabular}{lll}
\hline Stage & \multicolumn{1}{c}{ French* $^{*}$} & \multicolumn{1}{c}{ American* $^{*}$} \\
\hline 0 & $\begin{array}{l}\text { No ossification } \\
\text { Ossification within the first third } \\
\text { of the anterior apophysis (0-33\%) }\end{array}$ & $\begin{array}{l}\text { Ossification within the first quarter of } \\
\text { the anterior apophysis (0-25\%) }\end{array}$ \\
\hline $\begin{array}{l}\text { Ossification extending into the } \\
\text { second third of the anterior } \\
\text { apophysis (33-66\%) }\end{array}$ & $\begin{array}{l}\text { Ossification extending into the second } \\
\text { quarter of the anterior apophysis (25- } \\
49 \%)\end{array}$ \\
$\begin{array}{l}\text { Ossification of the entire anterior } \\
\text { apophysis (66-100\%) }\end{array}$ & $\begin{array}{l}\text { Ossification extending into the third } \\
\text { quarter of the anterior apophysis (50- } \\
74 \%)\end{array}$ \\
\hline $\begin{array}{l}\text { Ossification of the posterior } \\
\text { apophysis } \\
\text { Complete ossification of the iliac } \\
\text { crest }\end{array}$ & $\begin{array}{l}\text { Ossification of the entire anterior } \\
\text { apophysis (75-100\%) } \\
\text { Ossification of the posterior apophysis } \\
\text { to complete fusion of the iliac crest }\end{array}$ \\
\hline
\end{tabular}

* Adapted from (Bitan et al. 2005)

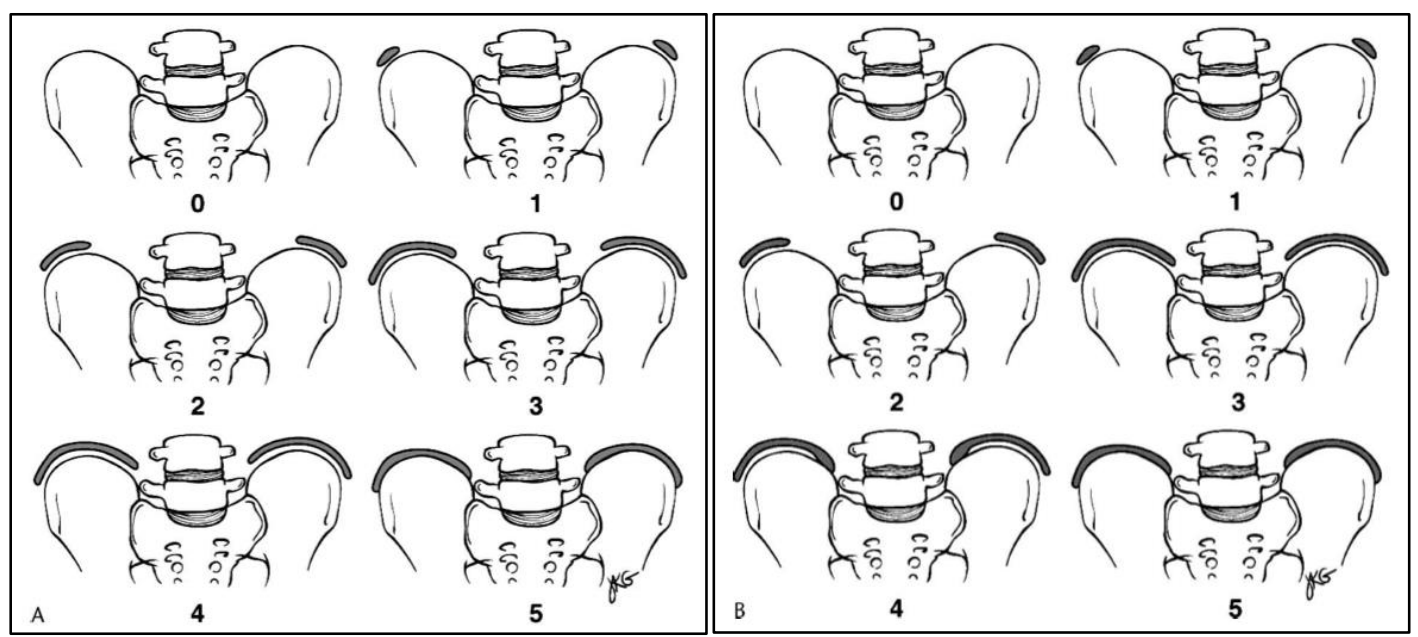

Figure 4.9. A) The American and B) French Risser scoring systems for the iliac crest. Stages are defined in Table 4.4. Source: Bitan et al. (2005). 


\subsection{Statistical analyses}

The following sections describe the statistical methods employed in the present study. Intra-observer accordance was evaluated prior to performing any statistical analyses. A selection of parametric tests are then undertaken to assess the following: sample descriptives; bilateral asymmetry; significance of sexual dimorphism in developmental timing (Cohen's Kappa); relationship between age and the assessment scores (regression analysis); and the age range during the transition between phases (transition analysis). Transition analysis is performed

using the software package Nphases2 (available at http://konig.la.utk.edu/nphases2.htm). All other analyses are performed with the statistical software Statistical Package for the Social Sciences, version 22 (IBM SPSS 22).

\subsubsection{Intra-observer precision}

Prior to data collection, a precision test was conducted to statistically quantify the degree of intra-observer error in the repeat assignment of developmental stages. The precision test involved the repeat assessment of 26 pelvic MDCT scans over 10 consecutive days (every second day) for a total of five assessments. The time between reassessment reduces the possibility of recalling the scores assigned during a previous assessment. The scans were selected by an independent party, with no data relating to age, so that the assessment remained unbiased. The morphological developmental attributes listed in Table 4.3 were evaluated in each scan. The age of the subjects evaluated ranged from 6 to 24 years to cover the developmental range representative of the total sample. All scans had a slice thickness between 0.75 to $1.40 \mathrm{~mm}$ to ensure the scans met the study threshold.

Fleiss' Kappa is used to assess intra-observer error; this statistic allows the calculation of the level of agreement between observations above that expected by chance. The ratio of observed versus expected values is expressed as a value between 0 (no agreement) and 1 (perfect agreement). Interpretation of the significance values follows Landis and Koch (1977a; 1977b) as shown in Table 4.5. 
Table 4.5. Significance of the Kappa statistic. Source: Landis and Koch (1977b).

\begin{tabular}{ll}
\hline Kappa Statistic & Strength of Agreement \\
\hline$<0.00$ & Poor \\
$0.00-0.20$ & Slight \\
$0.21-0.40$ & Fair \\
$0.41-0.60$ & Moderate \\
$0.61-0.80$ & Substantial \\
$0.81-1.00$ & Almost Perfect \\
\hline
\end{tabular}

\subsubsection{Descriptive statistics}

Summary age statistics for each morphological developmental attribute were calculated. These include the mean, standard deviation, minimum and maximum values and standard error of the mean and standard deviation (age in years).

\subsection{3 t-test}

A $t$-test is performed to evaluate if the means of two sets of data are significantly different from each other. The groups can either be unrelated (independent $t$-test) or related (dependent $t$-test) (Adam 2010). The $t$-test is performed to evaluate the statistical significance of the difference in mean age of the developmental stage in male and female subjects, and also the left and right side scores. The difference between the observations is calculated for each 'pair' producing a $t$ statistic and $p$ value. The $t$-statistic is the conversion of the individual attained scores to a standardized score and the $p$-value is the estimation of the probability of rejecting the null hypothesis (Adam 2010).

\subsubsection{Student $t$-test}

The independent $t$-test assumes that the difference between the groups are normally distributed (Adam 2010). To quantify the statistical significance of variation in sex-specific development as timing within the sample, an independent $t$-test is performed. The null hypothesis that there is no difference between the mean attained score of each morphological developmental attribute of each group. 


\subsubsection{Paired $t$-test}

The paired $t$-test assumes that the difference between groups is normally distributed (Adam 2010). A paired $t$-test is applied to test for asymmetry of bilateral scoring within the sample. The test will quantify the significance of any bilateral variation for the timing of fusion of the morphological developmental attributes. The dependent variable was the score each of the morphological developmental attributes and the independent variable was the side of body (left or right). The null hypothesis that there is no difference between the mean attained score of each morphological developmental attribute of each group.

\subsubsection{Polynomial regression analysis}

Regression analysis is used in the present study to formulate predictive models for the estimation of age. The predictive age models formulated can then be applied in a forensic context to estimate age of individuals of unknown age and sex. Regression analysis is used to test the correlation between dependent (represented by $y$ ) and independent variables (represented by $x$ ) (Spicer 2005). For each variable the regression analysis is used to assess the significance of the correlation between age and the scores assigned for all morphological developmental attributes. The relationship between age $(y)$ and a predictor variable $(x)$ can be non-liner or curvilinear and is modelled as a polynomial regression model (Armitage et al. 2008). The highest power to which $x$ is raised determines the degree (or order) of the polynomial; for example; if $x$ is raised to 2 , then the polynomial is second-degree. The degree of the polynomial affects the shape of the model (Figure 4.10). 


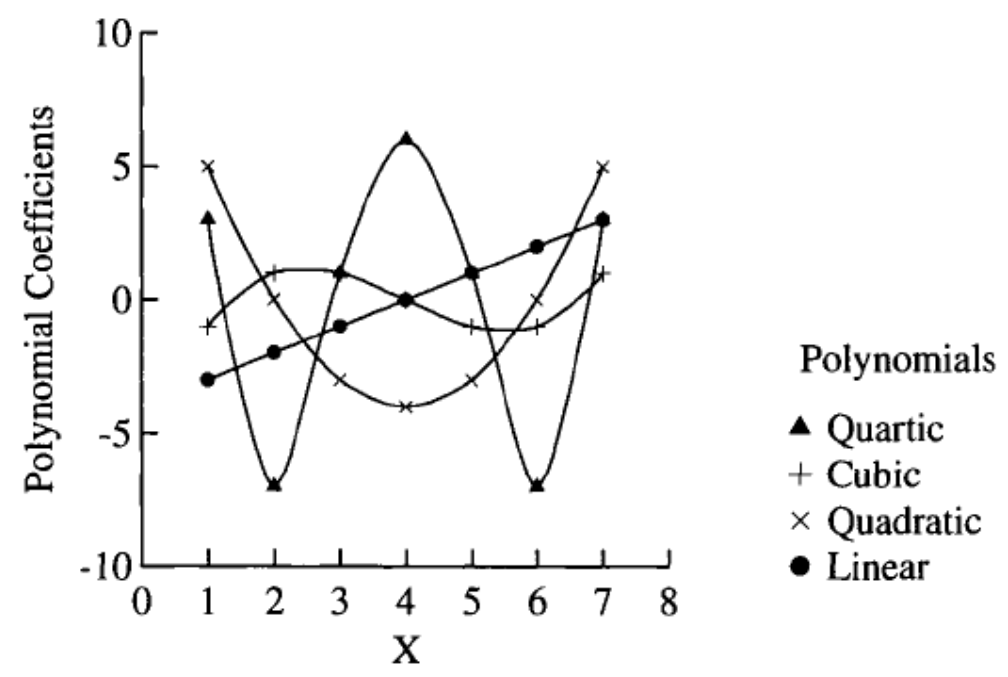

Figure 4.10. Shape of polynomial regression models up to the fourth degree. Source: von Eye and Schuster (1998).

Quadratic regression analysis considers the successive powers of the independent variable (in this study the stage score of the morphological developmental attribute) as separate predictor variables (Armitage et al. 2008; Bowerman et al. 2014). The polynomial regression model utilized in the present study is the quadratic model as follows:

$$
E(y)=\beta_{0}+\beta_{1} x+\beta_{2} x^{2}
$$

Where: $x$ represents the independent variable; $y$ represents the dependent variable; $\beta_{0}, \beta_{1}, \beta_{2}$ represents regression parameters (Armitage et al. 2008; Bowerman et al. 2014; von Eye and Schuster 1998).

A quadratic regression model assumes there is a curved relationship between the mean values of $y$ and $x$. The regression parameters, $\beta_{0}+\beta_{1} x+\beta_{2} x^{2}$, producing the mean value of $y$ is a curvilinear function (Armitage et al. 2008; Bowerman et al. 2014). The interaction between age and score is used to examine the statistical significance of the correlation between variables. Plots of the standardized residuals versus the fitted values confirm the conformity of the data to the assumptions of regression analysis (Spicer 2005). 


\subsubsection{Transition analysis}

Transition analysis models the transition of individuals from a defined developmental stage to the next stage in an ordered progression (Konigsberg et al. 2008). This method calculates the mean and standard error of the age of transition between defined stages using a log-age cumulative probit model (Franklin and Flavel 2014; Shirley and Jantz 2011). This method was developed to quantify the timing of the transition between stages and assumes that the independent variable being investigated can be "... arranged into an invariant series of senescent stages" (Boldsen et al. 2002). The age and assigned stage data is used to calculate an age and standard error for the transition between each stage. Transition analysis is applied in the present study to provide an alternative approach to traditional regression analysis. The method will provide insight into the applicability of the discrete age estimation provided by regression modelling, as compared to the age range provided by a transition analysis.

Transition analysis takes the known age morphological developmental attribute scores and uses an ordinal probit model (regression model where dependent variable only has two possible values) to generate the probability of being a certain morphological developmental stage at a certain age. Maximum likelihood analysis converts the parameters of the ordinal probit model to the mean and standard deviation for the age at transition from one stage to the next (Boldsen et al. 2002). This method reduces some issues common to age estimation techniques, including age mimicry, open-ended age intervals and inaccurate representation of estimation uncertainty (Dirkmaat et al. 2008). 


\section{CHAPTER FIVE: RESULTS}

\subsection{Introduction}

The objective of the present study was to formulate age estimation standards based on the analysis of the pelvic girdle for a Western Australian population. In this chapter the results for the assessment of the different bones (pooled sex sample) in the pelvic girdle are outlined; sex specific results are presented in Appendix II. Initial results comprise the test for intra-observer accordance and the analyses of bilateral developmental asymmetry. This is followed by descriptive statistics, including the mean, standard deviation, minimum and maximum values for the developmental scores assigned to the morphological developmental attributes assessed. Regression analyses are then used to model the relationship between age and morphological development. Finally transition analysis is used to model the age ranges for transition between successive developmental stages.

\subsection{Precision test}

The summary age statistics for the precision test data set are presented in Table 5.1. The results of assessment of intra-observer accordance of stage assignation based on the repeat assessment of 26 individuals are outlined in Table 5.2. All the morphological developmental attributes analysed had a Kappa statistic $(\mathcal{x})$, that correlated to either 'substantial' or 'almost perfect' agreement (Landis and Koch 1977b). The mean level of intra-observer agreement based on analysis of the total sample is: $x=0.79$. The ischial tuberosity had the highest Kappa value of $x=0.88$, the lowest value of 0.64 of for the sacrum.

Table 5.1. Summary age statistics of the precision test data set.

\begin{tabular}{cccccc}
\hline Data Set & N & Average & SD & Min & Max \\
\hline Male & 13 & 14.72 & 5.27 & 6.35 & 24.00 \\
Female & 13 & 14.89 & 5.14 & 6.34 & 24.00 \\
\hline
\end{tabular}

\subsection{Bilateral asymmetry}

Bilateral asymmetry was evaluated using a paired $t$-test (see Table 5.3). All the 
morphological developmental attributes analysed showed no significant difference ( $p=<0.01$ ) between the stages assigned to the left and right sides; all attributes examined had an almost perfect correlation $(r=\geq 0.99)$. As no bilateral asymmetry was observed, all subsequent parametric analyses are performed using left side scores unless otherwise stated.

Table 5.2. Intra-observer accordance for each morphological developmental attribute assessed.

\begin{tabular}{|c|c|c|c|c|c|}
\hline Attributes & $x$ & SE & $95 \% \mathrm{Cl}$ & $\mathbf{z}$ & $\mathbf{p}$ \\
\hline Femoral Head & 0.83 & 0.05 & $0.73-0.93$ & 16.15 & $* * *$ \\
\hline Greater Trochanter & 0.87 & 0.06 & $0.76-0.98$ & 15.36 & $* * *$ \\
\hline Lesser Trochanter & 0.86 & 0.05 & $0.76-0.97$ & 15.90 & *** \\
\hline Sacrum & 0.64 & 0.04 & $0.56-0.71$ & 16.27 & $\star * \star$ \\
\hline Os Coxa & 0.83 & 0.01 & $0.80-0.85$ & 58.58 & $* * *$ \\
\hline $\begin{array}{l}\text { Anterior Inferior lliac } \\
\text { Spine }\end{array}$ & 0.83 & 0.06 & $0.71-0.97$ & 12.92 & $\star \star \star$ \\
\hline Ischial Tuberosity & 0.88 & 0.06 & $0.77-0.99$ & 15.48 & $* \star \star$ \\
\hline Iliac Crest & 0.75 & 0.04 & $0.66-0.84$ & 16.88 & $* \star *$ \\
\hline Risser (USA \& FRE) & 0.67 & 0.03 & $0.60-0.73$ & 20.23 & $* * *$ \\
\hline
\end{tabular}

Key: $\mathcal{x}=$ Kappa; $\mathrm{SE}=$ Standard Error; $\mathrm{Cl}=$ Confidence Interval Significance: ${ }^{*} p<0.05 ;{ }^{* *} p<0.01 ;{ }^{* * *} p<0.001$

Table 5.3. Analyses of bilateral asymmetry of the morphological developmental attributes.

\begin{tabular}{|c|c|c|}
\hline Attributes & $r$ & $\mathbf{p}$ \\
\hline Femoral Head & 1.00 & *** \\
\hline Greater Trochanter & 0.99 & *** \\
\hline Lesser Trochanter & 1.00 & *** \\
\hline llium-Ischium & 0.99 & *** \\
\hline llium-Pubis & 1.00 & *** \\
\hline Ischium-Pubis & 1.00 & *** \\
\hline Anterior Inferior lliac Spine & 1.00 & *** \\
\hline Ischial Tuberosity & 1.00 & *** \\
\hline Iliac Crest & 1.00 & *** \\
\hline French Risser & 1.00 & *** \\
\hline American Risser & 1.00 & $\star \star \star *$ \\
\hline
\end{tabular}

Significance: ${ }^{*} p<0.05 ;{ }^{* *} p<0.01 ;{ }^{* * *} p<0.001$ 


\subsection{Sex specific variation}

The sex specific variation within each stage of each morphological developmental attribute was evaluated using Levene's test (Table 5.4) with the definition of a significant difference being a 'difference less than 0.05 '. If the ttest significance result is equal to or less than 0.05 , then the difference in means is not due to chance, if the significance results if above 0.05 then the difference between the means could be due to chance. In the proximal femur, significant sex differences were observed at FH1, FH3, GT1 and GT2. In the sacrum significant sex differences were noted at S1-2 Stage 2, S-3 Stage 1, S34 Stage 1, and S4-5 Stages 1 and 2. In the os coxa significant sex differences were observed at ILIS1, ILP1, ISP1, AIIS1, ITE1 and ITE2. The results for the iliac crest did not note any significant sex differences not due to chance.

\subsection{Descriptive statistics}

The mean age, standard deviation and age range for the stage of development for each attribute is presented by region (femur, os coxa and sacrum). Due to the known difficulties in accurately assigning sex in the sub-adult skeleton, pooled sex data is provided in this chapter. The mean age data for the male and female subjects are provided in this chapter; individual male and female data tables are provided in Appendix II.

\subsubsection{Proximal femur}

Three morphological developmental attributes were investigated in the proximal femur; the femoral head (FH), greater trochanter (GT) and lesser trochanter (LT). All epiphyses were scored as having no fusion (Stage 1), incomplete fusion (Stage 2) or complete fusion (Stage 3). Summary data and distribution frequencies for the age of fusion in the proximal femur is presented in Table 5.5 . 
Table 5.4. Analyses of sex variances of the morphological developmental attributes.

\begin{tabular}{|c|c|c|c|c|c|c|}
\hline \multirow{2}{*}{\multicolumn{2}{|c|}{$\begin{array}{l}\text { Attribute }^{\#} \\
\text { and stage }\end{array}$}} & \multicolumn{2}{|c|}{ Age (Mean \pm SD) } & \multicolumn{2}{|c|}{ Levene's Test } & \multirow{2}{*}{$\begin{array}{c}\text { t-test } \\
\mathrm{p} \text { (2-tailed) }\end{array}$} \\
\hline & & Female & Male & $\mathbf{F}$ & $\mathbf{p}$ & \\
\hline \multirow{3}{*}{ FH } & 1 & $4.04 \pm 2.57$ & $5.47 \pm 3.41$ & 7.92 & ** & 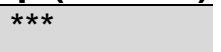 \\
\hline & 2 & $9.99 \pm 2.83$ & $12.37 \pm 2.60$ & 0.41 & 0.52 & $\star \star \star *$ \\
\hline & 3 & $19.96 \pm 4.34$ & $21.74 \pm 3.70$ & 3.95 & * & $* * *$ \\
\hline \multirow{3}{*}{ GT } & 1 & $4.49 \pm 2.85$ & $6.00 \pm 3.62$ & 7.47 & ** & *** \\
\hline & 2 & $10.82 \pm 2.82$ & $13.38 \pm 2.28$ & 1.10 & 0.30 & *** \\
\hline & 3 & $20.33 \pm 4.06$ & $21.82 \pm 3.67$ & 1.95 & 0.16 & *** \\
\hline \multirow{3}{*}{ LT } & 1 & $5.94 \pm 3.59$ & $7.46 \pm 4.33$ & 7.05 & ** & $* * *$ \\
\hline & 2 & $12.38 \pm 1.58$ & $15.21 \pm 1.18$ & 1.36 & 0.25 & *** \\
\hline & 3 & $20.44 \pm 3.99$ & $21.81 \pm 3.68$ & 1.21 & 0.27 & $* * *$ \\
\hline \multirow{3}{*}{ ILIS } & 1 & $5.40 \pm 3.24$ & $6.61 \pm 3.99$ & 5.66 & * & $\star \star *$ \\
\hline & 2 & $11.94 \pm 1.90$ & $13.62 \pm 1.73$ & 0.22 & 0.64 & $* * *$ \\
\hline & 3 & $20.14 \pm 4.21$ & $21.55 \pm 3.89$ & 1.26 & 0.26 & 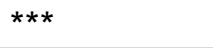 \\
\hline \multirow{3}{*}{ ILP } & 1 & $5.45 \pm 3.27$ & $6.66 \pm 3.99$ & 5.35 & * & ** \\
\hline & 2 & $11.98 \pm 1.89$ & $13.96 \pm 1.65$ & 0.36 & 0.55 & $* * *$ \\
\hline & 3 & $20.2 \pm 4.17$ & $21.77 \pm 3.72$ & 2.28 & 0.13 & $* * *$ \\
\hline \multirow{3}{*}{ ISP } & 1 & $5.22 \pm 3.10$ & $6.66 \pm 3.99$ & 8.19 & 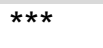 & $* * *$ \\
\hline & 2 & $11.93 \pm 1.78$ & $13.96 \pm 1.65$ & 0.05 & 0.82 & *** \\
\hline & 3 & $20.2 \pm 4.17$ & $21.77 \pm 3.72$ & 2.28 & 0.13 & $* * *$ \\
\hline \multirow{3}{*}{ AllS } & 1 & $6.45 \pm 3.84$ & $7.70 \pm 4.46$ & 5.14 & * & ** \\
\hline & 2 & $13.17 \pm 2.04$ & $14.89 \pm 2.26$ & 0.06 & 0.82 & 0.30 \\
\hline & 3 & $20.35 \pm 4.06$ & $21.65 \pm 3.76$ & 1.14 & 0.29 & ** \\
\hline \multirow{3}{*}{ ITE } & 1 & $6.62 \pm 3.90$ & $7.74 \pm 4.47$ & 4.09 & ** & ** \\
\hline & 2 & $14.13 \pm 1.76$ & $16.19 \pm 0.73$ & 4.05 & * & *** \\
\hline & 3 & $20.96 \pm 3.74$ & $21.98 \pm 3.61$ & 0.25 & 0.62 & ** \\
\hline \multirow{3}{*}{ ICE } & 1 & $7.40 \pm 4.35$ & $8.03 \pm 4.70$ & 1.10 & 0.29 & 0.23 \\
\hline & 2 & $17.91 \pm 2.65$ & $18.22 \pm 2.45$ & 1.05 & 0.31 & 0.57 \\
\hline & 3 & $22.74 \pm 3.21$ & $23.33 \pm 3.07$ & 0.16 & 0.69 & 0.23 \\
\hline \multirow{6}{*}{ FRE } & 0 & $7.40 \pm 4.35$ & $8.03 \pm 4.70$ & 1.10 & 0.29 & 0.23 \\
\hline & 1 & $16.25 \pm 1.90$ & $16.67 \pm 0.96$ & 5.11 & ** & 0.41 \\
\hline & 2 & $17.35 \pm 1.26$ & $18.99 \pm 1.76$ & 0.01 & 0.91 & 0.10 \\
\hline & 3 & $18.29 \pm 3.04$ & $20.92 \pm 2.91$ & 0.03 & 0.86 & 0.07 \\
\hline & 4 & $19.46 \pm 2.29$ & $18.58 \pm 2.10$ & 0.31 & 0.58 & 0.34 \\
\hline & 5 & $22.74 \pm 3.21$ & $23.33 \pm 3.07$ & 0.16 & 0.69 & 0.23 \\
\hline \multirow{6}{*}{ USA } & 0 & $7.40 \pm 4.35$ & $8.03 \pm 4.70$ & 1.10 & 0.29 & 0.23 \\
\hline & 1 & $16.22 \pm 1.95$ & $16.71 \pm 0.98$ & 4.92 & ** & 0.37 \\
\hline & 2 & $17.5 \pm 1.30$ & $17.38 \pm 1.32$ & 0.02 & 0.90 & 0.90 \\
\hline & 3 & $18.19 \pm 2.46$ & $17.75 \pm 1.80$ & 0.54 & 0.49 & 0.80 \\
\hline & 4 & $18.67 \pm 3.10$ & $21.41 \pm 3.12$ & 0.11 & 0.75 & 0.10 \\
\hline & 5 & $22.19 \pm 3.30$ & $22.87 \pm 3.30$ & 0.01 & 0.93 & 0.16 \\
\hline \multirow{3}{*}{ S12 } & 1 & $5.45 \pm 3.93$ & $6.75 \pm 4.22$ & 0.44 & 0.51 & $* *$ \\
\hline & 2 & $17.39 \pm 6.11$ & $20.07 \pm 4.91$ & 9.67 & $\star * *$ & $* * *$ \\
\hline & 3 & NA & NA & NA & NA & NA \\
\hline \multirow{3}{*}{ S23 } & 1 & $1.59 \pm 1.20$ & $5.22 \pm 4.22$ & 35.64 & $\star * \star$ & $* * *$ \\
\hline & 2 & $13.95 \pm 7.07$ & $16.82 \pm 6.82$ & 0.56 & 0.46 & 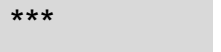 \\
\hline & 3 & $21.58 \pm 2.8$ & $22.7 \pm 1.86$ & 4.05 & * & 0.17 \\
\hline \multirow{3}{*}{ S34 } & 1 & $1.40 \pm 0.92$ & $3.22 \pm 3.23$ & 16.08 & $\star * \star$ & $* * *$ \\
\hline & 2 & $12.81 \pm 6.91$ & $14.93 \pm 7.33$ & 1.30 & 0.25 & *** \\
\hline & 3 & $21.23 \pm 3.54$ & $22.25 \pm 2.35$ & 8.75 & $\star \star *$ & 0.13 \\
\hline \multirow{3}{*}{ S45 } & 1 & $1.60 \pm 1.02$ & $4.51 \pm 4.69$ & 36.20 & $* * *$ & $* * *$ \\
\hline & 2 & $12.21 \pm 6.63$ & $13.84 \pm 7.47$ & 4.56 & $\star *$ & ** \\
\hline & 3 & $21.43 \pm 3.83$ & $22.24 \pm 3.79$ & 0.65 & 0.42 & 0.28 \\
\hline
\end{tabular}

${ }^{*}$ See Table 4.3 for key to attributes.

Significance: ${ }^{*} p<0.05 ;{ }^{* *} p<0.01 ;{ }^{* * *} p<0.001$ 
Table 5.5. Descriptive age statistics of the scored stages in the proximal femur (pooled sex data; age in years).

\begin{tabular}{|c|c|c|c|c|c|c|c|}
\hline \multicolumn{2}{|c|}{$\begin{array}{l}\text { Attribute* \& } \\
\text { Stage }\end{array}$} & \multirow{2}{*}{$\begin{array}{l}\mathbf{n} \\
176\end{array}$} & \multirow{2}{*}{$\begin{array}{l}\begin{array}{l}\text { Mean } \\
\text { Age }\end{array} \\
4.87 \\
\end{array}$} & \multirow{2}{*}{$\begin{array}{l}\text { SD } \\
3.16\end{array}$} & \multirow{2}{*}{$\begin{array}{l}\text { Range } \\
0.01-13.22\end{array}$} & \multirow{2}{*}{$\begin{array}{c}\begin{array}{c}\text { 25th } \\
\text { percentile }\end{array} \\
2.23\end{array}$} & \multirow{2}{*}{$\begin{array}{c}\begin{array}{c}75 \text { th } \\
\text { percentile }\end{array} \\
7.05\end{array}$} \\
\hline & 1 & & & & & & \\
\hline FH & 2 & 114 & 11.14 & 2.96 & $2.78-16.49$ & 9.20 & 13.42 \\
\hline & 3 & 272 & 20.84 & 4.13 & $10.34-30.00$ & 17.72 & 23.97 \\
\hline \multirow{3}{*}{ GT } & 1 & 202 & 5.36 & 3.39 & $0.01-13.45$ & 2.55 & 7.60 \\
\hline & 2 & 96 & 11.96 & 2.51 & $4.51-16.95$ & 9.88 & 13.83 \\
\hline & 3 & 264 & 21.08 & 3.93 & $12.91-30.00$ & 18.00 & 24.00 \\
\hline \multirow{3}{*}{ LT } & 1 & 265 & 6.79 & 4.09 & $0.01-16.42$ & 3.36 & 10.00 \\
\hline & 2 & 30 & 13.42 & 1.99 & $9.20-16.95$ & 12.15 & 15.11 \\
\hline & 3 & 261 & 21.14 & 3.89 & $12.94-30.00$ & 18.00 & 24.00 \\
\hline
\end{tabular}

* See Table 4.3 for key to attributes.

The oldest individual assessed as Stage 1 was 13.22 years (PEL000606, M) for the femoral head epiphysis, 13.45 years (PEL000527, M) for the greater trochanter and 16.42 (PEL000519, M) for the lesser trochanter. The $75^{\text {th }}$ percentile age for Stage 1 fusion of the femoral head was 6.00 years for females and 8.06 years for males. The greater trochanter $75^{\text {th }}$ percentile age for Stage 1 was 6.41 and 8.84 years for females and males respectively; the lesser trochanter $75^{\text {th }}$ percentile age for Stage 1 was 8.83 years for females and 11.17 years for males.

The sample size for Stage 2 at all sites was much smaller than either Stages 1 or 2; only $17 \%$ of subjects were assessed as having commenced, but not yet completed, fusion of the greater trochanter. The youngest individual assigned to Stage 2 was 6.22 years (PEL000524, F) while the oldest individual was 16.95 (PEL000702, M). The mean age for Stage 2 fusion of the femoral head was 9.99 years for females (range 2.78 - 15.43) and 12.37 for males (range 5.39 16.49). For the greater trochanter the mean Stage 2 female age was 10.82 years (range $4.51-15.43$ ) and 13.38 years for males (range $7.84-16.95$ ). The lesser trochanter Stage 2 mean was 12.38 years for females (range 9.20 15.43 ) and 15.21 for males (range $12.61-16.95$ ).

Of the 562 subjects assessed, $48 \%$ were assigned as having completed fusion (Stage 3) for all three femoral morphological developmental attributes; the youngest to attain the latter was 10.34 years (PEL000522, F). Females reach 
Stage 3 fusion status earlier than males at all three loci; the youngest age for femoral head fusion was 10.34 years (14.87 male), 12.91 years for the greater trochanter (14.87 male) and 12.94 years for the lesser trochanter (14.87 male).

The consistency in the scoring of the timing of fusion of the secondary ossification centres in the proximal femur is illustrated in Figure 5.1. The second and third quartile boxes are generally consistent in length, with the exception of Stage 2 at the lesser trochanter; this could be due to the small number of individuals $(5 \%)$ assigned to that stage. Although the majority of the sample displays distinct stage separation by age, the whiskers of the femoral box plots are generally quite long and overlap with the boxes of the next and/or previous stage (Figure 5.1).

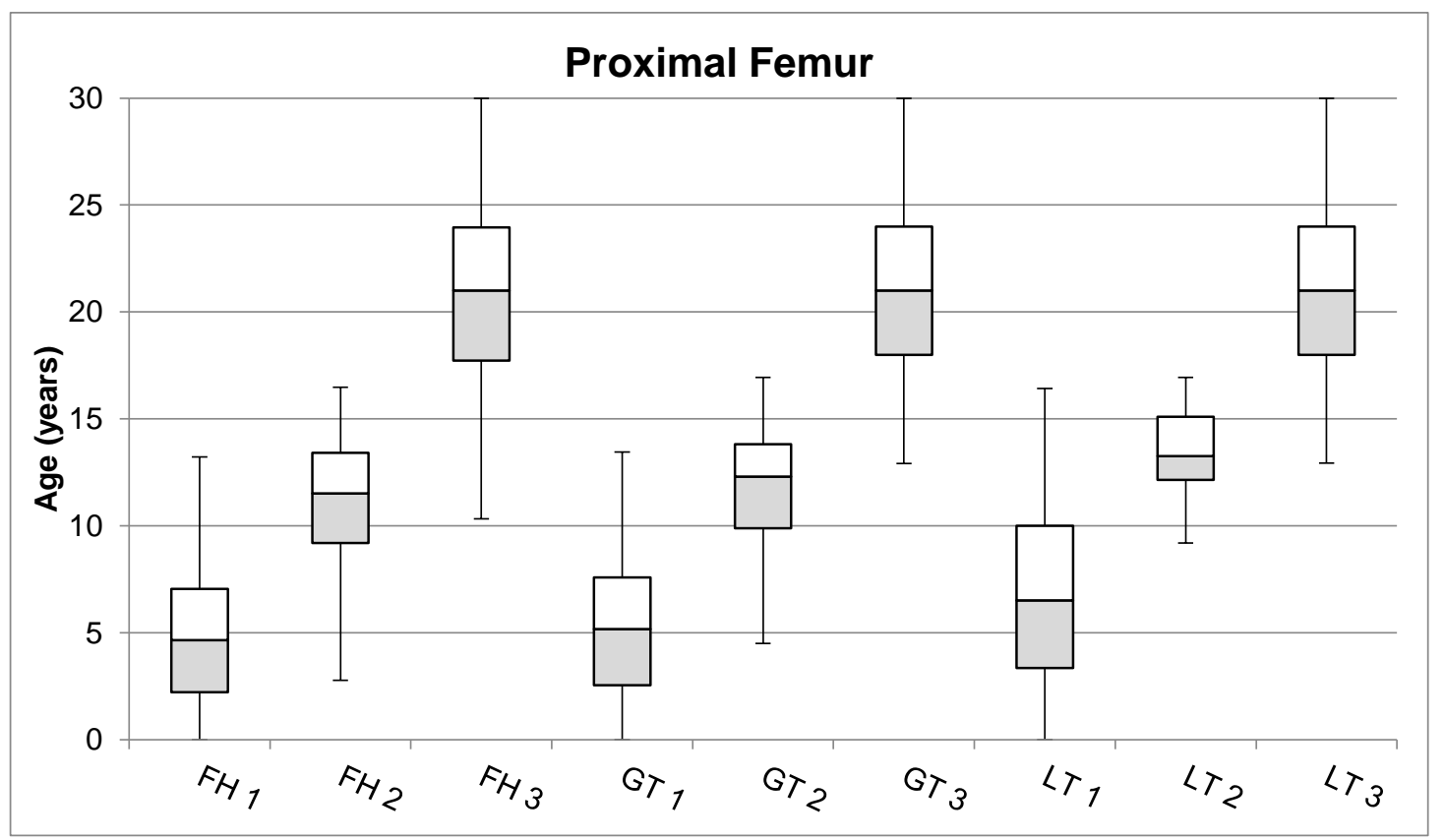

Figure 5.1. Mean age distribution of the Western Australian population according to the fusion stage of the proximal femur.

Fusion Stage 1-3 of the femoral head, greater trochanter, and lesser trochanter. (pooled sample); Median, Quartile: FH1 (4.66, 4.82); FH2 (11.53, 4.22); FH3 (21.00, 5.05); GT1 (5.18, 5.05); GT2 (12.30, 3.94); GT3 (21.00, 6.00); LT1 (6.52, 6.64); LT2 (13.27, 2.96); LT3 (21.00, 6.00).

\subsubsection{Os coxa}

Three regions were investigated in the os coxa: acetabulum (ILIS, ILP, ISP); iliac and ischial spines (AIIS, ITE); and the iliac crest - the latter of which was 
assessed using three scoring methods (ICE, FRE, USA). Summary pooled sex (male and female) data and distribution frequencies for the age of fusion of the os coxa is presented in Table 5.6., and Table 5.7. and illustrated in Figure 5.2 5.4 .

Table 5.6. Descriptive age statistics of the scored stages in the os coxa (pooled sex data; age in years)

\begin{tabular}{llllllll}
\hline $\begin{array}{l}\text { Attribute } \\
\text { \& Stage }\end{array}$ & $\mathbf{n}$ & $\begin{array}{l}\text { Mean } \\
\text { Age }\end{array}$ & SD & Range & $\begin{array}{l}\text { 25th } \\
\text { percentile }\end{array}$ & $\begin{array}{l}\text { 75th } \\
\text { percentile }\end{array}$ \\
\hline \multicolumn{4}{l}{ Acetabulum } \\
& 1 & 235 & 6.06 & 3.71 & $0.01-16.42$ & 2.94 & 8.83 \\
ILIS & 2 & 55 & 12.73 & 1.99 & $7.07-16.49$ & 11.20 & 14.20 \\
& 3 & 272 & 20.86 & 4.10 & $10.34-30.00$ & 17.72 & 23.97 \\
& 1 & 238 & 6.11 & 3.72 & $0.01-16.42$ & 3.02 & 8.92 \\
ILP & 2 & 57 & 12.95 & 2.02 & $7.07-16.64$ & 11.54 & 14.21 \\
& 3 & 267 & 20.99 & 4.02 & $10.34-30.00$ & 18.00 & 24.00 \\
& 1 & 234 & 6.02 & 3.69 & $0.01-16.42$ & 2.94 & 8.80 \\
ISP & 2 & 61 & 12.86 & 1.99 & $7.07-16.64$ & 11.52 & 14.20 \\
& 3 & 267 & 20.99 & 4.02 & $10.34-30.00$ & 18.00 & 24.00 \\
Iliac and Ischial Spines & & & & & \\
& 1 & 282 & 7.13 & 4.23 & $0.01-16.42$ & 3.46 & 10.70 \\
AIIS & 2 & 13 & 13.43 & 2.08 & $10.34-18.24$ & 12.48 & 13.69 \\
& 3 & 267 & 21.02 & 3.95 & $12.94-30.00$ & 17.99 & 24.00 \\
ITE & 1 & 287 & 7.22 & 4.25 & $0.01-16.42$ & 3.52 & 10.77 \\
& 2 & 28 & 14.79 & 1.78 & $10.34-18.00$ & 13.36 & 16.10 \\
& 3 & 246 & 21.49 & 3.70 & $13.80-30.00$ & 18.68 & 24.00 \\
\hline
\end{tabular}

* See Table 4.3 for key to attributes.

\section{i) Acetabulum}

The oldest individual assessed as unfused in any of the three morphological developmental attributes in the acetabulum was 16.42 years (PEL000519, M). For the ILIS the $75^{\text {th }}$ percentile age for Stage 1 was 8.00 years for females and 9.65 years for males. For the ILP the $75^{\text {th }}$ percentile age for Stage 1 was 8.01 years for females and 9.67 years for males. For the ISP the $75^{\text {th }}$ percentile age for Stage 1 was 7.82 years for females and 9.67 years for males.

The youngest individual assigned to Stage 2 (commenced but not yet completed fusion) of the ilium, ischium and pubis was 7.07 years (PEL000452. F). The mean age for Stage 2 fusion of the ILIS was 11.94 years for females (range $7.07-16.15$ years) and 13.62 for males (range $9.88-16.49$ years). For 
the ILP mean age for Stage 2 was 11.98 years for females (range $7.07-16.15$ years) and 13.96 for males (range 10.43 - 16.64 years). The youngest individual with complete fusion (Stage 3 ) in the ilium, ischium and pubis was 10.34 years for females (PEL000522, range 10.34 - 30.00 years) and 10.43 years for males (PEL000603, range $10.43-30.00$ years).

The box plots (Figure 5.2) illustrate the consistency in the scoring and timing of fusion at ILIS, ILP and ISP. The second and third quartile boxes of all three attributes are consistent in size and the length of the whiskers are also consistent; this demonstrates homogeneity in developmental timing between the three attributes

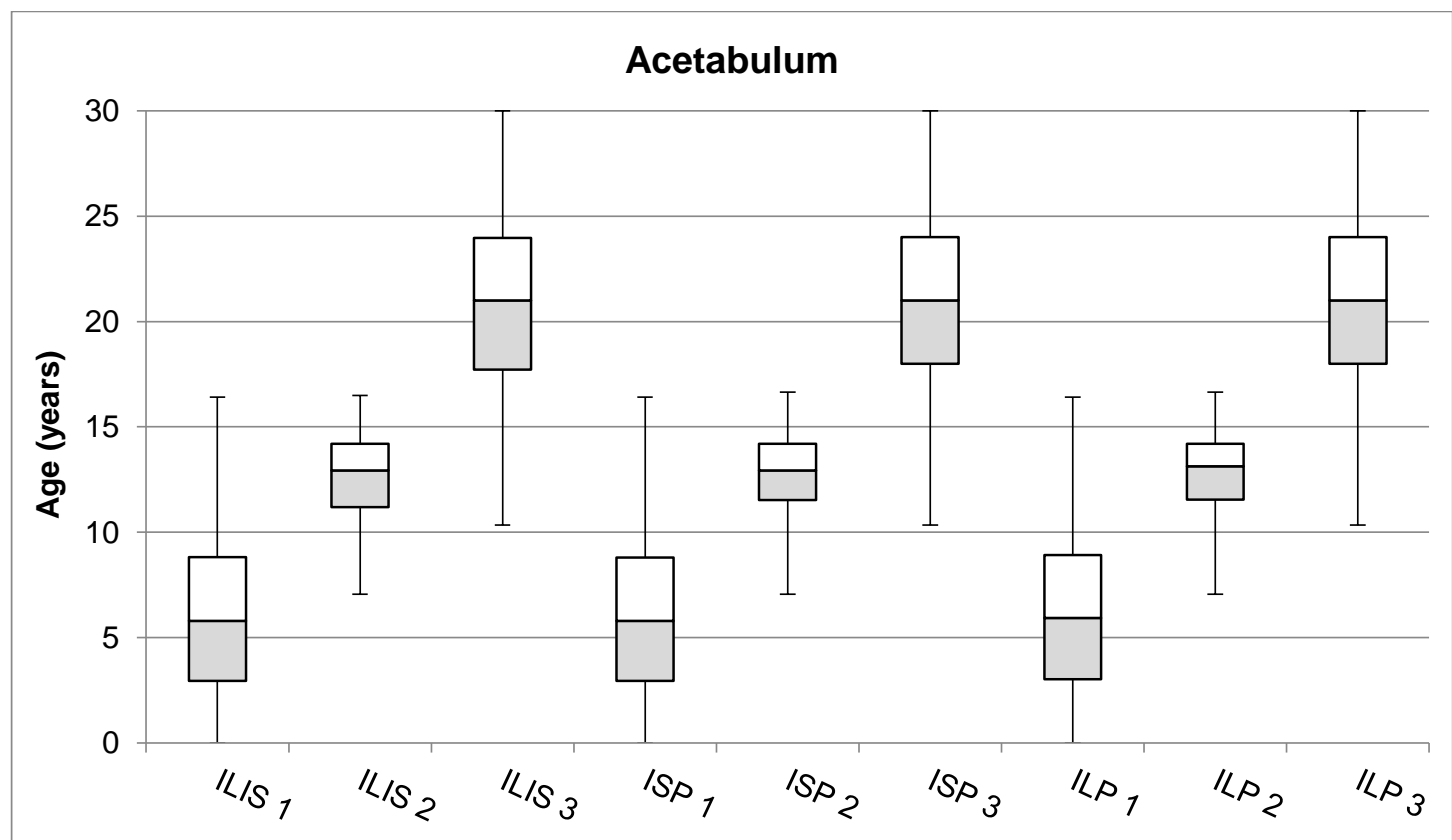

Figure 5.2. Mean age distribution of the Western Australian population according to the fusion stage of the acetabulum.

Fusion Stage 1-3 of the ilium-ischium, ischium-pubis, and ilium-pubis. (pooled sex); Median, Quartile: ILIS1 (5.80, 5.89); ILIS2 (12.94, 3.00); ILIS3 (21.00, 6.25); ISP1 (5.80, 5.86); ISP2 (12.94, 2.68); ISP3 (21.00, 6.00); ILP1 (5.94, 5.90); ILP2 (13.14, 2.67); ILP3 (21.00, 6.00).

\section{ii) Iliac and ischial spines}

The oldest individual assessed as Stage 1 for both the anterior inferior iliac spine epiphysis and the ischial tuberosity was 16.42 years (PEL000519, M). 
For the anterior inferior iliac spine, the $75^{\text {th }}$ percentile age for Stage 1 was 9.61 years for females and 11.52 years for males. For the ischial tuberosity the $75^{\text {th }}$ percentile age for Stage 1 was 9.87 years for females and 11.70 years for males.

The youngest individual assigned to Stage 1 for both the AllS and ITE was 10.34 years (PEL000522, F). The mean age for Stage 2 fusion of the AlIS was 13.17 years for females (range $10.34-18.24$ years) and 14.89 for males (range 13.29 - 16.49 years). For the ITE, mean age for Stage 2 was 14.13 years for females (range $10.34-18.00$ years) and 16.19 for males (range 15.11 - 17.52 years). The youngest age for Sage 3 was 14.87 years for the AllS (12.94= females, $14.87=$ males $)$ and 14.87 years $(13.80=$ females, $14.87=$ males $)$ for the ITE. Only two $(0.6 \%)$ of the males and 11 females (4\%) were assigned into Stage 2 at AlIS, therefore due to the small sample size any inferences draw would be statistically unreliable.

The consistency is in the scoring of the timing of fusion of the AIIS and ITE are illustrated in Figure 5.3. The size of the quartile boxes, medians and length of the whiskers visualise the uniformity in the fusion timing of both AllS and ITE. The second and third quartile boxes of AllS Stage 2 are very short in length, which is due to only $2 \%$ of the total sample being assigned to that developmental stage.

\section{iii) lliac crest}

Three scoring methods were used to assess the development of the iliac crest: the three-stage method scoring system (ICE); French Risser (FRE); and American Risser (USA). Summary data and distribution frequencies for the age of fusion of the iliac crest are summarized in Table 5.7. and illustrated in Figure 5.4. The number of subjects assessed as unfused (ICE Stage 1 or FRE/USA Stage 0 ) was consistent at 308 individuals (55\% of the subjects). The oldest individual presenting non-fusion (Stages 1 or 0 ) using all three methods of assessing the iliac crest was the same subject at 20.00 years (PEL000387, M). For all three scoring methods the $75^{\text {th }}$ percentile age for Stage 1 was 10.95 years for females and 11.96 years for males. 


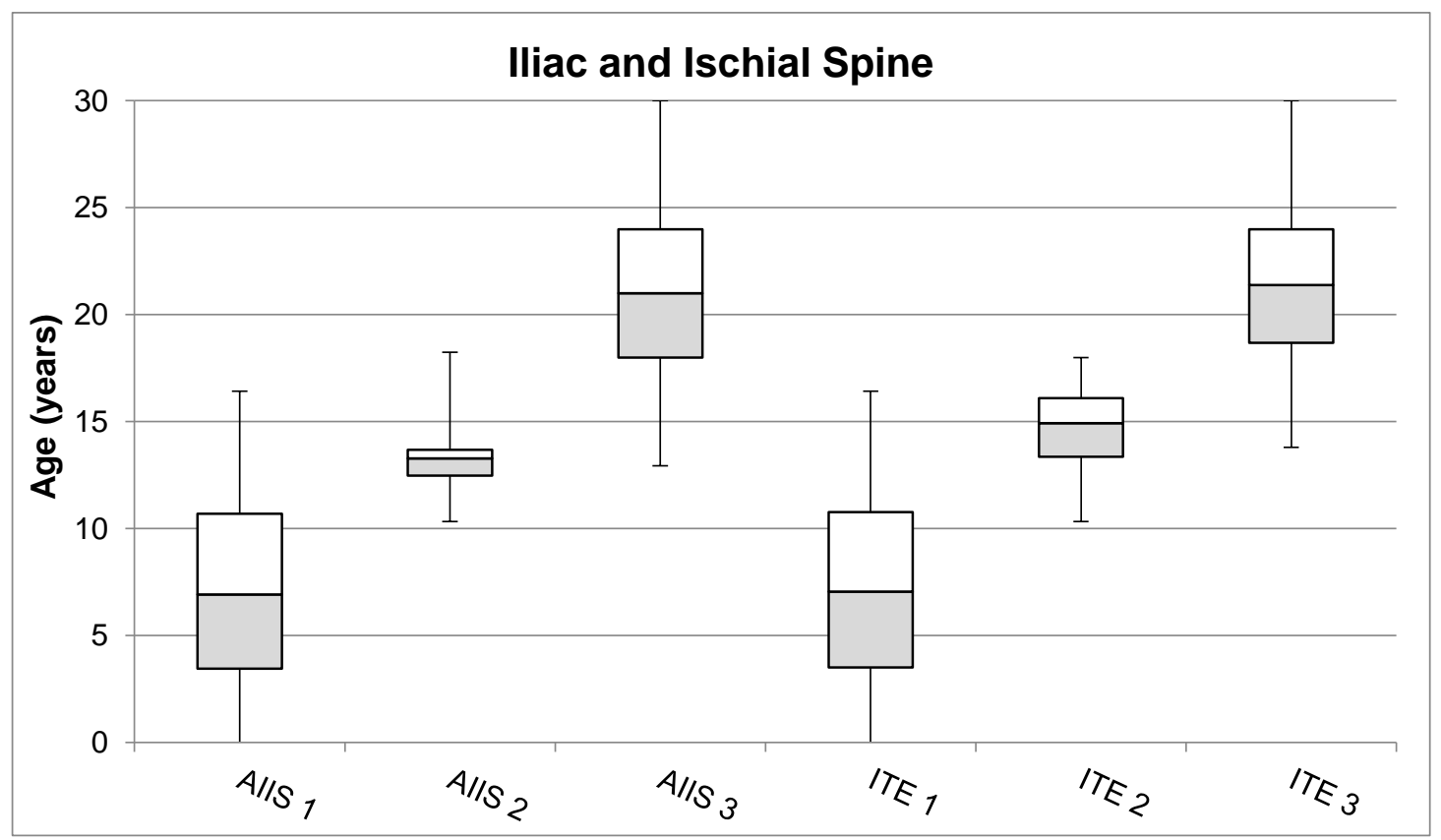

Figure 5.3. Mean age distribution of the Western Australian population according to the fusion stage of the anterior inferior iliac spine, and ischial tuberosity.

Fusion Stage 1-3 of the anterior interior iliac spine and ischial tuberosity. Pooled sex; Median, Quartile: AllS1 (6.93, 7.24); AlIS2 (13.29, 1.21); AlIS3 (21.00, 6.01); ITE1 (7.06, 7.25); ITE2 (14.93, 2.74); ITE3 (21.38, 5.32).

Table 5.7. Descriptive age statistics of the scored stages in the iliac crest (pooled sex data; age in years).

\begin{tabular}{lllllccc}
\hline $\begin{array}{l}\text { Attribute } \\
\text { Stage }\end{array}$ & $\mathbf{n}$ & $\begin{array}{l}\text { Mean } \\
\text { Age }\end{array}$ & SD & Age Range & $\begin{array}{c}\text { 25th } \\
\text { percentile }\end{array}$ & $\begin{array}{c}\text { 75th } \\
\text { percentile }\end{array}$ \\
\hline \multirow{2}{*}{ ICE } & 1 & 308 & 7.73 & 4.54 & $0.01-20.00$ & 3.85 & 11.50 \\
& 2 & 88 & 18.05 & 2.55 & $13.24-25.00$ & 16.25 & 19.00 \\
& 3 & 165 & 23.07 & 3.14 & $15.03-30.00$ & 20.87 & 25.05 \\
& 0 & 308 & 7.73 & 4.54 & $0.01-20.00$ & 3.85 & 11.50 \\
FRE & 1 & 33 & 16.43 & 1.56 & $13.24-21.00$ & 15.53 & 17.39 \\
& 2 & 10 & 17.82 & 1.63 & $16.00-21.00$ & 16.54 & 19.00 \\
& 3 & 19 & 19.53 & 3.19 & $13.80-25.00$ & 17.14 & 22.00 \\
& 4 & 26 & 19.12 & 2.22 & $14.63-23.28$ & 18.00 & 21.00 \\
& 5 & 165 & 23.07 & 3.14 & $15.03-30.00$ & 20.87 & 25.05 \\
& 0 & 308 & 7.73 & 4.54 & $0.01-20.00$ & 3.85 & 11.50 \\
USA & 1 & 30 & 16.42 & 1.63 & $13.24-21.00$ & 15.26 & 17.58 \\
& 2 & 10 & 17.42 & 1.24 & $15.56-19.00$ & 16.71 & 18.84 \\
& 3 & 7 & 17.94 & 1.92 & $16.08-21.00$ & 16.42 & 20.00 \\
& 4 & 16 & 19.87 & 3.32 & $13.80-25.00$ & 17.44 & 22.50 \\
& 5 & 190 & 22.55 & 3.31 & $14.63-30.00$ & 20.00 & 24.79 \\
\hline
\end{tabular}

* See Table 4.3 for key to attributes.

Only $14 \%$ of males and $18 \%$ of females analysed using the ICE method were 
assigned into Stage 2. The mean age for Stage 2 fusion (ICE) was 17.91 years for females (range $13.24-24.00$ years) and 18.22 for males (range 14.87 25.00 years). The youngest individual completely fused at the iliac crest epiphysis (Stage 3 ICE or Stage 5 FRE/USA) was a female at 14.63 years old using the USA method; with the USA and ICE methods was 15.03 year old

The consistency of the assignment of non-fusion (ICE Stage 1, FRE/USA Stage 0 ) at the iliac crest is illustrated in Figure 5.4. The whiskers of the unfused (ICE Stage 1, FRE/USA Stage 0) box plots are long and overlap with the boxes of the next stage; this could be due to the large number $(55 \%)$ of subjects assigned to this stage. The second and third quartile boxes of the French and American Risser stages of commenced/incomplete fusion (FRE/USA Stages $1,2,3,4)$ are uneven, which could be due to the small number of subjects assigned to those stages (15\% FRE; 11\%USA).

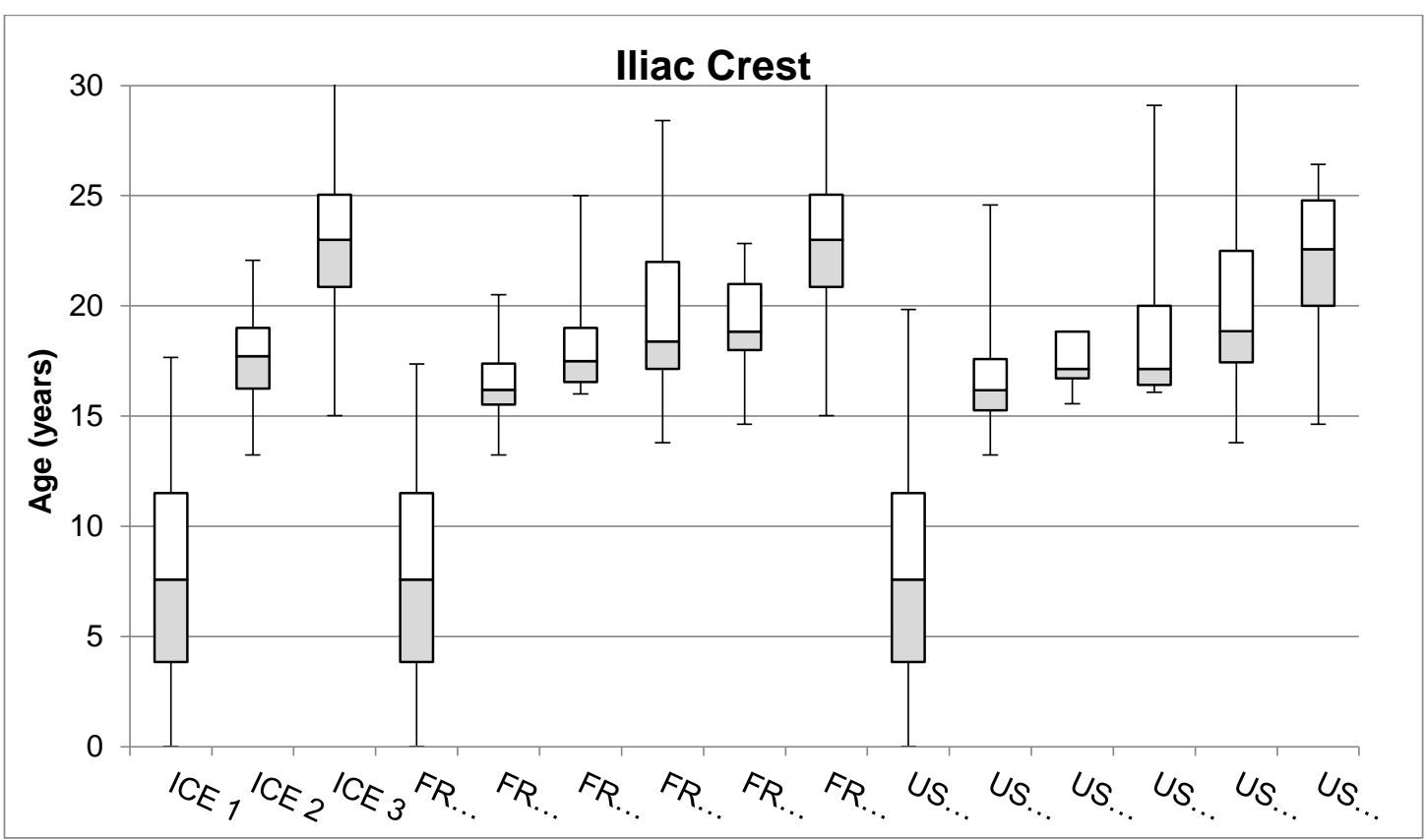

Figure 5.4. Mean age distribution of the Western Australian population according to the fusion stage of the iliac crest.

Fusion of the iliac crest- 3 stage scoring system, French Risser method and American Risser method. Pooled sex; Median, Quartile: ICE1 (7.59, 7.65); ICE2 (17.72, 2.75); ICE3 (23.00, 4.18); FREO (7.59, 7.65); FRE1 (16.19, 1.86); FRE2 (17.50, 2.46); FRE3 (18.38, 4.86); FRE4 (18.83, 3.00); FRE5 (23.00, 4.18); USAO (7.59, 7.65); USA1 (16.17, 2.32); USA2 (17.14, 2.13); USA3 (17.14, 3.58); USA4 (18.85, 5.07); USA5 (22.56, 4.79). 


\subsubsection{Sacrum}

The fusion status for each sacral element pair was assessed using the threestage model. Summary data and distribution frequencies for the age of fusion are summarized in Table 5.8. and illustrated in Figure 5.5. The mean age for Stage 2 fusion is 13.09 years (female 12.21; male 13.84) for fusion between sacral vertebrae 4 and 5 (S4-5); 13.95 years (female 12.81, male 14.93) for fusion between sacral vertebrae 3 and 4 (S3-4); 15.36 years (female 13.95, male 16.82) for fusion between sacral segments 2 and 3 (S2-3). The mean age for fusion of the first and second sacral segments (S1-2) is 18.67 years (female 17.39; male 20.07). It is important to note that the sample size for complete fusion of $51-2$ is too small to be statistically reliable.

Table 5.8. Descriptive age statistics of the scored stages in the sacrum (pooled sex data; age in years).

\begin{tabular}{llllllll}
$\begin{array}{l}\text { Attribute } \\
\text { Stage }\end{array}$ & $\mathbf{n}$ & $\begin{array}{l}\text { Mean } \\
\text { Age }\end{array}$ & SD & Age Range & $\begin{array}{l}\mathbf{2 5}^{\text {th }} \\
\text { percentile }\end{array}$ & $\begin{array}{l}\mathbf{7 5}^{\text {th }} \\
\text { percentile }\end{array}$ \\
\hline \multirow{3}{*}{ S1-2 } & 1 & 217 & 6.21 & 4.14 & $0.01-17.86$ & 2.70 & 9.53 \\
& 2 & 343 & 18.67 & 5.72 & $5.18-30.00$ & 14.74 & 23.00 \\
& 3 & 1 & 19.26 & N/A & $19.26-19.26$ & 19.26 & 19.26 \\
S2-3 & 1 & 97 & 4.21 & 3.98 & $0.01-15.10$ & 1.32 & 6.00 \\
& 2 & 428 & 15.36 & 7.09 & $1.82-30.00$ & 9.57 & 21.10 \\
& 3 & 35 & 21.93 & 2.57 & $16.71-25.63$ & 19.82 & 24.01 \\
S3-4 & 1 & 59 & 2.48 & 2.70 & $0.01-13.45$ & 0.86 & 2.73 \\
& 2 & 421 & 13.95 & 7.21 & $0.50-30.00$ & 7.89 & 19.05 \\
& 3 & 80 & 21.60 & 3.18 & $12.48-27.00$ & 19.66 & 24.17 \\
S4-5 & 1 & 52 & 3.17 & 3.78 & $0.01-16.06$ & 1.02 & 3.24 \\
& 2 & 399 & 13.09 & 7.13 & $0.19-30.00$ & 7.06 & 18.29 \\
& 3 & 108 & 21.78 & 3.82 & $9.61-30.00$ & 19.67 & 24.55 \\
\hline
\end{tabular}

* See Table 4.3 for key to attributes.

It is evident from Figure 5.5 that the whiskers of all attributes are long and inconsistent in size on either side of the second and third quartile boxes, illustrating inconsistency in the timing of fusion of the sacral vertebrae. The second and third quartile boxes of Stage 2 at all attributes are extremely long, demonstrating the large number of subjects (and hence increased variation) assigned to those stages (S1-2, 61\%; S2-3, 76\%; S3-4, 75\%; S4-5, 71\%). 


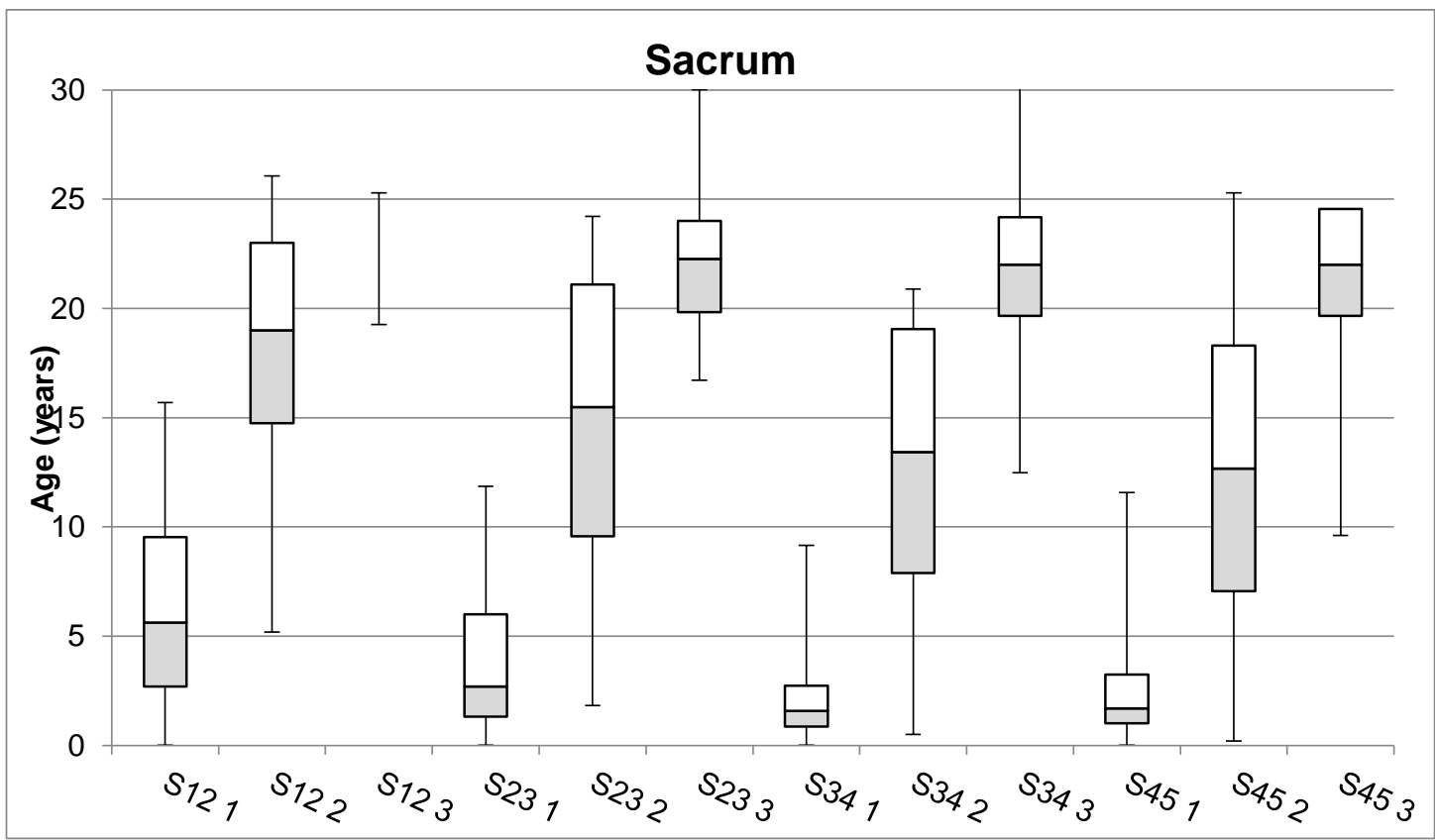

Figure 5.5. Mean age distribution of the Western Australian population according to the fusion stage of the sacral vertebrae.

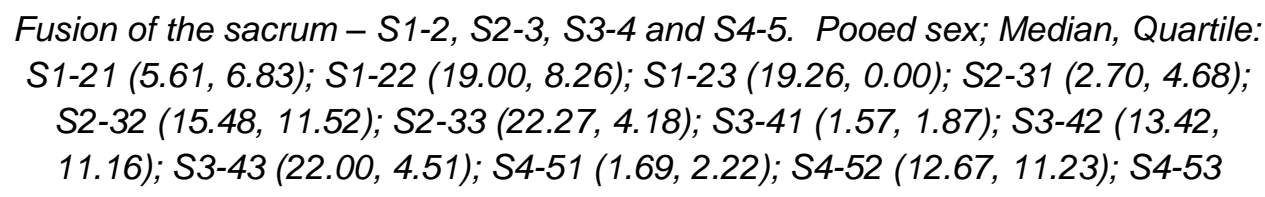

(22.00, 4.89).

\subsection{Polynomial regression analysis}

Polynomial regression was used to formulate age estimation models for all of the morphological developmental attributes examined. The equations presented are models for the individual bones with the highest predictive accuracy for the combination of attributes investigated. Preliminary tests on the data satisfy all required statistical assumptions for these tests.

The model comprises a constant value, a stage value for the attribute, and a stage attribute for the square of the attribute, all of which are summed to derive an estimate of age (see Table 5.9). The models for individual sexes are presented in Appendices III and IV. A worked example of Function 1 follows:

If $\mathrm{FH}$ has been assigned to Stage 2 then:

Age $=2.04+\left(1.11^{*} 2\right)+(1.72 * 2)^{2}$

Age $=16.09 \pm 3.63$ years. 
Table 5.9. Polynomial regression equations from fusion phase scores for age estimation (Pooled sex data).

\begin{tabular}{|c|c|c|c|c|c|c|c|}
\hline Function & $\mathbf{n}$ & $\mathbf{R}$ & $\mathbf{R}^{2}$ & $\mathbf{F}$ & $\mathbf{p}$ & ${ }^{\dagger}$ Equation & $\begin{array}{l}\text { SEE }( \pm \\
\text { years) }\end{array}$ \\
\hline $\begin{array}{l}\text { 1. Proximal } \\
\text { femur }\end{array}$ & 562 & 0.89 & 0.79 & 1077.07 & $* * *$ & $\mathrm{Age}=2.04+1.11(\mathrm{FH})+1.72(\mathrm{FH})^{2}$ & 3.63 \\
\hline $\begin{array}{l}\text { 2. }{ }^{*} \text { Os coxa } \\
\text { (primary) }\end{array}$ & 562 & 0.89 & 0.78 & 502.79 & $* * *$ & Age $=0.57+9.45($ ILIS $)+-1.70(\text { ILIS })^{2}+-4.71($ ILP $)+2.36(\text { ILP) })^{2}$ & 3.73 \\
\hline $\begin{array}{l}\text { 3. "Os coxa } \\
\text { (secondary) }\end{array}$ & 560 & 0.89 & 0.80 & 366.41 & $* \star *$ & $\begin{array}{l}\mathrm{Age}=-4.37+12.14(\text { AIIS })+-2.50(\text { AlIS })^{2}+3.69(\text { ITE })+-0.24(\text { ITE })^{2}+-3.18(\text { ICE })+1.57 \\
(\text { ICE })^{2}\end{array}$ & 3.59 \\
\hline 4. Sacrum & 559 & 0.82 & 0.67 & 142.35 & $* \star *$ & $\begin{array}{l}\mathrm{Age}=-25.88+27.82(\mathrm{~S} 12)+-6.20(\mathrm{~S} 12)^{2}+4.30(\mathrm{~S} 23)+-0.90(\mathrm{~S} 23)^{2}+-6.64(\mathrm{~S} 34)+-1.15 \\
(\mathrm{~S} 34)^{2}+-4.33(\mathrm{~S} 45)+1.80(\mathrm{~S} 45)^{2}\end{array}$ & 4.58 \\
\hline
\end{tabular}

Key: ${ }^{\dagger}$ see Table 4.3 for attribute codes; ${ }^{*}$ primary ossification centres; \#secondary ossification centres - three phase system

Significance: ${ }^{*}=p<0.05 ;{ }^{* *}=p<0.01 ;{ }^{* * *}=p<0.001$ 


\subsection{Transition analysis}

The results for the femur and os coxa (left side only) transition analyses are presented in Table 5.10.; results for the sacrum are presented in Table 5.11. The results for the right side are outlined in Appendix $\mathrm{V}$. The earliest mean age at which transition from Stage 2 to 3 occurs is for the femoral head; for females it was $13.14 \pm 1.75$ years and for the males it occurred later at $15.70 \pm 0.68$ years. The first attribute expected to transition to complete fusion in males is the ILIS at 15.24 \pm 1.57 years; for females this occurred at $13.45 \pm 1.57$ years.

Table 5.10. Transition analysis of the fusion phase scores of the proximal femur, os coxa and iliac crest (individual and pooled sex) [results in years].

\begin{tabular}{llcccccc}
\hline \multicolumn{2}{l}{$\begin{array}{l}\text { Attribute } \\
\text { \& Stage }\end{array}$} & \multicolumn{2}{l}{ Female } & \multicolumn{3}{c}{ Male } & \multicolumn{3}{c}{ Pooled } \\
\hline FH & $1-2$ & 7.20 & 2.42 & 10.14 & 2.60 & 8.70 & 2.89 \\
& $2-3$ & 13.14 & 1.75 & 15.70 & 0.68 & 14.36 & 1.85 \\
GT & $1-2$ & 8.47 & 2.09 & 11.56 & 1.92 & 10.02 & 2.52 \\
& $2-3$ & 13.77 & 1.09 & 15.88 & 0.81 & 14.82 & 1.44 \\
LT & $1-2$ & 11.80 & 1.62 & 14.89 & 0.81 & 13.30 & 1.98 \\
& $2-3$ & 13.89 & 1.02 & 15.86 & 0.78 & 14.89 & 1.45 \\
ILIS & $1-2$ & 10.52 & 1.63 & 12.78 & 1.98 & 11.69 & 2.16 \\
& $2-3$ & 13.45 & 1.57 & 15.24 & 1.57 & 14.36 & 1.77 \\
ILP & $1-2$ & 10.61 & 1.65 & 13.01 & 1.82 & 11.83 & 2.11 \\
& $2-3$ & 13.55 & 1.52 & 15.73 & 0.95 & 14.63 & 1.67 \\
ISP & $1-2$ & 10.21 & 1.40 & 13.01 & 1.82 & 11.65 & 2.13 \\
& $2-3$ & 13.55 & 1.50 & 15.73 & 0.95 & 14.62 & 1.65 \\
AlIS & $1-2$ & 12.77 & 1.65 & 15.23 & 0.95 & 13.97 & 1.74 \\
& $2-3$ & 13.94 & 1.54 & 15.45 & 0.90 & 14.64 & 1.56 \\
ITE & $1-2$ & 13.10 & 1.36 & 15.42 & 0.60 & 14.21 & 1.53 \\
& $2-3$ & 15.13 & 1.41 & 16.19 & 1.00 & 15.66 & 1.39 \\
ICE & $1-2$ & 14.72 & 1.22 & 15.82 & 1.44 & 15.29 & 1.49 \\
& $2-3$ & 19.57 & 2.91 & 19.54 & 2.47 & 19.55 & 2.67 \\
FRE & $0-1$ & 14.72 & 1.20 & 15.92 & 1.36 & 15.26 & 1.49 \\
& $1-2$ & 16.65 & 1.85 & 17.15 & 0.96 & 16.81 & 1.80 \\
& $2-3$ & 16.78 & 2.69 & 17.62 & 0.87 & 17.32 & 2.33 \\
& $3-4$ & 17.92 & 2.78 & 17.12 & 4.34 & 18.31 & 2.75 \\
& $4-5$ & 19.55 & 2.96 & 19.27 & 2.77 & 19.58 & 2.54 \\
USA & $0-1$ & 14.72 & 1.21 & 15.90 & 1.38 & 15.27 & 1.50 \\
& $1-2$ & 16.54 & 1.82 & 16.95 & 1.23 & 16.67 & 1.76 \\
& $2-3$ & 16.76 & 2.25 & 17.46 & 1.26 & 17.14 & 2.08 \\
& $3-4$ & 17.05 & 2.59 & 17.75 & 1.25 & 17.53 & 2.38 \\
& $4-5$ & 18.03 & 2.79 & 17.85 & 3.58 & 18.36 & 2.74 \\
\hline * See Table & 4.3 y for key to attributes. & & & \\
& & & & & & &
\end{tabular}


The probability density plot (Figure 5.6) of age at transition between Stages 2 and 3 (fusing to fused) for the nine three-stage scoring systems are presented in Table 5.10.; this provides a visual representation of the clustered fusion of morphological developmental attributes at the 14-15 year age range. The exception is the ischial tuberosity (ITE) for which the transition from Stage 2 to 3 in the pooled data had a mean age of $15.66 \pm 1.39$ years, and the iliac crest (ICE) which has a mean age of transition of $19.55 \pm 2.67$ years.



Figure 5.6. Probability density plot: phase 2-3 transition distribution for pooled data (left side).

The results of the transition analysis of the sacrum are summarized in Table 5.11. The largest difference between male and female age at transition age between Stages 1 and 2 is for sacral vertebrae S2-3; the mean female age is $2.73 \pm 1.12$ years compared to $6.68 \pm 5.14$ years for males. The transition from Stage 1 to 2 at sacral vertebrae $\mathrm{S} 1-2$ in the males had a mean age of $12.63 \pm 2.89$ years compared to $8.88 \pm 4.21$ for females. Standard deviation values for the mean transition ages indicate that fusion times are highly variable. This is particularly true for the transition between Phases 2 and 3 for attribute S4-5 (transitioning between fusing and completely fused) where the SD ranges from 6.40 years in females to 10.44 years in males. 


\section{CHAPTER FIVE}

Table 5.11. Transition analysis of the fusion phase scores of the sacrum (individual and pooled sex).

\begin{tabular}{llllllll}
\hline \multicolumn{2}{l}{$\begin{array}{l}\text { Attribute } \\
\text { Stage }\end{array}$} & \multicolumn{2}{l}{ Female } & \multicolumn{3}{l}{ Male } & \multicolumn{3}{l}{ Pooled } \\
\cline { 2 - 7 } & Mean & SD & Mean & SD & Mean & SD \\
\hline S1-2 & $1-2$ & 8.88 & 4.21 & 12.63 & 2.89 & 10.71 & 4.06 \\
S2-3 & $1-2$ & 2.73 & 1.12 & 6.86 & 5.14 & 4.36 & 5.09 \\
& $2-3$ & 29.52 & 8.97 & 37.40 & 10.44 & 33.91 & 10.38 \\
S3-4 & $1-2$ & 2.36 & 0.96 & 3.00 & 4.20 & 2.60 & 3.31 \\
& $2-3$ & 23.31 & 7.46 & 30.02 & 9.16 & 26.88 & 8.88 \\
S4-5 & $1-2$ & 2.31 & 1.40 & -0.34 & 7.52 & 0.98 & 5.25 \\
& $2-3$ & 21.33 & 6.40 & 26.06 & 8.22 & 23.84 & 7.65 \\
\hline
\end{tabular}

* See Table 4.3 for key to attributes. 


\section{THIS PAGE HAS INTENTIONALLY BEEN LEFT BLANK}




\section{CHAPTER SIX: DISCUSSION AND CONCLUSIONS}

\subsection{Introduction}

The present chapter addresses the research aims of the present study in the context of the results obtained. The first research aim evaluated the reliability and accuracy of the three stage and the Risser scoring methods. A precision test was performed prior to data collection to quantify intra-observer error and data were also assessed for bilateral asymmetry in the timing of epiphyseal fusion. The timing of epiphyseal fusion was then analysed for statistically significant sex-specific variation and compared to published literature in line with the first research aim. To satisfy the second research aim, regression analyses were used to develop age estimation models for a modern Western Australian population based on the morphological assessment of the fusion of the pelvic girdle and proximal femur. For the third aim, a transition analysis of epiphyseal fusion timing was performed. The chapter finishes with a discussion of forensic applications, limitations, future research potential, and a series of final conclusions are then outlined.

\subsection{Aim One: to evaluate the reliability and accuracy of the selected age estimation methods in a Western Australian sub-adult population}

The accuracy and reliability of age estimation methods are essential to the forensic applicability and potential replication of the present research study. Legislation in Australia states that an individual under 10 years of age cannot be charged with a criminal offence. From 10, to under 14 years of age, doli incapax (due to immaturity the individual is deemed not to be responsible) can be claimed; and the age of criminal responsibility in Australia is 18 years (Australian Institute of Criminology 2005). The attainment of the $10^{\text {th }}$ year of age is an important legal milestone in Australia because this age determines whether an individual will be held legally responsible. Data relating to the timing of fusion collected in the present study thus has potential to assist in the assessment of whether an individual has reached the $10^{\text {th }}$ year of life and thus whether they can be held criminally responsible. 


\subsubsection{Precision of scoring methods}

A precision test was undertaken to evaluate the repeatability of the scoring methods by quantifying the degree of intra-observer error. As previously discussed (see Section 5.2) six of the nine morphological attributes had a Kappa value $(x)$ above 0.83 (mean $x=0.79$ ). The significance of the Kappa statistic (as defined by Landis and Koch (1977b) is used as a measure of observer agreement of the scoring methods (three stage and Risser). The ischial tuberosity had the highest Kappa value of $x=0.88$, whilst the lowest score of $x=0.64$ was for the sacrum. The morphology and developmental sequence of the sacrum is known to be relatively variable (e.g. Flander and Corruccini 1980; Plochocki 2002) and thus inconsistencies in the fusion timing and an irregular morphology, may have contributed to the relatively lower level of agreement between repeat assessments for this bone.

Reem et al. (2009) investigated inter- and intra-observer agreement of the American Risser method using 100 anterior-posterior pelvic radiographs drawn from an American population. The radiographs were assessed in a random order by three observers and statistical significance of agreement was calculated using the Kappa coefficient $(x)$ and bootstrapped to derive confidence intervals. Intra-observer precision was $x=0.88,0.86$ and 0.93 for three individual observers. The inter-observer agreement was $\chi=0.76$ with a $95 \%$ confidence lower bound of 0.69 , and 63 of the 100 radiographs assessed had perfect agreement within the same Risser stage. The results of that study are directly comparable to the present study.

Reem et al. (2009) also compared their inter-observer Kappa values to that of Goldberg et al. (1988) and Shuren et al. (1992). Shuren et al. (1992) included four observers who assessed 34 radiographs, with a calculated Kappa statistic of 0.31 to 0.53 (poor agreement). In contrast, Goldberg et al. (1988) achieved a Kappa statistic of 0.80 when four observers rated 30 radiographs. The present study obtained a Kappa statistic of 0.67 using the American and French Risser methods which slightly lower then reported by Reem et al. (2009). The variability in the observed intra-observer accuracy highlights the difficulty in 
using the six stage Risser scoring method. Thus demonstrating higher levels of accordance when applying three stage scoring methods providing support for the present studies application of a three stage scoring method.

\subsubsection{Bilateral asymmetry in fusion timing}

The present study assessed whether the timing of fusion was significantly different between the left and right sides; no evidence of statistically significant bilateral asymmetry was found in the morphological developmental attributes investigated in the femur and os coxa. This implies that the left and right side scores are interchangeable and data for either side can be used. Thereafter only the left side as standard was assessed.

Bilateral asymmetry in fusion timing has been extensively studied in the postcranial skeleton (e.g. Albert and Greene 1999; Auerbach and Ruff 2006; Plochocki 2002). There are, however, relatively few published studies specifically examining fusion asymmetry in the proximal femur and os coxa. Epiphyseal ossification is a continuous process at an inherent risk of bilateral asymmetry during growth due to mechanical loading associated with routine activities (Carter 1987; Carter et al. 1996). The exact timing of fusion from one arbitrary stage to another is also largely unobservable using current technology. Therefore, during any research into epiphyseal fusion, assessment of bilateral asymmetry is prudent, as the exact point of fusion cannot be established.

Coqueugniot and Weaver (2007) assessed bilateral postcranial fusion asymmetry in a Portuguese population. A total of eight of the 26 morphological developmental attributes investigated displayed significant bilateral asymmetry. The fusion of the sternal end of the clavicle and distal end of the fibula exhibited the largest degree of bilateral asymmetry in both sexes $(13.7 \%$ and $5.3 \%$ respectively). Statistically significant bilateral asymmetry was observed in the fusion of the femoral head, iliac crest, ilium-pubis and ischium-ilium. The results of the present study do not support such high levels of agreement as identified by Coqueugniot and Weaver (2007), as no significant bilateral asymmetry was observed. The more stages that are used in the assessment of fusion, then the 
more likely the observation of differences in the timing of fusion; this is due to the increased subjectivity in making a judgment (see above).

\subsubsection{Sex variation in the timing of epiphyseal fusion}

Statistically significant sex differences were observed in the assignment of Stage 1 (non-fusion) in the proximal femur (FH, GT, LT) and os coxa (ILIS, ILP, ISP, AlIS, ITE); it was evident that the mean age of commencement of fusion is significantly earlier (2-4 years) in females. Published literature commonly reports the timing of epiphyseal fusion is advanced in females, by approximately two years, albeit there do not appear to be any statistical analyses in support of this conclusion (Cardoso 2008; Schaefer and Black 2007). There were no sex differences in the timing of fusion in the iliac crest. The inconsistent sexual variation of fusion timing provides justification for the application of pooled sex standards for sub-adult age estimation. The results of the present study support the use of pooled sex standards and this is why only pooled sex results were outlined in Chapter Five, albeit individual sex data was calculated and is presented in Appendix II.

\subsubsection{Timing of epiphyseal fusion}

The Scientific Working Group for Forensic Anthropology (2013) recommend that in the absence of the dentition, age should be estimated based on assessment of the fusion of ossification centers. Prior to the present study, however, there was no data on the timing of epiphyseal fusion in the pelvic girdle and proximal femur for a Western Australian population. Forensic investigation often requires age estimation of living individuals (e.g. Blenkin and Taylor 2010; Lampl and Johnston 1996; Schmdit et al. 2011). In Australia the age of consent, age of criminal responsibility and age of maturity will determine how an individual is subsequently treated in legal investigations. The legal process is determined by the age of the individual and thus the accuracy of the requisite assessment is vitally important. Fusion of the proximal femur and os coxa can be used to estimate age in such situations following the standards formulated in the present study. 


\section{i) Proximal femur}

The reported fusion timing of the femoral head and the greater and lesser trochanter is known to vary between populations (see Table 6.1.). The observed mean age range of active fusion (Stage 2) in the present study is clearly much younger than other populations. This could be due to the larger representation of individuals under 15 years of age, thus capturing/representing a greater degree of variation. The apparent variation in fusion timing could also be attributed to inherent differences in observations of digital scans versus dry bones. Dry bones are static examples of an individual at death that has been subjected to post-mortem cleaning and storage whereas digital scans are a visualization of a living individual who could be undergoing active fusion. In the visualization of a MDCT scan, the bone can be dissected and reinstated in a manner that is not possible in the physical analysis of dry bone thus enabling a more detailed visualization of the fusion state. The vast differences in visualization methodology are highlighted when comparing the two methods (see Table 6.1.).

The variation in fusion timing of the proximal femur could also be attributed to sex differences. It is well documented that fusion in females proceeds males, and the results of this study support this assumption. This aligns with the assumption that (in general) fusion of the FH, GT and LT epiphysis occurs approximately two years later in males. This two year discrepancy (see Table 6.1.) in the reported fusion timing of the lesser trochanter could be due to the small number of subjects in both Bosnian and Portuguese samples. The present study had a much larger representation of subjects less than 15 years of age. Further the comparative studies all examined dry bone collections, which typically have a small representation of sub-adult subjects. Less than $5 \%$ $(n=30)$ of the study sample was assigned to active fusion (Stage 2) at the LT. The consistent coverage of both sexes across this time period permits the conclusion that the time it takes to transition from Stage 1 to Stage 3 is relatively small. 
Scheuer et al. (2000b) also note that some anatomical literature has questioned the existence of the LT apophysis. In the present study a clear apophysis was always present (as shown in Figure 4.3). The short fusion time reported in the results of the present study could explain why the existence of the LT apophysis has been questioned. 
Table 6.1. Comparison of the fusion timing of the proximal femur based on morphological observations.

\begin{tabular}{|c|c|c|c|c|c|c|c|c|c|c|c|}
\hline \multirow[t]{2}{*}{ Reference } & \multirow[t]{2}{*}{ Population } & \multirow[t]{2}{*}{ Medium } & \multicolumn{3}{|c|}{ Femoral Head } & \multicolumn{3}{|c|}{ Greater Trochanter } & \multicolumn{3}{|c|}{ Lesser Trochanter } \\
\hline & & & Unfused & $\begin{array}{l}\text { Active } \\
\text { fusion }\end{array}$ & $\begin{array}{l}\text { Complete } \\
\text { fusion }\end{array}$ & Unfused & $\begin{array}{l}\text { Active } \\
\text { fusion }\end{array}$ & $\begin{array}{l}\text { Complete } \\
\text { fusion }\end{array}$ & Unfused & $\begin{array}{l}\text { Active } \\
\text { fusion }\end{array}$ & $\begin{array}{l}\text { Complete } \\
\text { fusion }\end{array}$ \\
\hline \multirow[t]{2}{*}{ Present study^ } & \multirow{2}{*}{$\begin{array}{l}\text { Western } \\
\text { Australian }\end{array}$} & \multirow{2}{*}{$\begin{array}{l}\text { MDCT } \\
\text { scans }\end{array}$} & $0^{1} \leq 9$ & o $10-15$ & $\hat{0} \geq 18$ & $\hat{0} \leq 10$ & ô $11-15$ & $\hat{0} \geq 18$ & $\hat{0} \leq 12$ & o $14-16$ & $0 \geq 18$ \\
\hline & & & $q \leq 7$ & 우 7-13 & $q \geq 16$ & $q \leq 7$ & ㅇ 9-13 & $q \geq 16$ & $q \leq 10$ & o $11-14$ & $q \geq 16$ \\
\hline Schaefer (2008) & Bosnian & Dry bone & $\hat{0} \leq 18$ & ठ $16-20$ & $\delta \geq 16$ & $\delta \leq 18$ & ठ $16-20$ & $\delta \geq 16$ & $\hat{0} \leq 18$ & ภ 16-20 & $\delta \geq 16$ \\
\hline \multirow[t]{2}{*}{ Cardoso (2008) } & \multirow[t]{2}{*}{ Portuguese } & \multirow[t]{2}{*}{ Dry bone } & $\hat{0} \leq 16$ & ô $15-18$ & $0 \geq 16$ & $0 \leq 16$ & ô $15-18$ & $\hat{O} \geq 16$ & $\hat{0} \leq 16$ & ô. $15-18$ & $\hat{O} \geq 16$ \\
\hline & & & $q \leq 15$ & o $14-16$ & $q \geq 15$ & $q \leq 15$ & $+13-16$ & $q \geq 14$ & $q \leq 15$ & q 13-16 & q $\geq 14$ \\
\hline \multirow{2}{*}{$\begin{array}{l}\text { Scheuer } \\
\text { (2000a) }\end{array}$} & \multirow[t]{2}{*}{ Unknown } & \multirow[t]{2}{*}{ Dry bone } & $\mathrm{N} / \mathrm{A}$ & ○ $14-19$ & $\mathrm{~N} / \mathrm{A}$ & $\mathrm{N} / \mathrm{A}$ & ô $16-18$ & $\mathrm{~N} / \mathrm{A}$ & $\mathrm{N} / \mathrm{A}$ & $\mathrm{N} / \mathrm{A}$ & $\mathrm{N} / \mathrm{A}$ \\
\hline & & & $\mathrm{N} / \mathrm{A}$ & o $12-16$ & $N / A$ & $\mathrm{~N} / \mathrm{A}$ & q 14-16 & $\mathrm{N} / \mathrm{A}$ & $\mathrm{N} / \mathrm{A}$ & $\mathrm{N} / \mathrm{A}$ & $\mathrm{N} / \mathrm{A}$ \\
\hline \multirow{2}{*}{$\begin{array}{l}\text { Coqueugniot and } \\
\text { Weaver (2007) }\end{array}$} & \multirow{2}{*}{ Portuguese } & \multirow[t]{2}{*}{ Dry bone } & $\hat{0} \leq 20$ & o $16-24$ & $\hat{0} \geq 19$ & $0 \leq 20$ & ô $16-20$ & $0 \geq 16$ & $0 \leq 20$ & ô $16-21$ & $\hat{0} \geq 19$ \\
\hline & & & $q \leq 17$ & o 12-22 & ㅇ $\geq 17$ & $q \leq 12$ & o 17-19 & $q \geq 14$ & $q \leq 12$ & ㅇ 14-19 & o $\geq 17$ \\
\hline
\end{tabular}

${ }^{\wedge}$ Ranges presented based on the mean ( \pm standard deviation). 


\section{ii) Acetabulum}

The reported timing of fusion of the ilium-ischium (ILIS), ilium-pubis (ILP) and ischium-pubis (ISP) also clearly varies between populations (see Table 6.2). The present study observed that the fusion of the ILIS, ILP and ISP occurred concurrently. In comparison to Cardoso (2008) and Coqueugniot and Weaver (2007), the present study observed a period of fusion that was much shorter, with a notable difference in timing between the sexes. This could be due to the significantly larger sample size in the present study $(n=55-61$ assigned as actively fusing) compared to Cardoso (2008) and Coqueugniot and Weaver (2007) $(n=1-4$ and $n=5-23)$ respectively.

\section{iii) Ilial and Ischial Spines}

Of the 562 subjects assessed at the anterior inferior iliac spine (AIIS), only $2 \%$ $(2 \lambda, 11$ + ) were in a state of active fusion. This indicates that the fusion of AlIS epiphysis occurs early and rapidly. Table 6.2 presents a comparison of reported fusion timings for the AlIS epiphysis, which further supports the latter assumption. For example, Cardoso (2008) only observed three females and one male in active fusion, and Coqueugniot and Weaver (2007) observed only five females and nine males in active fusion at the AllS epiphysis.

Of the 561 subjects assessed for fusion states of the ischial tuberosity (ITE), only $5 \%(9 \hat{0}, 19$ +) were assigned as having commenced fusion without completion. Again this indicates that the period of active fusion at the ITE epiphysis is short and early. This postulation is also supported by Cardoso (2008) who observed only 12 females and 7 males in active fusion at ITE, the same was not found in Coqueugniot and Weaver (2007) who observed a total of 91 subjects in active fusion at the ITE (see Table 6.2). The observations by Coqueugniot and Weaver (2007) oppose those found by the present study and this is likely due to the differences in visualization methodology not sample size. 
Table 6.2. Comparison of the fusion timing of the acetabulum, ilial and ischial based on morphological observations.

\begin{tabular}{|c|c|c|c|c|c|c|c|c|c|c|c|}
\hline \multirow[t]{2}{*}{ Reference } & \multirow[t]{2}{*}{ Population } & \multirow[t]{2}{*}{ Medium } & \multicolumn{3}{|c|}{ Acetabulum } & \multicolumn{3}{|c|}{ Anterior Inferior Iliac Spine } & \multicolumn{3}{|c|}{ Ischial Tuberosity } \\
\hline & & & Unfused & $\begin{array}{l}\text { Active } \\
\text { fusion }\end{array}$ & $\begin{array}{l}\text { Complete } \\
\text { fusion }\end{array}$ & Unfused & $\begin{array}{l}\text { Active } \\
\text { fusion }\end{array}$ & $\begin{array}{l}\text { Complete } \\
\text { fusion }\end{array}$ & Unfused & $\begin{array}{l}\text { Active } \\
\text { fusion }\end{array}$ & $\begin{array}{l}\text { Complete } \\
\text { fusion }\end{array}$ \\
\hline \multirow[t]{2}{*}{ Present study^ } & Western & MDCT & $0^{\lambda} \leq 11$ & o $12-16$ & $\hat{0} \geq 18$ & $0 \leq 12$ & ô 13-17 & $\hat{0} \geq 18$ & $0 \leq 12$ & ô 15-17 & $\hat{0} \geq 18$ \\
\hline & Australian & scans & $q \leq 9$ & o $10-14$ & $q \geq 16$ & $q \leq 10$ & o $11-15$ & $q \geq 16$ & $q \leq 11$ & o $12-16$ & $q \geq 17$ \\
\hline Schaefer (2008) & Bosnian & $\begin{array}{l}\text { Dry } \\
\text { bone }\end{array}$ & $0 \leq 16$ & o $11-18$ & $0 \geq 15$ & $0 \leq 18$ & ô 16-18 & $0 \geq 16$ & $0 \leq 18$ & o $16-20$ & $0 \geq 17$ \\
\hline \multirow[t]{2}{*}{ Cardoso (2008) } & Portuguese & Dry & $q \leq 14$ & ㅇ $11-13$ & $q \geq 11$ & $\mathrm{~N} / \mathrm{A}$ & $\mathrm{N} / \mathrm{A}$ & $\mathrm{N} / \mathrm{A}$ & $0 \leq 16$ & ô $15-21$ & $0 \geq 17$ \\
\hline & & bone & $\hat{0} \leq 19$ & ô $15-26$ & $\hat{0} \geq 17$ & $\mathrm{~N} / \mathrm{A}$ & $\mathrm{N} / \mathrm{A}$ & $\mathrm{N} / \mathrm{A}$ & $q \leq 15$ & o 14-19 & $q \geq 16$ \\
\hline Coqueugniot and & Portuguese & Dry & $q \leq 16$ & q 11-29 & $q \geq 12$ & $0 \leq 16$ & đ 16-20 & $\delta \geq 16$ & $\lambda \leq 20$ & ) 16-20 & $\delta \geq 23$ \\
\hline Weaver (2007) & & bone & & & & $q \leq 12$ & o 14-19 & $q \geq 17$ & $q \leq 12$ & o 14-19 & $q \geq 20$ \\
\hline
\end{tabular}

\footnotetext{
$\wedge$ Ranges presented based on the mean \pm standard deviation
} 


\section{iv) Iliac Crest}

The iliac crest has been extensively investigated as an indicator of skeletal maturity (e.g. Scoles et al. 1988; Webb and Suchey 1985; Wittschieber et al. 2013b). The present study used three assessment methods to investigate the correlation between fusion of the iliac epiphysis and chronological age. The low level of variation in the timing of active and complete fusion timings reported demonstrate consistency across different populations (see Table 6.3). In considering the age range of unfused epiphyses, the present study observed a larger number of individuals under 15 years of age. This may be related to the other studies only reporting the oldest observed subject assigned to that stage. In the present study there was no statistically significant sex difference in the timing of fusion (at any of the three stages) of the iliac crest.

Table 6.3. Comparison of the fusion timing of the iliac crest based on morphological observations.

\begin{tabular}{|c|c|c|c|c|c|}
\hline \multirow[t]{2}{*}{ Reference } & \multirow[t]{2}{*}{ Population } & \multirow[t]{2}{*}{ Medium } & \multicolumn{3}{|c|}{ Iliac Crest* } \\
\hline & & & Unfused & $\begin{array}{l}\text { Active } \\
\text { fusion }\end{array}$ & $\begin{array}{l}\text { Complete } \\
\text { fusion }\end{array}$ \\
\hline \multirow{2}{*}{$\begin{array}{l}\text { Present } \\
\text { study^}^{\wedge}\end{array}$} & \multirow{2}{*}{$\begin{array}{l}\text { Western } \\
\text { Australian }\end{array}$} & \multirow{2}{*}{$\begin{array}{l}\text { MDCT } \\
\text { scans }\end{array}$} & $\hat{0} \leq 13$ & ô 16-21 & $0 \geq 20$ \\
\hline & & & $q \leq 12$ & ㅇ $15-21$ & $q \geq 20$ \\
\hline $\begin{array}{l}\text { Schaefer } \\
(2008)\end{array}$ & Bosnian & Dry bone & $\pi \leq 20$ & ô 17-21 & $0 \geq 18$ \\
\hline \multirow{2}{*}{$\begin{array}{l}\text { Cardoso } \\
\text { (2008) }\end{array}$} & \multirow[t]{2}{*}{ Portuguese } & \multirow[t]{2}{*}{ Dry bone } & $0 \leq 14$ & ô $16-21$ & $0 \geq 19$ \\
\hline & & & $q \leq 16$ & 우 15-21 & $q \geq 18$ \\
\hline \multirow{2}{*}{$\begin{array}{l}\text { Coqueugniot } \\
\text { and Weaver } \\
\text { (2007) }\end{array}$} & \multirow[t]{2}{*}{ Portuguese } & \multirow[t]{2}{*}{ Dry bone } & $\lambda \leq 20$ & ô $16-24$ & $0 \geq 20$ \\
\hline & & & $q \leq 19$ & o 17-26 & $q \geq 22$ \\
\hline
\end{tabular}

\footnotetext{
${ }^{\wedge}$ Ranges presented based on the mean \pm standard deviation

${ }^{*}$ Results are presented using the three stage method.
}

The timing of fusion observed according to the American and French Risser methods is compared in Table 6.4. The variation in fusion timings from Stage 0 to Stage 4 is most likely due to the differences in imaging modalities. For example, Krestan et al. (2006) compared digital radiographs to MDCT scans in Page 90 
the assessment of bone healing in an Austrian population. They found that the analysis of MDCT scans resulted in age estimates closer to chronological age than digital radiographs and thus concluded that MDCT scans produced more accurate estimates. The use of MDCT scans in the present study should thus more accurately estimate fusion age.

Table 6.4. Cross-tabulation agreement between the French and American Risser scoring methods.

\begin{tabular}{llllllll}
\hline $\begin{array}{l}\text { American } \\
\begin{array}{l}\text { Risser } \\
\text { Method }\end{array}\end{array}$ & $\mathbf{0}$ & $\mathbf{1}$ & $\mathbf{2}$ & $\mathbf{3}$ & $\mathbf{4}$ & $\mathbf{5}$ & Total \\
\cline { 2 - 7 } & $308^{*}$ & - & - & - & - & - & 308 \\
\hline $\mathbf{0}$ & - & $30^{*}$ & - & - & - & - & 30 \\
$\mathbf{2}$ & - & 3 & $7^{*}$ & - & - & - & 10 \\
$\mathbf{3}$ & - & - & 3 & $4^{*}$ & - & - & 7 \\
$\mathbf{4}$ & - & - & - & 15 & $1^{*}$ & - & 16 \\
$\mathbf{5}$ & - & - & - & - & 25 & $165^{*}$ & 190 \\
\hline Total & 308 & 33 & 10 & 19 & 26 & 165 & 561 \\
\hline
\end{tabular}

* Indicates agreement between American and French Risser scoring systems

\section{v) Iliac crest methodologies}

The timing of the commencement of fusion in the iliac crest was consistent across the three assessment methods (ICE, USA, FRE). The assignment of unfused (Stage 0 USA/FRE, Stage $1 \mathrm{ICE}$ ) and complete fusion (Stage 5 USA/FRE, Stage 3 ICE) of all three scoring method was in complete agreement (Table 6.4.). The main discrepancy occurred in the assignment of active fusion (see Table 6.5. and Table 6.4.). The use of four fusion stages in the Risser scoring system resulted in 46 cases of disagreement, which were all assigned to Stage 2 using the three stage method (ICE). The disagreement between the Risser methods (FRE and USA) can be avoided with a simpler three-stage scoring system (ICE). 
Bitan et al. (2005) reported $49.2 \%$ disagreement between the USA and FRE methods based on a radiographic clinical assessment of American patients diagnosed with adolescent idiopathic scoliosis. The present study observed 8.2\% disagreement between the USA and FRE methods (see Table 6.4.). The majority (54\%) of disagreements involved the assignment of USA Stage 5 and FRE Stage 4. The FRE method assigns posterior apophyseal fusion to Stage 4 while the USA method assigns to Stage 5 . The present study's higher level of agreement between Risser methods may be attributed to the differences between the assessment of radiographs and MDCT scans. The forensic applicability of the Risser scoring system is limited due to the difficulty in assigning stages 1-4 (Kotwicki 2008; Wittschieber et al. 2013a). The 6 stage Risser scoring systems (FRE and USA) could be replaced by the more user friendly three stage scoring system (ICE).

Table 6.5. Cross-tabulation of agreement between the three-stage scoring method (ICE) and the Risser (FRE/USA) scoring methods.

\begin{tabular}{llll}
\hline \multirow{2}{*}{ Risser scores* $^{*}$} & \multicolumn{3}{c}{ 3 Stage system } \\
\cline { 2 - 4 } & $\mathbf{1}$ & $\mathbf{2}$ & $\mathbf{3}$ \\
\hline $\mathbf{0}$ & 308 & - & - \\
$\mathbf{1}$ & - & 30 & - \\
$\mathbf{2}$ & - & 7 & - \\
$\mathbf{3}$ & - & 4 & - \\
$\mathbf{4}$ & - & 1 & - \\
$\mathbf{5}$ & - & - & 165 \\
Disagreement & - & 46 & - \\
\hline Total & 308 & 88 & 165 \\
\hline
\end{tabular}

Key: Combined FRE and USA methods; ${ }^{\S}$ ICE method. 
Table 6.6. Comparisons of fusion timing in the iliac crest epiphysis based on morphological observations using the Risser scoring methods.

\begin{tabular}{|c|c|c|c|c|c|c|c|c|c|}
\hline Reference & Population & Modality & Method & Stage 0 & Stage 1 & Stage 2 & Stage 3 & Stage 4 & Stage 5 \\
\hline \multirow{4}{*}{$\begin{array}{l}\text { Present } \\
\text { study }\end{array}$} & \multirow{4}{*}{$\begin{array}{l}\text { Western } \\
\text { Australian }\end{array}$} & \multirow[t]{4}{*}{ MDCT } & \multirow[t]{2}{*}{ FRE } & ก $8.03 \pm 4.70$ & d $16.67 \pm 0.96$ & o $17.35 \pm 1.26$ & đ $20.92 \pm 2.91$ & స $18.58 \pm 2.10$ & o $23.33 \pm 3.07$ \\
\hline & & & & $q 7.40 \pm 4.35$ & 우 $16.25 \pm 1.90$ & 우 $18.90 \pm 2.15$ & 우 $18.29 \pm 3.04$ & 우 $19.46 \pm 2.29$ & 우 $22.74 \pm 3.21$ \\
\hline & & & \multirow[t]{2}{*}{ USA } & $8.03 \pm 4.70$ & o $16.71 \pm 0.98$ & $17.38 \pm 1.32$ & o $17.75 \pm 1.80$ & స $21.41 \pm 3.12$ & ○ $22.87 \pm 3.30$ \\
\hline & & & & $q 7.40 \pm 4.35$ & 우 $16.22 \pm 1.95$ & ㅇ $17.50 \pm 1.30$ & 우 $18.19 \pm 2.46$ & 우 $18.67 \pm 3.10$ & ㅇ $22.19 \pm 3.30$ \\
\hline \multirow{4}{*}{$\begin{array}{l}\text { Wittschieber } \\
2013\end{array}$} & \multirow[t]{4}{*}{ German } & \multirow[t]{4}{*}{ X-ray } & \multirow[t]{2}{*}{ FRE } & ô $12.46 \pm 1.38$ & ô $13.31 \pm 0.98$ & o $14.30 \pm 0.88$ & ô $15.34 \pm 0.40$ & đ $17.97 \pm 2.06$ & o $24.87 \pm 3.50$ \\
\hline & & & & o $11.31 \pm 1.22$ & ㅇ $13.54 \pm 1.67$ & ㅇ $14.11 \pm 2.21$ & 우 $15.23 \pm 1.06$ & ㅇ $17.40 \pm 1.91$ & $+24.14 \pm 3.29$ \\
\hline & & & \multirow[t]{2}{*}{ USA } & $12.46 \pm 1.38$ & స̂ $13.49 \pm 1.12$ & ภ $14.17 \pm 1.15$ & స $14.28 \pm 0.78$ & đ $15.55 \pm 1.06$ & ก $23.84 \pm 4.14$ \\
\hline & & & & o $11.31 \pm 1.22$ & o N/A & ㅇ $13.83 \pm 1.63$ & o N/A & 우 $15.23 \pm 1.06$ & ㅇ $22.22 \pm 4.10$ \\
\hline
\end{tabular}




\section{vi) Sacrum}

In the present study there was only one subject assigned to completed fusion (Stage 3) at S1-2; an insufficient number to perform statistical analysis. This indicates that the complete fusion at S1-2 occurs outside of the population age range (post 25 years) assessed in this study. An investigation into the complete fusion at S1-2 would require an adult sample with a high proportion of subjects aged 25 years and over.

It was difficult to assign fusion stage in the sacrum, as the centra fuses medially (from the outside in). This fusion pattern made it difficult to determine complete fusion, as the interior of the centra appeared unfused. Digital imaging provides the observer with the ability to view the degree of fusion, which is not observable in dry bone specimens. The lack of literature assessing the fusion of the sacrum using digital imagery means that the results of this study cannot be directly compared. There is a clear opportunity for further investigation into the order and timing of appearance and fusion of the ossification centres in the sacrum using digital imagery.

The sacrum was the least precise attribute scored in the MDCT scans. Scheuer et al. (2000d) note the lack of published data on the timing of fusion of the secondary ossification centres in the vertebral column. Cardoso et al. (2014c) and Coqueugniot and Weaver (2007) investigated epiphyseal fusion of the sacrum in a Portuguese dry bone sample. These studies are not directly comparable to the present study as different sacral attributes were assessed. Scheuer et al. (2000d) state that the secondary centres of ossification in the sacrum appear between 12 16 years, commence fusing at 18 years, with fusion completed by 24 years. Cardoso et al. (2014c) reported that their oldest unfused female was 16 years of age and the oldest male was 18 years at the annular epiphysis in a Portuguese population. In that population the youngest female and male to complete fusion were 18 years and 16 years respectively. This published data highlights inconsistency in the timing of fusion of the annular epiphyses in the sacrum. 


\subsection{Aim two: development of Australian standards}

The second aim of the present study attempted to address the lack of age estimation standards specific for the Western Australian population. The Scientific Working Group for Forensic Anthropology recommends the application of population specific standards for estimating the age of unidentified remains (SWGANTH 2013). The 'best practice' of using population specific standards is known to increase accuracy and reduce the effects of sex and ancestry-based variation. Polynomial regression analysis of the data resulted in the formulation of age estimation models based on the relationship between chronological age and skeletal maturation. The assessment of the degree of epiphyseal fusion was used as an indicator of skeletal age. This score can be input into the regression models (see Table 5.9) derive an age estimate specific to a Western Australian population.

The standard error of the estimate ( \pm 3.59 to \pm 4.58 years) is larger than other published models utilizing skeletal elements other than the pelvic girdle and proximal femur. Franklin and Cardini (2007) reported a SEE of \pm 2.4 years based on the analysis of linear measurements of the mandible in a sample ranging in age from 1 to 17 years. Cardoso et al. (2014c) reported the mean standard error (MSE) of models utilising long bone lengths (femur; fibula) as between \pm 0.92 years to \pm 1.39 years. Rissech et al. (2012) reported the SEE of models using humeral development ranging between \pm 1.34 years and \pm 2.36 years. The lack of published age estimation models using the timing of fusion of the pelvic girdle and proximal femur result in the inability to directly compare error rates. The accuracy of the model produced in the present study, however, is relatively more accurate than other available methodologies. For example, SWGANTH (2013) note that best practice for age assessment in the absence of dentition is the analysis of the timing of fusion of epiphyseal fusion. Thus the models formulated in this study fulfil the best practice criteria as set out by SWGANTH when estimating age of a sub-adult from the Western Australian population. 


\section{CHAPTER SIX}

\subsection{Aim three: novel statistical approaches}

Traditionally age estimation standards have lacked sophisticated statistical analyses and as a result are largely qualitative (Boldsen et al. 2002; Milner et al. 2008). The requirements of forensic age estimations in medico-legal investigation is that it must demonstrate a minimum standard of accuracy and precision (SWGANTH 2013). For the third research aim, transition analysis was used to attempt to address osteological and statistical issues (such as small sample sizes and age mimicry) that arise during the process of age estimation (Boldsen et al. 2002; Milner et al. 2008). Transition analysis is applicable to any skeletal attribute that can be categorized into invariant series of senescent stages.

The transition analysis performed highlighted significant differences in the timing of transition fusion stages between males and females. On average the femoral head commenced fusing (transitioning from Stage 1 to 2 ) at $7.20 \pm 2.42$ years in females, versus $10.14 \pm 2.60$ years in males. The average three year delay in the timing of fusion in the $\mathrm{FH}, \mathrm{GT}$ and $\mathrm{LT}$ in males is highlighted by their respective mean ages at transition (see Table 5.10). This is consistent with previous research in the literature; for example, Hansman (1962b) demonstrated fusion of the femoral head at 11-16 years for females and 14-19 years for males. The $\mathrm{FH}$ had the largest standard deviation of the combined sex data, with a mean age at transition of 8.70 \pm 2.89 years, which indicates considerable variability in timing of commencement of fusion. The standard deviation at transition from Stage 2 to 3 fell significantly, with a mean age at transition of $14.36 \pm 1.85$ years.

The ischial tuberosity (ITE) had the smallest mean standard deviation of the male (Stage 1 to 2 ) and combined sex (Stage 2 to 3 ) groups ( \pm 0.60 and \pm 1.39 years respectively). This identifies the ITE as the least variable morphological developmental attribute. The ischial tuberosity had a mean age at transition from Stages 1 to 2 of $13.10 \pm 1.36$ years in females. The mean age of sacral transition (between Stages 1 and 2) was less variable compared to Stages 2 to 3 . The large standard deviation values of mean age at transition between Stages 2 to 3 
highlights the variability in the timing of complete fusion in the sacrum. The sacrum demonstrated more variability as age increased. Rios (2008) used transition analysis in their assessment of the timing of sacral fusion of subjects between 1659 years of age. The mean age at transition from Stage 1 to 2 at S1-2 for males was $25.6 \pm 8.7$ years and for females it was $21.1 \pm 3.7$ years. This is markedly different to the results of the present study which were for $12.63 \pm 2.89$ years and $8.88 \pm 4.21$ years in males and females respectively. The discrepancy could be attributable to the difference in analysing dry bone versus radiographic scans. This study highlights the opportunity for further investigation into the timing appearance and fusion of primary and secondary centres of ossification in the sacrum. Rios (2008) noted that the start of fusion at the S1-2 vertebrae could be useful in assigning unidentified remains to broad age categories (e.g. under or over 18 years, adult or juvenile), but the results of this study do not support that supposition.

\section{5 .Forensic applications}

The application of population specific standards is integral to the accuracy of a biological profile (Cattaneo 2007; Franklin 2010; SWGANTH 2013). The use of a foreign population standard could result in the incorrect estimation of age due to the variation in growth and maturation between populations (Harper and Crews 2000). The models produced in this study are designed for forensic application in Western Australia, with possible extended applicability to the entire Australian population (see Section 6.7). The forensic applicability of these models in the living could be limited due to gonadal radiation exposure associated with scanning the pelvic region. The sequence and timing of fusion of the primary and secondary epiphyses could also assist towards the identification of comingled remains (e.g. mass graves, natural disaster) (SWGANTH 2011; Schaefer and Black 2007; Schaefer 2008). Resolving comingled remains involves the separation of two or more individuals. The anthropological data collected during the present study could be utilized in the assessment comingled Australian remains by eliminating mismatches, or assigning together, based on estimated age. 


\subsection{Limitations}

The sample in the present study is limited by the availability of, and access to, suitable MDCT scans. The sample was collected from the Western Australian DoH PACS database that comprises clinical scans taken during examination of hospital patients. Only suitable scans were included, which eliminated all patients who had any pathology or trauma of the os coxa, proximal femur or sacral vertebrae. Thus, there is an inherent population bias to individuals that visited these specific hospitals and had an MDCT scan. The replication of this study on a larger Western Australian (or Australian) sample would increase the discrimination power of the results.

Another potential limitation was a lack of ancestral data specific to each individual scan, thus the population distribution of the sample is unknown. This has the potential to create an unknown sampling bias. If it were actually possible it would be interesting to replicate the present study in a sample of known ancestry and socioeconomic status. Replication according to frequencies of ancestry reported by the 2011 Australian Census (Department of Immigration and Border Protection 2014) would result in higher discrimination power. This data, however, is not collected at the time of scanning and is difficult to accurately collect as not all individuals know their ancestry.

\subsection{Future research}

The present study could be replicated to include other Australian sub-populations to compare and analyse any significant differences in the timing of epiphyseal fusion. The investigation could also be further extended to compare foreign populations with similar ancestral dynamics and socio-economic climates (e.g. New Zealand, United Kingdom). The 2011 Australian Census shows that $26 \%$ of the population was born overseas (Australian Bureau of Statistics 2012); the United Kingdom and New Zealand accounts for $20.8 \%$ and $9.1 \%$ of the Australian population born overseas (Australian Bureau of Statistics 2012). Therefore, it would be beneficial to investigate the growth and maturation of individuals from 
those three countries. This could provide anthropologists with insights into the accuracy of using foreign population standards in cases where local standards are unavailable.

\subsection{Conclusion}

Current literature has highlighted the improved accuracy of age estimations when applying standards formulated from a local population (e.g. Cattaneo 2007; Dirkmaat et al. 2008; Franklin 2010; SWGANTH 2013). This study addressed the lack of Australian standards through the formulation of sub-adult age estimation standards based on the morphological assessment of a modern Western Australian population. This data can now be added to the database of human identification protocols being developed as part of present research projects at the Centre for Forensic Science, at the University of Western Australia. Forensic age estimation is a crucial component of the biological profile and is required to be highly accurate and precise. The results of the present study demonstrate that the fusion of the ossification centres of the pelvic girdle and proximal femur have a strong correlation with, and can be used to accurately estimate chronological age ( $\pm 3.59-4.58$ years). 


\section{REFERENCES}

Acheson RM. 1954. A Method of Assessing Skeletal Maturity from Radiographs: A Report from the Oxford Child Health Survey. Journal of Anatomy 88(4): pp 498-508.

Acheson RM. 1957. The Oxford method of assessing skeletal maturity. Clinical Orthopedics 10: pp 19-39.

Adam C. 2010. Essential Mathematics and Statistics for Forensic Science. Wiltshire: John Wiley \& Sons Ltd.

Albert A, and Greene D. 1999. Bilateral asymmetry in skeletal growth and maturation as an indicator of environmental stress. American Journal Of Physical Anthropology 110(3): pp 341-349.

AlQahtani SJ, Hector MP, and Liversidge HM. 2010. Brief communication: The London atlas of human tooth development and eruption. American Journal of Physical Anthropology142(3): pp 481-490.

Alsup B. 2008. Investigation of Second, Fourth and Eighth Sternal Rib End Variation Related to Age Estimation. Proceedings of the American Academy of Forensic Sciences. Washington D.C: American Academy of Forensic Sciences. pp 344-345.

Andersen E. 1971. Comparisons of Tanner-Whitehouse and Grulich-Pule methods in a large Danish survey. American Journal of Physical Anthropology 35(3): pp 373-376.

Anderson M. 1971. Use of the Greulich-Pyle "Atlas of Skeletal Development of the Hand and Wrist" in a Clinical Context. American Journal of Physical Anthropology 35(3): pp 347-352.

Armitage P, Berry G, and Matthews J. 2008. Statistical Methods in Medical

Research. Chichester: John Wiley \& Sons, Ltd.

Auerbach BM, and Ruff CB. 2006. Limb bone bilateral asymmetry: variability and commonality among modern humans. Journal of Human Evolution 50(2): pp 203-218.

Australian Bureau of Statistics. 2012. Cultural Diversity in Australia: Reflecting a

Nation: Stories from the 2011 Census.

Australian Human Rights Commission. 2012. An age of uncertainty - Inquiry into 


\section{REFERENCES}

the treatment of individuals suspected of people smuggling offences who say that they are children. In: Australian Human Rights Commission, editor. Sydney, NSW: Australian Human Rights Commission.

Australian Institute of Criminology. 2005. Crime Facts Info: The age of criminal responsibility. Canberra: Australian Government.

Bassed RB, Briggs C, and Drummer OH. 2010. Analysis of time of closure of the spheno-occipital synchondrosis using computed tomography. Forensic Science International 200(1-3): pp 161-164.

Bengston R. 1935. A study of the time of eruption and root development of the permanent teeth between six and thirteen years. Northwest University Bulletin 35: pp 3-9.

Beunen G, Lefevre, J, Ostyn, M, Renson, R, Simons, J \& Van Gerven, D 1990. Skeletal maturity in Belgian youths assessed by the Tanner-Whitehouse method (TW2). Annals of Human Biology 17(5): pp 355-376.

Biondi J, Weiner DS, Bethem D, and Reed JF. 1985. Correlation of Risser sign and bone age determination in adolescent idiopathic scoliosis. Journal of Pediatric Orthopaedics 5(6): pp 697-701.

Bitan FD, Veliskakis KP, and Campbell BC. 2005. Differences in the Risser Grading Systems in the United States and France. Clinical Orthopaedics and Related Research 436(1): pp 190-195.

Blenkin M, and Taylor J. 2010. Age Evaluation and Odontology in the Living. In: Black S, Aggrawal A, and Payne-James J, editors. Age Estimation in the Living: The Practitioner's Guide. New Jersey: Wiley-Blackwell.

Boldsen JL, Milner GR, Konigsberg LW, and Wood JW. 2002. Transition analysis: a new method for estimating age from skeletons. In: Hoppa RD, and Vaupel JW, editors. Paleodemography: age distributions from skeletal samples. Cambridge: Cambridge University Press. pp 73-106.

Bowerman BL, O'Connell R, and Murphree ES. 2014. Regression Analysis : Unified Concepts, Practical Applications, Computer Implementation. New York: Business Expert Press.

Braga J, Heuze Y, Chabadel O, Sonan NK, and Gueramy A. 2005. Non-adult dental age assessment: correspondence analysis and linear regression versus Bayesian predictions. International Journal of Legal Medicine 119(5): 


\section{REFERENCES}

pp 260-274.

Buikstra JE, and Ubelaker DH, editors. 1994. Standards for data collection from human skeletal remains. Fayetteville: Arkansas Archeological Survey.

Bull RK, Edwards PD, Kemp PM, Fry S, and Hughes IA. 1999. Bone age assessment: a large scale comparison of the greulich and pyle, and tanner and whitehouse (TW2) methods. Archives of Disease in Childhood 81(2): pp 172-173.

Cardoso H, Abrantes J, and Humphrey L. 2014a. Age estimation of immature human skeletal remains from the diaphyseal length of the long bones in the postnatal period. International Journal of Legal Medicine 128(5): pp 809824.

Cardoso H, Pereira V, and Rios L. 2014b. Chronology of Fusion of the Primary and Secondary Ossification Centres in the Human Sacrum and Age Estimation in Chil and Adolescent Skeletons. American Journal of Physical Anthropology 153(2): pp 214-2256.

Cardoso HF. 2007. Environmental effects on skeletal versus dental development: Using a documented subadult skeletal sample to test a basic assumption in human osteological research. American Journal of Physical Anthropology 132(2): pp 223-233.

Cardoso HF, Pereira V, and Rios L. 2014c. Chronology of fusion of the primary and secondary ossification centers in the human sacrum and age estimation in child and adolescent skeletons. American Journal of Physical Anthropology 153(2): pp 214-225.

Cardoso HFV. 2008. Epiphyseal union at the innominate and lower limb in a modern Portuguese skeletal sample, and age estimation in adolescent and young adult male and female skeletons. American Journal of Physical Anthropology 135(2): pp 161-170.

Carter D. 1987. Mechanical loading history and skeletal biology. Journal of Biomechanics 20(11-12): pp 1095-1109.

Carter DR, Van Der Meulen MC, and Beaupré GS. 1996. Mechanical factors in bone growth and development. Bone 18(1): pp 5S-10S.

Cattaneo C. 2007. Forensic anthropology: developments of a classical discipline in the new millennium. Forensic Science International 165(2-3): pp 185-193. 


\section{REFERENCES}

Chritensen AM, Crowder CM, Ousley SD, and Houck MM. 2014. Error and its Meaning in Forensic Science. Journal of Forensic Sciences 59(1): pp 123126.

Coqueugniot $\mathrm{H}$, and Weaver TD. 2007. Brief Communication: Infracranial maturation in the skeletal collection from Coimbra, Portugal: New aging standards for epiphyseal union. American Journal of Physical Anthropology 134(3): pp 424-437.

Coqueugniot H, Weaver TD, and Houët F. 2010. Brief Communication: A

Probabilistic Approach to Age Estimation from Infracranial Sequences of Maturation. American Journal of Physical Anthropology 142(4): pp 655-664.

Cunha E, Baccino E, Martrille L, Ramsthaler F, Prieto J, Schuliar Y, Lynnerup N, and Cattaneo C. 2009. The problem of aging human remains and living individuals: A review. Forensic Science International 193(1-3): pp 1-13.

Demirjian A. 1994. Dental development. CD Rom. Norwood, MA: Silver Platter Education.

Demirjian A, Buschang PH, Tanguay R, and Patterson DK. 1985. Interrelationships among Measures of Somatic, Skeletal, Dental, and Sexual Maturity. American Journal of Orthodontics and Dentofacial Orthopedics 88(5): pp 433-438.

Demirjian A, and Goldstein H. 1976. New systems for dental maturity based on seven and four teeth. Annals of Human Biology 3(5): pp 411-421.

Demirjian A, Goldstein H, and Tanner J. 1973. A new system of dental age assessment. Human Biology 45(2): pp 211-227.

Department of Immigration and Border Protection. 2014. The People of Australia :

Statistics from the 2011 Census. Commonwealth of Australia.

Dirkmaat DC, Cabo LL, Ousley SD, and Symes SA. 2008. New perspectives in forensic anthropology. American Journal of Physical Anthropology Supplement 47: pp 33-52.

Drake RL, Vogl AW, Mitchell AWM, and Gray H. 2010. Gray's Anatomy for Students. Philadelphia: Churchill Livingstone/Elsevier.

Eveleth P, and Tanner J. 1990. Worldwide variation in human growth. Cambridge:

Cambridge University Press.

Fanning E. 1961. A Longitudinal Study of Tooth Formation and Root Resorption. 
REFERENCES

New Zealand Dental Journal 57: pp 202-217.

Flander L, and Corruccini R. 1980. Shape differences in the sacral alae. American Journal of Physical Anthropology 52: pp 399-403.

Flecker H. 1932. Roentgenographic Observations of the Times of Appearance of Epiphyses and their Fusion with the Diaphyses. Journal of Anatomy 67(1): pp 118-164.

Francis C, Werle $P$, and Behm A. 1939. The apperance of centers of ossification from birth to 5 years. American Journal of Physical Anthropology 24(1): pp 273-299.

Franklin D. 2010. Forensic age estimation in human skeletal remains: Current concepts and future directions. Journal of Legal Medicine 12(1): pp 1-7.

Franklin D, and Cardini A. 2007. Mandibular morphology as an indicator of human subadult age: Interlandmark approaches. Journal of Forensic Sciences 52(5): pp 1015-1019.

Franklin D, and Flavel A. 2014. Brief Communication: Timing of Spheno-Occipital Closure in Modern Western Australians. American Journal of Physical Anthropology 153(1): pp 132-138.

Garvin HM, Passalacqua NV, Uhl NM, Gipson DR, Overbury RS, and Cabo LL. 2012. Developments in Forensic Anthropology: Age-at-Death Estimation. In: Dirkmaat DC, editor. A Companion to Forensic Anthropology. First Edition ed. Oxford: Blackwell Publishing Ltd. pp 202-238.

Goldberg MS, Poitras B, Mayo NE, Labelle H, Bourassa R, and Cloutier R. 1988. Observer variation in assessing spinal curvature and skeletal development in adolescent idiopathic scoliosis. Spine 13(12): pp 1371-1377.

Greulich W, and Pyle S. 1959. Radiographic atlas of skeletal development of the hand and wrist. Stanford: Stanford University Press.

Hackman L, and Black S. 2013. The Reliability of the Greulich and Pyle Atlas When Applied to a Modern Scottish Population. Journal of Forensic Sciences 58(1): pp 114-119.

Hackman L, Buck A, and Black S. 2010. Age Evaluation from the Skeleton. In:

Black S, Aggrawal A, and Payne-James J, editors. Age Estimation in the Living: The Practitioner's Guide. United Kingdom: John Wiley \& Sons Ltd. pp 202-235. 


\section{REFERENCES}

Hägg U, and Matsson L. 1985. Dental maturity as an indicator of chronological age: the accuracy and precision of three methods. European Journal of Orthodontics 7: pp 25-34.

Hansman C. 1962a. Appearance and fusion of ossification centres in the human skeleton. American Journal of Roentgenology 88: pp 476-482.

Hansman CF. 1962b. Appearance and fusion of ossification centers in the human skeleton. The American journal of roentgenology, radium therapy, and nuclear medicine 88: pp 476-482.

Harper G, and Crews D. 2000. Aging, senescence, and human variation. In: Stinson S, Bogin B, Huss-Ashmore R, and O'Rourke D, editors. Human biology. an evolutionary and biocultural perspective. New York: Wiley-Liss. pp 465-505.

Holobinko A. 2012. Forensic human identification in the United States and Canada: A review of the law, admissible techniques, and the legal implications of their application in forensic cases. Forensic Science International 222(1-3): pp 394e.391-394e.313.

Izumi Y. 1995. The Accuracy of Risser Staging. Spine (Phila Pa 1976) 20(17): pp 1868-1871.

Jitt I, and Singh B. 1971. A radiological study of the time of fusion of certain epiphyses in Punjabees. Journal of Anatomical Society India 20(1): pp 1-27.

Johnston FE. 1961. Sequence of epiphyseal union in a prehistoric Kentucky population from Indian Knoll. Human Biology 33: pp 66-81.

Kemkes-Grottenthaler A. 2002. Aging through the ages: historical perspective on age indicator metods. In: Hopps RV, J, editor. Paleodermography: age distributions from skeletal samples. Cambridge: Cambridge University Press. pp 48-72.

Klepinger LL. 2001. Stature, maturation variation and secular trends in forensic anthropology. Journal Of Forensic Sciences 46(4): pp 788-790.

Konigsberg LW, Herrmann NP, Wescott DJ, and Kimmerle EH. 2008. Estimation and Evidence in Forensic Anthropology: Age-at-Death. Journal of Forensic Sciences 53(3): pp 541-557.

Kotwicki T. 2008. Improved accuracy in Risser sign grading with lateral spinal radiography. European Spine Journal 17(12): pp 1676-1685. 


\section{REFERENCES}

Krestan C, Noske H, Vasilevska V, Weber M, Schueller G, Imhof H, and Czerny C. 2006. MDCT Versus Digital Radiography in the Evaluation of Bone Healing in Orthopedic Patients. American Journal of Roentgenology 180(6): pp 1754-1760.

Lampl M, and Johnston FE. 1996. Problems in the Aging of Skeletal Juveniles: Perspectives From Maturation Assessments of Living Children. American Journal of Physical Anthropology 101(3): pp 345-355.

Landis JR, and Koch GG. 1977a. An Application of Hierarchical Kappa-type

Statistics in the Assessment of Majority Agreement among Multiple

Observers. Biometrics 33(2): pp 363-374.

Landis JR, and Koch GG. 1977b. The measurement of observer agreement for categorical data. Biometrics 33(1): pp 159-174.

Laurenson R. 1964a. The chondrification of the human ilium. The Anatomical

Record 148(2): pp 197-202.

Laurenson R. 1964b. The primary ossification of the human ilium. The Anatomical Record 148(2): pp 209-217.

Lewis AB, and Garn SM. 1960. The relationship between tooth formation and other malnutritional factors. The Angle Orthodonist 30(3): pp 70-77.

Lewis ME, and Flavel A. 2007. Age Assessment of Child Skeletal Remains in Forensic Context. In: Schmitt A, Cunha E, and Pinheiro J, editors. Forensic Anthropology and Medicine: Complementary Sciences From Recovery to Cause of Death. New York: Humana Press.

Little DG, and Sussman MD. 1994. The Risser Sign: A Critical Analysis. Journal of Pediatric Orthopaedics 14(5): pp 569-575.

Lottering N, MacGregor DM, Meredith M, Alston CL, and Gregory LS. 2013.

Evaluation of the Suchey-Brooks Method of Age Estimation in an Australian Subpopulation using Computed Tomography of the Pubic Symphyseal Surface. American Journal of Physical Anthropology 150(3): pp 386-399.

Lucy D, Aykroyd R, Pollard A, and Solheim T. 1996. A Bayesian approach to adult human age estimation from dental observations by Johanson's age changes. Journal of Forensic Sciences 41(2): pp 189-194.

McKern T, and Stewart T. 1957. Skeletal age changes in young American males, analysed form the standpoint of age identification. Headquarters 


\section{REFERENCES}

Quartermaster Research and Development Command Technical Report. Massachusetts.

Milner GR, Buikstra JE, Murray EA, and Boldsen JL. 2008. Transition Analysis: A New Approach to Skeletal Age Estimation for Anthropologists. Proceedings of American Academy of Forensic Sciences. Washington D.C,: American Academy of Forensic Sciences. pp 28.

Moananui RT, Kieser JA, Herbison P, and Liversidge HM. 2008. Advanced dental maturation in New Zealand Maori and Pacific Island children. American Journal of Human Biology 20(1): pp 43-50.

Moore K, Dalley A, and Agur A. 2010. Clinically oriented anatomy. Philadelphia, PA: Wolters Kluwer : Lippincott Williams \& Wilkins.

Moorrees CF, Fanning EA, and Hunt EE. 1963a. Age Variation of Formation Stages for Ten Permanent Teeth. Journal of Dental Research 42(6): pp 1490-1502.

Moorrees CF, Fanning EA, and Hunt EE. 1963b. Formation and Resorption of

Three Deciduous Teeth in Children. American Journal of Physical Anthropology 21(2): pp 205-213.

Netter F. 2014. Atlas of Human Anatomy. Pennsylvania: Elsevier.

NHMRC. 2007. National Statement on Ethical Conduct in Human Research. Australian Government.

Norris SP. 2002. Mandibular Ramus Height as an Indicator of Human Infant Age. Journal of Forensic Sciences 47(1): pp 8-11.

O'Connor JE, Coyle J, Bogue C, Spence LD, and Last J. 2014. Age prediction formulae from radiographic assessment of skeletal maturation at the knee in an Irish population. Forensic Science International 234: pp 188 e181-188.

Office of Multicultural Interests. 2013. Cultural Diversity in Western Australia: A

Demographic Profile. In: Department of Local Government and Communitites, editor: Government of Western Australia.

Passalacqua NV. 2009. Forensic Age-at-Death Estimation from the Human Sacrum. Journal of Forensic Sciences 54(2): pp 255-262.

Passalacqua NV. 2010. Applications of the human sacrum in age at death estimation. In: Latham KE and Fineegan M, editors. Age Estimation of the Human Skeleton. Springfield: Charles C Thomas Publisher. pp 102-117. 
REFERENCES

Plochocki JH. 2002. Directional bilateral asymmetry in human sacral morphology. International Journal of Osteoarchaeology 12(5): pp 349-355.

Reem J, Carney J, Stanley M, and Cassidy J. 2009. Risser sign inter-rater and intra-rater agreement: is the Risser sign reliable? Skeletal Radiology 38(4): pp 371-375.

Ríos L, Weisensee K, and Rissech C. 2008. Sacral fusion as an aid in age estimation. Forensic Science International 180(2-3): pp 111e.111-111e.117.

Rissech C, López - Costas O, and Turbón D. 2013. Humeral development from neonatal period to skeletal maturity-application in age and sex assessment International Journal of Legal Medicine 126(1): pp 201-202.

Rissech C, Márquez-Grant N, and Turbón D. 2012. A Collation of Recently Published Western European Formulae for Age Estimation of Subadult Skeletal Remains: Recommendations for Forensic Anthropology and Osteoarchaeology. Journal of Forensic Sciences 58 Suppl 1: pp S163-168.

Risser J. 1958. The lliac Apophysis: An Invaluable Sign in the Management of Scoliosis. Clinical Orthopaedics and Related Research 11: pp 111-119.

Ritz-Timme S, Cattaneo C, Collins MJ, Waite ER, Schutz HW, Kaatsch HJ, and Borrman HI. 2000. Age estimation: the state of the art in relation to the specific demands of forensic practise. International Journal of Legal Medicine 113(3): pp 129-136.

Roche A. 1979. Secular Trends in Stature, Weight, and Maturation. Monographs of the Society for Research in Child Development 44(3-4): pp 3-27.

Rosset A, Spadola L, and Ratib O. 2004. OsiriX: An Open-Source Software for Navigating in Multidimensional DICOM Images. Journal of Digital Imaging 17(3): pp 205-216.

Rózyło-Kalinowska I, Kiworkowa-Raczkowska E, and Kalinowski P. 2008. Dental Age in Central Poland. Forensic Science International 174(2-3): pp 207-216. Santoro V, Roca R, De Donno A, Fiandaca C, Pinto G, Tafuri S, and Introna F. 2012. Applicability of Greulich and Pyle and Demirijan aging methods to a sample of Italian population. Forensic Science International 221(1-3): pp 153e.151-155.

Santos C, Ferreira M, Alves FC, and Cunha E. 2011. Comparative study of Greulich and Pyle Atlas and Maturos 4.0 program for age estimation in a 


\section{REFERENCES}

Portuguese sample. Forensic Science International 212(1-3): pp 276 e271277.

Schaefer M, and Black S. 2007. Epiphyseal Union Sequencing: Aiding in the Recognition and Sorting of Commingled Remains. Journal of Forensic Sciences 52(2): pp 277-285.

Schaefer MC. 2008. A Summary of Epiphyseal Union Timings in Bosnian Males. International Journal of Osteoarchaeology 18(5): pp 536-545.

Scheuer JL, Black S, and Christe A. 2000a. The Head, Neck and Dentition. In: Scheuer JL, Black S, and Christe A, editors. Developmental Juventile Osteology. London: Academic Press. pp 36-170.

Scheuer L. 2002. Application of osteology to forensic medicine. Clinical Anatomy 15(4): pp 297-312.

Scheuer L, and Black S. 2004. The Juvenile Skeleton. London: Elsevier Academic Press.

Scheuer L, Black S, and Christe A. 2000b. The Lower Limb. In: Scheuer L, Black S, and Christe A, editors. Developmental Juvenile Osteology. London: Academic Press. pp 374-467.

Scheuer L, Black S, and Christie A. 2000c. The Pelvic Girdle. In: Scheuer L, Black $S$, and Christie A, editors. Developmental Juvenile Osteology. London: Academic Press. pp 341-373.

Scheuer L, Black S, and Christie A. 2000d. The Vertebral Column. In: Scheuer L, Black S, and Christie A, editors. Developmental Juvenile Osteology. London: Academic Press. pp 171-218.

Schmdit S, Schmeling A, Zwiesigk P, Pfeiffer H, and Schulz R. 2011. Sonographic evaluation of apophyseal ossification of the iliac crest in forensic age diagnositcs in living individuals. International Journal of Legal Medicine 125: pp 271-276.

Schmidt S, Nitz I, Schulz R, and Schmeling A. 2008. Applicability of the skeletal age determination method of Tanner and Whitehouse for forensic age diagnostics. International Journal of Legal Medicine 122(4): pp 309-314.

Schmitt A, Murail P, Cunha E, and Rougé D. 2002. Variability of the pattern of aging on the human skeleton: evidence from bone indicators and implications on age at death estimation. Journal of Forensic Sciences 47(6): 


\section{REFERENCES}

pp 1203-1209.

Schour I, and Massler M. 1941. The development of human dentition. Journal of the American Dental Association 28: pp 1153.

Scientific Working Group for Forensic Anthropology (SWGANTH). 2011. Resolving Commingled Human Remains. In: FederalBureauof Investigation(FBI), and Laboratory(DODCIL), editors. pp 1-7.

Scientific Working Group for Forensic Anthropology (SWGANTH). 2013. Age

Estimation. Federal Bureau of Investigation (FBI), and Laboratory(DODCIL), editors. Second Edition. pp 1-4.

Scoles PV, Salvagno R, Villalba K, and Riew D. 1988. Relationship of iliac crest maturation to skeletal and chronological age. Journal of Pediatric Orthopaedics 8(6): pp pp 639-644.

Serinelli S, Panetta V, Pasqualetti P, and Marchetti D. 2011. Accuracy of three age determination X-ray methods on the left hand-wrist: A systematic review and meta-analysis. Journal of Legal Medicine 13(3): pp pp 120-133.

Shirley NR, and Jantz RL. 2011. Spheno-Occipital Synchondrosis Fusion in Modern Americans. Journal of Forensic Sciences 56(3): pp pp 580-585.

Shuren N, Kasser JR, Emans JB, and Rand F. 1992. Reevaluation of the Use of the Risser Sign in Idiopathic Scoliosis. Spine 17(3): pp pp 359-361.

Spicer J. 2005. Multiple Regression. In: Spicer J, editor. Making Sence of Multivariate Data Analysis. Thousand Oaks: SAGE Publications, Inc.

Steadman DW, Adams BJ, and Konigsberg LW. 2006. Statistical Basis for Positive Identification in Forensic Anthropology. American Journal of Physical Anthropology 131(1): pp 15-26.

Stevenson P. 1924. Age order of Epiphyseal Union in Man. American Journal of Physical Anthropology 7(1): pp 53-93.

Sykes A. 2000. An introduction to regression analysis. In: Posner E, editor. Chicago Lectures in Law and Economics: Foundation Press.

Tanner J, Healy M, Goldstein H, and Cameron N. 2001. Assessment of skeletal maturity and prediction of adult height (TW3 method). London, UK: Saunders.

Tanner J, Whitehouse R, and Healy M. 1962. A new system for estimating skeletal maturity from the hand and wrist with standards derived from a study of 


\section{REFERENCES}

2600 healthy British children. Part II. The scoring system. Paris, France: International Child Centre.

Tanner JM. 1971. The essential characteristics of a rating system American Journal of Physical Anthropology 35(3): pp 339-340.

Tanner JM, Whitehouse R, Marshall W, Healy M, and Goldstein H. 1975. Assessment of skeletal maturity and predication of adult height (TW2 method). London: Academic.

Tunc ES, and Koyuturk AE. 2008. Dental age assessment using Demirjian's method on northern Turkish children. Forensic Science International 175(1): pp 23-26.

Ubelaker DH. 1999. Human Skeletal Remains: Excavation, Analysis, Interpretation. Chicago: Aldine Publishing Company.

Villa C, Hansen MN, Buckberry J, Cattaneo C, and Lynnerup N. 2013. Forensic age estimation based on the trabecular bone changes of the pelvic bone using post-mortem CT. Forensic Science International 233(1-3): pp 393402.

von Eye A, and Schuster C. 1998. Regression analysis for social sciences. San Diego: Academic Press

Webb PA, and Suchey JM. 1985. Epiphyseal union of the anterior iliac crest and medial clavicle in a modern multiracial sample of American males and females. American Journal of Physical Anthropology 68(4): pp pp 457-466.

White TD, Black MT, and Folkens PA. 2012. Human Osteology. California: Elsevier Academic Press.

White TD, and Folkens PA. 2005. The Human Bone Manual Burlington: Elsevier.

Wittschieber D, Schmeling A, Schmidt S, Heindel W, Pfeiffer H, and Vieth V. 2013a. The Risser sign for forensic age estimation in living individuals: a study of 643 pelvic radiographs. Forensic Science, Medicine and Pathology 9(1): pp 36-43.

Wittschieber D, Vieth V, Domnick C, Pfeiffer H, and Schmeling A. 2013b. The iliac crest in forensic age diagnostics: evaluation of the apophyseal ossification in conventional radiography. International Journal of Legal Medicine 127(2): pp 473-479.

Wood K, and Cunningham CA. 2011. Age Determination in the Juvenile. In: Black 


\section{REFERENCES}

S, and Ferguson E, editors. Forensic Anthropology: 2000 to 2010. Hoboken: Taylor and Francis.

Zander G. 1943. 'Os Acetabuli' and Other Bone Nuclei; Periarticular Calcifications At the Hip. Joint Acta Radiologica. 24(4): pp pp 317-327. 


\section{APPENDICES}

\subsection{Appendix I - Human Ethics Approval}

THE UNIVERSITY OF

WESTERN AUSTRALIA

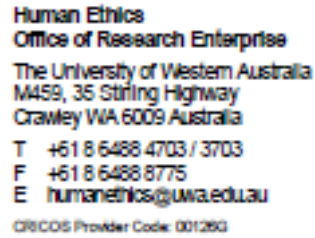

gocos Proder Cose misos

Our Ref: RA/4/1/4362

Associate Professor Daniel Franklin

Centre for Forensic Science

MBDP: M309

Dear Professor Franklin

HUMAN RESEARCH ETHICS OFFICE - ETHICS APPROVAL RENEWED

Novel approaches to the forensic identification of human remains: bone morphometrics

Student(s): Siobhan Lee Sullivan, Jacqueline Mary Elizabeth Noble, Eden Centaine Johnstone-Belford

Thank you for submitting your Progress Report for the above project. The report is satisfactory and ethics approval for the project bas been renewed.

You will receive a request for your next progress report approximately one month before the next renewal date of 01 September 2016.

If you have any queries, please contact the Human Ethics office at humanethics@uwa.edn.au.

Please ensure that you quote the file reference $-\mathrm{RA} / 4 / 1 / 4362$ - and the associated project title in all future correspondence.

Yours sincerely

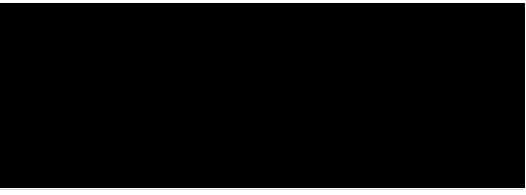

Dr Caixia Li

Manager, Human Ethics 


\subsection{Appendix II - Descriptive statistics for individual sexes (left side only)}

Table 8.1. Descriptive statistics for each stage at each morphological developmental attribute for female data (left side only).

\begin{tabular}{|c|c|c|c|c|c|c|c|c|c|}
\hline \multicolumn{2}{|c|}{$\begin{array}{l}\text { Location } \\
\text { \& Stage }\end{array}$} & Count & Mean & $\begin{array}{c}\text { St } \\
\text { Dev }\end{array}$ & $\begin{array}{c}\text { St } \\
\text { Error }\end{array}$ & Min & Max & $\begin{array}{c}\text { Percentile } \\
25\end{array}$ & $\begin{array}{c}\text { Percentile } \\
75\end{array}$ \\
\hline \multirow{3}{*}{ FH } & 1 & 74 & 4.04 & 2.57 & 0.30 & 0.03 & 10.09 & 1.82 & 6.00 \\
\hline & 2 & 59 & 9.99 & 2.83 & 0.37 & 2.78 & 15.43 & 8.61 & 12.15 \\
\hline & 3 & 137 & 19.96 & 4.34 & 0.37 & 10.34 & 30.00 & 16.80 & 23.41 \\
\hline & 1 & 86 & 4.49 & 2.85 & 0.31 & 0.03 & 11.53 & 2.36 & 6.41 \\
\hline \multirow[t]{2}{*}{ GT } & 2 & 53 & 10.82 & 2.28 & 0.31 & 4.51 & 15.43 & 9.19 & 12.53 \\
\hline & 3 & 131 & 20.33 & 4.06 & 0.35 & 12.91 & 30.00 & 17.14 & 23.50 \\
\hline \multirow{3}{*}{ LT } & 1 & 117 & 5.94 & 3.59 & 0.33 & 0.03 & 13.96 & 2.94 & 8.83 \\
\hline & 2 & 19 & 12.38 & 1.58 & 0.36 & 9.20 & 15.43 & 11.04 & 13.37 \\
\hline & 3 & 129 & 20.44 & 3.99 & 0.35 & 12.94 & 30.00 & 17.38 & 23.50 \\
\hline & 1 & 90 & 5.45 & 3.93 & 0.41 & 0.03 & 17.86 & 2.38 & 9.06 \\
\hline \multirow[t]{2}{*}{$\mathrm{S} 12$} & 2 & 179 & 17.39 & 6.11 & 0.46 & 5.18 & 30.00 & 13.14 & 22.00 \\
\hline & 3 & 1 & 19.26 & & & 19.26 & 19.26 & 19.26 & 19.26 \\
\hline \multirow{3}{*}{ S23 } & 1 & 27 & 1.59 & 1.20 & 0.23 & 0.03 & 4.80 & 0.85 & 2.38 \\
\hline & 2 & 218 & 13.95 & 7.07 & 0.48 & 1.82 & 30.00 & 8.00 & 19.47 \\
\hline & 3 & 24 & 21.58 & 2.80 & 0.57 & 16.71 & 25.63 & 19.40 & 23.87 \\
\hline & 1 & 24 & 1.40 & 0.92 & 0.19 & 0.03 & 3.56 & 0.86 & 2.11 \\
\hline \multirow[t]{2}{*}{ S34 } & 2 & 194 & 12.81 & 6.91 & 0.50 & 0.62 & 30.00 & 7.07 & 18.08 \\
\hline & 3 & 51 & 21.23 & 3.54 & 0.50 & 12.48 & 27.00 & 19.00 & 24.52 \\
\hline \multirow{3}{*}{ S45 } & 1 & 24 & 1.60 & 1.02 & 0.21 & 0.03 & 3.56 & 0.87 & 2.43 \\
\hline & 2 & 183 & 12.21 & 6.63 & 0.49 & 0.26 & 30.00 & 6.67 & 17.11 \\
\hline & 3 & 62 & 21.43 & 3.83 & 0.49 & 9.61 & 30.00 & 19.26 & 24.58 \\
\hline \multirow{3}{*}{ ILIS } & 1 & 107 & 5.40 & 3.24 & 0.31 & 0.03 & 12.28 & 2.70 & 8.00 \\
\hline & 2 & 29 & 11.94 & 1.90 & 0.35 & 7.07 & 16.15 & 10.95 & 13.16 \\
\hline & 3 & 134 & 20.14 & 4.21 & 0.36 & 10.34 & 30.00 & 16.90 & 23.45 \\
\hline \multirow{3}{*}{ ILP } & 1 & 108 & 5.45 & 3.27 & 0.31 & 0.03 & 12.28 & 2.74 & 8.01 \\
\hline & 2 & 29 & 11.98 & 1.89 & 0.35 & 7.07 & 16.15 & 11.04 & 13.16 \\
\hline & 3 & 133 & 20.20 & 4.17 & 0.36 & 10.34 & 30.00 & 17.11 & 23.45 \\
\hline \multirow{3}{*}{ ISP } & 1 & 104 & 5.22 & 3.10 & 0.30 & 0.03 & 11.53 & 2.67 & 7.82 \\
\hline & 2 & 33 & 11.93 & 1.78 & 0.31 & 7.07 & 16.15 & 11.04 & 13.14 \\
\hline & 3 & 133 & 20.20 & 4.17 & 0.36 & 10.34 & 30.00 & 17.11 & 23.45 \\
\hline \multirow{3}{*}{ AllS } & 1 & 129 & 6.45 & 3.84 & 0.34 & 0.03 & 15.43 & 3.07 & 9.61 \\
\hline & 2 & 11 & 13.17 & 2.04 & 0.61 & 10.34 & 18.24 & 12.15 & 13.69 \\
\hline & 3 & 130 & 20.35 & 4.06 & 0.36 & 12.94 & 30.00 & 17.14 & 23.50 \\
\hline \multirow{3}{*}{ ITE } & 1 & 133 & 6.62 & 3.90 & 0.34 & 0.03 & 14.22 & 3.17 & 9.87 \\
\hline & 2 & 19 & 14.13 & 1.76 & 0.40 & 10.34 & 18.00 & 12.94 & 15.43 \\
\hline & 3 & 118 & 20.96 & 3.74 & 0.34 & 13.80 & 30.00 & 18.08 & 23.93 \\
\hline \multirow{3}{*}{ ICE } & 1 & 149 & 7.40 & 4.35 & 0.36 & 0.03 & 16.04 & 3.52 & 10.95 \\
\hline & 2 & 48 & 17.91 & 2.65 & 0.38 & 13.24 & 24.00 & 15.96 & 19.00 \\
\hline & 3 & 73 & 22.74 & 3.21 & 0.38 & 15.03 & 30.00 & 20.57 & 24.95 \\
\hline \multirow{6}{*}{ FRE } & 0 & 149 & 7.40 & 4.35 & 0.36 & 0.03 & 16.04 & 3.52 & 10.95 \\
\hline & 1 & 19 & 16.25 & 1.90 & 0.44 & 13.24 & 21.00 & 14.78 & 17.86 \\
\hline & 2 & 3 & 18.90 & 2.15 & 1.24 & 16.71 & 21.00 & 16.71 & 21.00 \\
\hline & 3 & 10 & 18.29 & 3.04 & 0.96 & 13.80 & 24.00 & 16.90 & 21.00 \\
\hline & 4 & 16 & 19.46 & 2.29 & 0.57 & 14.63 & 23.28 & 18.38 & 21.50 \\
\hline & 5 & 73 & 22.74 & 3.21 & 0.38 & 15.03 & 30.00 & 20.57 & 24.95 \\
\hline \multirow{6}{*}{ USA } & 0 & 149 & 7.40 & 4.35 & 0.36 & 0.03 & 16.04 & 3.52 & 10.95 \\
\hline & 1 & 18 & 16.22 & 1.95 & 0.46 & 13.24 & 21.00 & 14.78 & 17.86 \\
\hline & 2 & 3 & 17.50 & 1.30 & 0.75 & 16.71 & 19.00 & 16.71 & 19.00 \\
\hline & 3 & 3 & 18.19 & 2.46 & 1.42 & 16.42 & 21.00 & 16.42 & 21.00 \\
\hline & 4 & 9 & 18.67 & 3.10 & 1.03 & 13.80 & 24.00 & 16.90 & 21.00 \\
\hline & 5 & 88 & 22.19 & 3.30 & 0.35 & 14.63 & 30.00 & 19.66 & 24.66 \\
\hline
\end{tabular}




\section{APPENDICES}

Table 8.2. Descriptive statistics for each stage at each morphological developmental attribute for male data (left side only).

\begin{tabular}{|c|c|c|c|c|c|c|c|c|c|}
\hline \multicolumn{2}{|c|}{$\begin{array}{l}\text { Location } \\
\text { \& Stage }\end{array}$} & Count & Mean & $\begin{array}{c}\text { St } \\
\text { Dev }\end{array}$ & $\begin{array}{c}\text { St } \\
\text { Error }\end{array}$ & Min & Max & $\begin{array}{c}\text { Percentile } \\
25\end{array}$ & $\begin{array}{c}\text { Percentile } \\
75\end{array}$ \\
\hline \multirow{3}{*}{ FH } & 1 & 102 & 5.47 & 3.41 & 0.34 & 0.01 & 13.22 & 2.41 & 8.06 \\
\hline & 2 & 55 & 12.37 & 2.60 & 0.35 & 5.39 & 16.49 & 10.71 & 14.21 \\
\hline & 3 & 135 & 21.74 & 3.70 & 0.32 & 14.87 & 30.00 & 18.74 & 24.07 \\
\hline & 1 & 116 & 6.00 & 3.62 & 0.34 & 0.01 & 13.45 & 2.89 & 8.84 \\
\hline \multirow[t]{2}{*}{ GT } & 2 & 43 & 13.38 & 2.03 & 0.31 & 7.84 & 16.95 & 12.30 & 14.93 \\
\hline & 3 & 133 & 21.82 & 3.67 & 0.32 & 14.87 & 30.00 & 18.98 & 24.07 \\
\hline & 1 & 148 & 7.46 & 4.33 & 0.36 & 0.01 & 16.42 & 3.80 & 11.17 \\
\hline \multirow[t]{2}{*}{ LT } & 2 & 11 & 15.21 & 1.18 & 0.36 & 12.61 & 16.95 & 14.42 & 15.84 \\
\hline & 3 & 132 & 21.81 & 3.68 & 0.32 & 14.87 & 30.00 & 18.91 & 24.17 \\
\hline \multirow{3}{*}{ S12 } & 1 & 127 & 6.75 & 4.22 & 0.37 & 0.01 & 16.31 & 3.32 & 10.05 \\
\hline & 2 & 164 & 20.07 & 4.91 & 0.38 & 8.87 & 30.00 & 16.59 & 23.66 \\
\hline & 3 & 0 & & & & & & & \\
\hline \multirow{3}{*}{ S23 } & 1 & 70 & 5.22 & 4.22 & 0.50 & 0.01 & 15.10 & 1.72 & 8.59 \\
\hline & 2 & 210 & 16.82 & 6.82 & 0.47 & 2.13 & 30.00 & 11.30 & 22.00 \\
\hline & 3 & 11 & 22.70 & 1.86 & 0.56 & 19.82 & 25.43 & 20.90 & 24.26 \\
\hline \multirow{3}{*}{ S34 } & 1 & 35 & 3.22 & 3.23 & 0.55 & 0.01 & 13.45 & 1.14 & 4.43 \\
\hline & 2 & 227 & 14.93 & 7.33 & 0.49 & 0.50 & 30.00 & 8.92 & 20.94 \\
\hline & 3 & 29 & 22.25 & 2.35 & 0.44 & 16.31 & 27.00 & 20.90 & 24.01 \\
\hline \multirow{3}{*}{ S45 } & 1 & 28 & 4.51 & 4.69 & 0.89 & 0.01 & 16.06 & 1.29 & 8.49 \\
\hline & 2 & 216 & 13.84 & 7.47 & 0.51 & 0.19 & 30.00 & 7.19 & 19.04 \\
\hline & 3 & 46 & 22.24 & 3.79 & 0.56 & 10.08 & 29.00 & 20.90 & 24.26 \\
\hline \multirow{3}{*}{ ILIS } & 1 & 128 & 6.61 & 3.99 & 0.35 & 0.01 & 16.42 & 3.34 & 9.65 \\
\hline & 2 & 26 & 13.62 & 1.73 & 0.34 & 9.88 & 16.49 & 12.61 & 14.55 \\
\hline & 3 & 138 & 21.55 & 3.89 & 0.33 & 10.43 & 30.00 & 18.38 & 24.01 \\
\hline \multirow{3}{*}{ ILP } & 1 & 130 & 6.66 & 3.99 & 0.35 & 0.01 & 16.42 & 3.36 & 9.67 \\
\hline & 2 & 28 & 13.96 & 1.65 & 0.31 & 10.43 & 16.64 & 12.71 & 15.11 \\
\hline & 3 & 134 & 21.77 & 3.72 & 0.32 & 14.87 & 30.00 & 18.84 & 24.07 \\
\hline & 1 & 130 & 6.66 & 3.99 & 0.35 & 0.01 & 16.42 & 3.36 & 9.67 \\
\hline \multirow[t]{2}{*}{ ISP } & 2 & 28 & 13.96 & 1.65 & 0.31 & 10.43 & 16.64 & 12.71 & 15.11 \\
\hline & 3 & 134 & 21.77 & 3.72 & 0.32 & 14.87 & 30.00 & 18.84 & 24.07 \\
\hline \multirow{3}{*}{ Alls } & 1 & 153 & 7.70 & 4.46 & 0.36 & 0.01 & 16.42 & 3.98 & 11.52 \\
\hline & 2 & 2 & 14.89 & 2.26 & 1.60 & 13.29 & 16.49 & 13.29 & 16.49 \\
\hline & 3 & 137 & 21.65 & 3.76 & 0.32 & 14.87 & 30.00 & 18.45 & 24.01 \\
\hline \multirow{3}{*}{ ITE } & 1 & 154 & 7.74 & 4.47 & 0.36 & 0.01 & 16.42 & 3.98 & 11.70 \\
\hline & 2 & 9 & 16.19 & 0.73 & 0.24 & 15.11 & 17.52 & 15.84 & 16.49 \\
\hline & 3 & 128 & 21.98 & 3.61 & 0.32 & 14.87 & 30.00 & 19.00 & 24.43 \\
\hline \multirow{3}{*}{ ICE } & 1 & 159 & 8.03 & 4.70 & 0.37 & 0.01 & 20.00 & 4.20 & 11.96 \\
\hline & 2 & 40 & 18.22 & 2.45 & 0.39 & 14.87 & 25.00 & 16.51 & 18.99 \\
\hline & 3 & 92 & 23.33 & 3.07 & 0.32 & 17.10 & 30.00 & 21.00 & 25.32 \\
\hline \multirow{6}{*}{ FRE } & 0 & 159 & 8.03 & 4.70 & 0.37 & 0.01 & 20.00 & 4.20 & 11.96 \\
\hline & 1 & 14 & 16.67 & 0.96 & 0.26 & 14.87 & 18.29 & 15.97 & 17.28 \\
\hline & 2 & 7 & 17.35 & 1.26 & 0.48 & 16.00 & 19.00 & 16.08 & 18.84 \\
\hline & 3 & 9 & 20.92 & 2.91 & 0.97 & 17.88 & 25.00 & 18.38 & 23.00 \\
\hline & 4 & 10 & 18.58 & 2.10 & 0.66 & 15.73 & 22.00 & 17.14 & 19.00 \\
\hline & 5 & 92 & 23.33 & 3.07 & 0.32 & 17.10 & 30.00 & 21.00 & 25.32 \\
\hline \multirow{6}{*}{ USA } & 0 & 159 & 8.03 & 4.70 & 0.37 & 0.01 & 20.00 & 4.20 & 11.96 \\
\hline & 1 & 12 & 16.71 & 0.98 & 0.28 & 14.87 & 18.29 & 16.02 & 17.29 \\
\hline & 2 & 7 & 17.38 & 1.32 & 0.50 & 15.56 & 19.00 & 16.00 & 18.84 \\
\hline & 3 & 4 & 17.75 & 1.80 & 0.90 & 16.08 & 20.00 & 16.31 & 19.19 \\
\hline & 4 & 7 & 21.41 & 3.12 & 1.18 & 17.88 & 25.00 & 18.00 & 25.00 \\
\hline & 5 & 102 & 22.87 & 3.30 & 0.33 & 15.73 & 30.00 & 20.76 & 25.22 \\
\hline
\end{tabular}


APPENDICES

8.3 Appendix III - Polynomial regression models for males (left side only)

\begin{tabular}{|c|c|c|c|c|c|}
\hline \multirow{2}{*}{\multicolumn{2}{|c|}{ Parameter }} & \multirow{2}{*}{ B } & \multirow{2}{*}{ Sig. } & \multicolumn{2}{|c|}{$95 \%$ Confidence Interval } \\
\hline & & & & Lower Bound & Upper Bound \\
\hline \multicolumn{2}{|c|}{ Intercept } & 22.70 & 0.00 & 21.07 & 24.34 \\
\hline \multirow[t]{2}{*}{$\mathrm{FH}$} & 1 & -5.57 & 0.01 & -10.04 & -1.10 \\
\hline & $\begin{array}{l}2 \\
3\end{array}$ & -2.57 & 0.23 & -6.74 & 1.60 \\
\hline \multirow[t]{2}{*}{ GT } & 1 & -5.00 & 0.03 & -9.50 & -0.51 \\
\hline & $\begin{array}{l}2 \\
3\end{array}$ & -1.75 & 0.41 & -5.90 & 2.39 \\
\hline \multirow[t]{2}{*}{ S23 } & 1 & -1.19 & 0.32 & -3.53 & 1.15 \\
\hline & $\begin{array}{l}2 \\
3\end{array}$ & 0.38 & 0.72 & -1.71 & 2.47 \\
\hline \multirow[t]{2}{*}{ S34 } & 1 & -2.41 & 0.01 & -4.29 & -0.53 \\
\hline & $\begin{array}{l}2 \\
3\end{array}$ & 0.36 & 0.61 & -1.03 & 1.76 \\
\hline \multirow[t]{2}{*}{ ICE } & 1 & -5.57 & 0.00 & -8.57 & -2.57 \\
\hline & $\begin{array}{l}2 \\
3\end{array}$ & -5.04 & 0.00 & -6.10 & -3.97 \\
\hline
\end{tabular}

${ }^{\star}$ Model $=22.70+$ FH + GT + S23 + S34 + ICE [Error: 2.75]; Dependent variable: age

\begin{tabular}{|c|c|c|c|c|c|}
\hline \multirow{2}{*}{ Parameter } & & \multirow{2}{*}{ B } & \multirow{2}{*}{ Sig. } & \multicolumn{2}{|c|}{$95 \%$ Confidence Interval } \\
\hline & & & & Lower Bound & Upper Bound \\
\hline \multicolumn{2}{|l|}{ Intercept } & 22.70 & 0.00 & 21.10 & 24.31 \\
\hline \multirow[t]{2}{*}{$\mathrm{FH}$} & 1 & -5.96 & 0.01 & -10.36 & -1.55 \\
\hline & $\begin{array}{l}2 \\
3\end{array}$ & -2.96 & 0.16 & -7.07 & 1.15 \\
\hline \multirow[t]{2}{*}{ GT } & 1 & -4.01 & 0.08 & -8.51 & 0.49 \\
\hline & $\begin{array}{l}2 \\
3\end{array}$ & -0.74 & 0.73 & -4.90 & 3.43 \\
\hline \multirow[t]{2}{*}{ S23 } & 1 & -1.39 & 0.24 & -3.70 & 0.92 \\
\hline & $\begin{array}{l}2 \\
3\end{array}$ & 0.19 & 0.86 & -1.87 & 2.25 \\
\hline \multirow[t]{2}{*}{ S34 } & 1 & -2.18 & 0.02 & -4.04 & -0.31 \\
\hline & $\begin{array}{l}2 \\
3\end{array}$ & 0.60 & 0.40 & -0.80 & 1.99 \\
\hline \multirow[t]{6}{*}{ FRE } & 0 & -6.21 & 0.00 & -9.21 & -3.22 \\
\hline & 1 & -6.50 & 0.00 & -8.12 & -4.88 \\
\hline & 2 & -6.14 & 0.00 & -8.25 & -4.02 \\
\hline & 3 & -2.51 & 0.01 & -4.38 & -0.63 \\
\hline & 4 & -4.73 & 0.00 & -6.52 & -2.93 \\
\hline & 5 & & & & \\
\hline
\end{tabular}

*Model $=22.70+$ FH + GT + S23 + S34 + FRE [Error: 2.71]; Dependent variable: age

\begin{tabular}{cccccc}
\hline \multirow{2}{*}{ Parameter } & \multirow{2}{*}{ B } & Sig. & \multicolumn{2}{c}{$\begin{array}{c}\text { 95\% Confidence Interval } \\
\text { Lower Bound }\end{array}$} & Upper Bound \\
\hline Intercept & & 22.90 & 0.00 & 22.23 & 23.56 \\
ILP & 1 & -9.85 & 0.00 & -12.28 & -7.41 \\
& 2 & -2.87 & 0.02 & -5.30 & -0.45 \\
USA & 3 & & & & -3.95 \\
& 0 & -6.38 & 0.00 & -8.82 & -3.62 \\
& 1 & -5.70 & 0.00 & -7.78 & -2.46 \\
& 2 & -5.10 & 0.00 & -7.74 & -1.72 \\
& 3 & -5.14 & 0.00 & -8.56 & 1.14 \\
\hline
\end{tabular}

${ }^{\star}$ Model $=22.90$ + ILP + USA [Error: 3.41]; Dependent variable: age 


\section{APPENDICES}

\begin{tabular}{cccccc}
\hline Parameter & & B & Sig. & \multicolumn{2}{c}{$95 \%$ Confidence Interval } \\
& & & & Lower Bound & Upper Bound \\
\hline Intercept & & 23.33 & 0.00 & 22.65 & 24.01 \\
ILP & 1 & -9.36 & 0.00 & -11.76 & -6.97 \\
& 2 & -2.29 & 0.06 & -4.68 & 0.11 \\
FRE & 3 & & & & -4.88 \\
& 0 & -7.31 & 0.00 & -9.73 & -4.23 \\
& 1 & -6.17 & 0.00 & -8.11 & -3.42 \\
& 2 & -5.98 & 0.00 & -8.54 & -0.14 \\
& 3 & -2.41 & 0.04 & -4.69 & -2.33 \\
\hline
\end{tabular}

${ }^{*}$ Model $=23.33+$ ILP + FRE [Error: 3.31]; Dependent variable: age

\begin{tabular}{cccccc}
\hline \multirow{2}{*}{ Parameter } & B & Sig. & \multicolumn{2}{c}{ 95\% Confidence Interval } \\
& & & & Lower Bound & Upper Bound \\
\hline Intercept & & 23.33 & 0.00 & 22.65 & 24.02 \\
ILP & 1 & -9.74 & 0.00 & -12.12 & -7.36 \\
& 2 & -2.74 & 0.02 & -5.10 & -0.37 \\
ICE & 3 & & & & -4.52 \\
& 1 & -6.93 & 0.00 & -9.34 & -3.57 \\
\hline
\end{tabular}

${ }^{*}$ Model $=23.33+$ ILP + ICE [Error: 3.34]; Dependent variable: age

\begin{tabular}{cccccc}
\hline Parameter & B & Sig. & \multicolumn{2}{c}{ 95\% Confidence Interval } \\
& & Lower Bound & Upper Bound \\
\hline Intercept & & 23.35 & 0.00 & 21.79 & 24.91 \\
S12 & 1 & -11.08 & 0.00 & -12.20 & -9.95 \\
& 2 & & & & \\
S34 & 3 & & & & -2.02 \\
& 1 & -4.90 & 0.00 & -7.78 & 1.21 \\
& 2 & -0.77 & 0.45 & -2.75 & -1.81 \\
S45 & 3 & & & & -1.84 \\
& 1 & -4.54 & 0.00 & -7.26 & \\
\hline
\end{tabular}

${ }^{*}$ Model = $23.35+$ S12 + S34 + S45 [Error: 4.17]; Dependent variable: age

\begin{tabular}{|c|c|c|c|c|c|}
\hline \multirow{2}{*}{\multicolumn{2}{|c|}{ Parameter }} & \multirow{2}{*}{ B } & \multirow{2}{*}{ Sig. } & \multicolumn{2}{|c|}{$95 \%$ Confidence Interval } \\
\hline & & & & Lower Bound & Upper Bound \\
\hline \multicolumn{2}{|c|}{ Intercept } & 22.67 & 0.00 & 21.50 & 23.84 \\
\hline \multirow{2}{*}{$\mathrm{FH}$} & 1 & -4.96 & 0.05 & -9.87 & -0.05 \\
\hline & $\begin{array}{l}2 \\
3\end{array}$ & -2.29 & 0.32 & -6.79 & 2.21 \\
\hline \multirow[t]{2}{*}{ GT } & 1 & -8.05 & 0.00 & -12.85 & -3.24 \\
\hline & $\begin{array}{l}2 \\
3\end{array}$ & -4.92 & 0.03 & -9.31 & -0.53 \\
\hline \multirow[t]{2}{*}{ S12 } & 1 & -1.75 & 0.02 & -3.25 & -0.25 \\
\hline & $\begin{array}{l}2 \\
3\end{array}$ & & & & \\
\hline \multirow[t]{2}{*}{ S34 } & 1 & -2.73 & 0.01 & -4.92 & -0.55 \\
\hline & 2 & 0.39 & 0.60 & -1.10 & 1.89 \\
\hline \multirow[t]{2}{*}{ S45 } & 1 & -2.34 & 0.03 & -4.40 & -0.27 \\
\hline & $\begin{array}{l}2 \\
3\end{array}$ & -1.75 & 0.01 & -3.02 & -0.48 \\
\hline
\end{tabular}

*Model $=22.67+\mathrm{FH}+\mathrm{GT}+\mathrm{S} 12+\mathrm{S} 34+\mathrm{S} 45$ [Error: 3.12]; Dependent variable: age 
APPENDICES

\begin{tabular}{lccccc}
\hline Parameter & \multirow{2}{*}{ B } & Sig. & \multicolumn{2}{c}{$\begin{array}{c}\text { 95\% Confidence Interval } \\
\text { Lower Bound }\end{array}$} & Upper Bound \\
\hline Intercept & & 23.33 & 0.00 & 22.73 & 23.93 \\
FH & 1 & -6.21 & 0.01 & -11.07 & -1.35 \\
& 2 & -2.08 & 0.37 & -6.62 & 2.47 \\
GT & 3 & & & & \\
& 1 & -2.75 & 0.28 & -7.72 & 4.27 \\
ILP & 2 & -0.28 & 0.90 & -4.84 & -0.46 \\
& 3 & & & & 0.94 \\
FRE & 1 & -3.20 & 0.02 & -5.93 & -2.47 \\
& 2 & -1.45 & 0.23 & -3.83 & -4.42 \\
& 3 & & & & -3.73 \\
& 1 & -5.70 & 0.00 & -8.94 & -0.41 \\
& 2 & -6.16 & 0.00 & -7.90 & -2.68 \\
& 3 & -5.98 & 0.00 & -8.23 & \\
\hline
\end{tabular}

${ }^{*}$ Model $=23.33+$ FH + GT + ILP + FRE [Error: 2.91]; Dependent variable: age

\begin{tabular}{lccccc}
\hline Parameter & \multirow{2}{*}{ B } & Sig. & \multicolumn{2}{c}{$95 \%$ Confidence Interval } \\
Lower Bound & Upper Bound \\
\hline Intercept & & 23.33 & 0.00 & 22.73 & 23.94 \\
FH & 1 & -5.75 & 0.02 & -10.65 & -0.85 \\
& 2 & -1.61 & 0.49 & -6.18 & 2.97 \\
GT & 3 & & & & \\
& 1 & -3.52 & 0.16 & -8.49 & 3.44 \\
ILP & 2 & -1.07 & 0.64 & -5.61 & -0.74 \\
& 3 & & & & 0.59 \\
ICE & 1 & -3.49 & 0.01 & -6.23 & -1.89 \\
& 2 & -1.79 & 0.14 & -4.18 & -3.71 \\
& 3 & & & & \\
\hline
\end{tabular}

*Model $=23.33+$ FH + GT + ILP + ICE [Error: 2.95]; Dependent variable: age

\begin{tabular}{cccccc}
\hline Parameter & \multirow{2}{*}{ B } & Sig. & \multicolumn{2}{c}{$95 \%$ Confidence Interval } \\
Lower Bound & Upper Bound \\
\hline Intercept & & 22.60 & 0.00 & 21.51 & 23.70 \\
S12 & 1 & -3.31 & 0.00 & -4.60 & -2.02 \\
& 2 & & & & \\
S34 & 3 & & & -5.50 & -2.02 \\
& 1 & -3.76 & 0.00 & -0.89 & 1.68 \\
ILP & 2 & 0.39 & 0.55 & & -4.12 \\
& 3 & & & -8.73 & 0.21 \\
USA & 2 & -6.43 & 0.00 & -4.09 & -3.69 \\
& 3 & -1.94 & 0.08 & -8.08 & -4.10 \\
& 0 & -5.89 & 0.00 & -7.82 & -2.16 \\
& 1 & -5.96 & 0.00 & -7.68 & 0.74 \\
& 2 & -5.34 & 0.00 & -8.14 & \\
\hline
\end{tabular}

${ }^{\star}$ Model $=22.60+$ S12 + S34 + ILP + USA [Error: 2.98]; Dependent variable: age 


\section{APPENDICES}

\begin{tabular}{cccccc}
\hline Parameter & B & Sig. & \multicolumn{2}{c}{ 95\% Confidence Interval } \\
Lower Bound & Upper Bound \\
\hline Intercept & & 21.82 & 0.00 & 21.25 & 22.39 \\
FH & 1 & -7.55 & 0.00 & -12.66 & -2.43 \\
& 2 & -3.16 & 0.19 & -7.92 & 1.60 \\
GT & 3 & & & -13.91 & -3.70 \\
& 1 & -8.81 & 0.00 & -10.11 & -0.75 \\
\hline
\end{tabular}

${ }^{\star}$ Model $=21.82+$ FH + GT [Error: 3.34]; Dependent variable: age

\begin{tabular}{cccccc}
\hline Parameter & B & Sig. & \multicolumn{2}{c}{$95 \%$ Confidence Interval } \\
Upper Bound & Upper Bnd \\
\hline Intercept & 1 & 22.93 & 0.00 & 21.85 & -1.93 \\
S12 & -3.18 & 0.00 & -4.43 & \\
& 2 & & & & -1.97 \\
S34 & 3 & & & -5.33 & 1.75 \\
& 1 & -3.65 & 0.00 & -0.72 & -3.77 \\
ILP & 2 & 0.52 & 0.41 & & 0.73 \\
& 3 & & & -8.28 & -4.68 \\
FRE & 1 & -6.02 & 0.00 & -3.51 & -4.75 \\
& 2 & -1.39 & 0.20 & -9.01 & -3.84 \\
& 3 & & & -8.20 & -0.48 \\
& 1 & -6.84 & 0.00 & -8.34 & -2.34 \\
& 2 & -6.47 & 0.00 & -4.46 & -6.15 \\
\hline
\end{tabular}

${ }^{*}$ Model $=22.93+$ S12 + S34 + ILP + FRE [Error: 2.88]; Dependent variable: age

\begin{tabular}{cccccc}
\hline Parameter & \multirow{2}{*}{ B } & Sig. & \multicolumn{2}{c}{$\begin{array}{c}\text { 95\% Confidence Interval } \\
\text { Lower Bound }\end{array}$} & Upper Bound \\
\hline Intercept & & 23.09 & 0.00 & 22.01 & 24.17 \\
S12 & 1 & -3.11 & 0.00 & -4.37 & -1.84 \\
& 2 & & & & \\
S34 & 3 & & & -5.58 & -2.20 \\
& 1 & -3.89 & 0.00 & -0.94 & 1.53 \\
ISP & 2 & 0.29 & 0.64 & & -4.25 \\
& 3 & & & -8.75 & 0.17 \\
ICE & 1 & -6.50 & 0.00 & -4.02 & -4.20 \\
& 2 & -1.93 & 0.07 & -8.54 & -3.72 \\
& 3 & & & -6.00 & \\
\hline
\end{tabular}

${ }^{*}$ Model $=23.09+$ S12 + S34 + ISP + ICE [Error: 2.93]; Dependent variable: age 
APPENDICES

\begin{tabular}{|c|c|c|c|c|c|}
\hline \multirow{2}{*}{ Parameter } & & \multirow{2}{*}{ B } & \multirow{2}{*}{ Sig. } & \multicolumn{2}{|c|}{ 95\% Confidence Interval } \\
\hline & & & & Lower Bound & Upper Bound \\
\hline \multicolumn{2}{|l|}{ Intercept } & 22.48 & 0.00 & 21.44 & 23.53 \\
\hline \multirow[t]{2}{*}{$\mathrm{FH}$} & 1 & -5.51 & 0.02 & -10.24 & -0.79 \\
\hline & $\begin{array}{l}2 \\
3\end{array}$ & -2.74 & 0.22 & -7.12 & 1.65 \\
\hline \multirow[t]{2}{*}{ GT } & 1 & -3.79 & 0.11 & -8.49 & 0.91 \\
\hline & $\begin{array}{l}2 \\
3\end{array}$ & -0.82 & 0.71 & -5.16 & 3.52 \\
\hline \multirow[t]{3}{*}{ S12 } & 1 & -1.77 & 0.01 & -3.11 & -0.44 \\
\hline & 2 & & & & \\
\hline & 3 & & & & \\
\hline \multirow[t]{3}{*}{ S34 } & 1 & -3.00 & 0.00 & -4.67 & -1.32 \\
\hline & 2 & 0.51 & 0.41 & -0.71 & 1.73 \\
\hline & 3 & & & & \\
\hline \multirow[t]{6}{*}{ USA } & 0 & -5.34 & 0.00 & -8.48 & -2.21 \\
\hline & 1 & -6.21 & 0.00 & -7.99 & -4.44 \\
\hline & 2 & -5.10 & 0.00 & -7.36 & -2.85 \\
\hline & 3 & -5.12 & 0.00 & -7.96 & -2.27 \\
\hline & 4 & -1.58 & 0.16 & -3.79 & 0.62 \\
\hline & 5 & & & & \\
\hline
\end{tabular}

${ }^{*}$ Model $=22.84+\mathrm{FH}+\mathrm{GT}+\mathrm{S} 12+\mathrm{S} 34+\mathrm{USA}$ [Error: 2.84]; Dependent variable: age 
APPENDICES

\subsection{Appendix IV - Polynomial regression models for females (left side only)}

\begin{tabular}{|c|c|c|c|c|c|}
\hline \multirow{2}{*}{\multicolumn{2}{|c|}{ Parameter }} & \multirow{2}{*}{ B } & \multirow{2}{*}{ Sig. } & \multicolumn{2}{|c|}{$95 \%$ Confidence Interval } \\
\hline & & & & Lower Bound & Upper Bound \\
\hline \multicolumn{2}{|c|}{ Intercept } & 22.11 & 0.00 & 21.17 & 23.06 \\
\hline \multirow[t]{2}{*}{ GT } & 1 & -3.87 & 0.00 & -6.04 & -1.70 \\
\hline & $\begin{array}{l}2 \\
3\end{array}$ & -1.07 & 0.26 & -2.95 & 0.80 \\
\hline \multirow[t]{2}{*}{ S23 } & 1 & -1.36 & 0.14 & -3.18 & 0.46 \\
\hline & $\begin{array}{l}2 \\
3\end{array}$ & 1.52 & 0.01 & 0.35 & 2.69 \\
\hline \multirow[t]{2}{*}{ S45 } & 1 & -3.03 & 0.00 & -4.72 & -1.33 \\
\hline & $\begin{array}{l}2 \\
3\end{array}$ & -1.03 & 0.02 & -1.91 & -0.14 \\
\hline \multirow[t]{2}{*}{ ISP } & 1 & -5.02 & 0.00 & -6.72 & -3.32 \\
\hline & $\begin{array}{l}2 \\
3\end{array}$ & -2.10 & 0.00 & -3.56 & -0.65 \\
\hline \multirow[t]{2}{*}{ ICE } & 1 & -7.83 & 0.00 & -9.50 & -6.17 \\
\hline & $\begin{array}{l}2 \\
3\end{array}$ & -4.87 & 0.00 & -5.79 & -3.95 \\
\hline
\end{tabular}

${ }^{*}$ Model = 22.11 + GT + S23 + S45 + ISP + ICE [Error: 2.34]; Dependent variable: age

\begin{tabular}{lccccc}
\hline Parameter & & B & Sig. & \multicolumn{2}{c}{$\begin{array}{c}\text { 95\% Confidence Interval } \\
\text { Lower Bound }\end{array}$} \\
& & 22.03 & 0.00 & 21.09 & 22.97 \\
Untercept & & -4.11 & 0.00 & -6.25 & -1.98 \\
GT & 2 & -1.30 & 0.17 & -3.14 & 0.54 \\
& 3 & & & & 0.39 \\
S23 & 1 & -1.40 & 0.12 & -3.20 & 2.64 \\
& 2 & 1.48 & 0.01 & 0.32 & -1.07 \\
S45 & 3 & & & & 0.14 \\
& 1 & -2.74 & 0.00 & -4.41 & -3.02 \\
ISP & 2 & -0.75 & 0.10 & -1.63 & -0.25 \\
& 3 & & & & \\
& 1 & -4.70 & 0.00 & -6.38 & -6.42 \\
FRE & 2 & -1.70 & 0.02 & -3.15 & -5.10 \\
& 3 & & & & -1.20 \\
& 0 & -8.07 & 0.00 & -9.71 & -3.16 \\
& 1 & -6.37 & 0.00 & -7.63 & -2.33 \\
& 2 & -3.87 & 0.00 & -6.53 & -6.24 \\
\hline
\end{tabular}

${ }^{\star}$ Model $=22.03+$ GT + S23 + S45 + ISP + FRE [Error: 2.30]; Dependent variable: age

\begin{tabular}{cccccc}
\hline Parameter & \multirow{2}{*}{ B } & Sig. & \multicolumn{2}{c}{$95 \%$ Confidence Interval } \\
Lower Bound & Upper Bound \\
\hline Intercept & & 20.44 & 0.00 & 19.87 & 21.01 \\
FH & 1 & -2.59 & 0.19 & -6.44 & 1.26 \\
& 2 & 0.64 & 0.70 & -2.65 & 3.92 \\
GT & 3 & & & & \\
& 1 & -3.76 & 0.20 & -9.48 & 4.97 \\
LT & 2 & -1.07 & 0.69 & -6.35 & -4.92 \\
& 3 & & & & -2.87 \\
& 1 & -10.06 & 0.00 & -15.20 & \\
\hline
\end{tabular}

${ }^{*}$ Model $=20.44+\mathrm{FH}+\mathrm{GT}+\mathrm{LT}$ [Error: 3.29]; Dependent variable: age 


\section{APPENDICES}

\begin{tabular}{|c|c|c|c|c|c|}
\hline \multirow{2}{*}{\multicolumn{2}{|c|}{ Parameter }} & \multirow{2}{*}{ B } & \multirow{2}{*}{ Sig. } & \multicolumn{2}{|c|}{ 95\% Confidence Interval } \\
\hline & & & & Lower Bound & Upper Bound \\
\hline \multicolumn{2}{|l|}{ Intercept } & 22.02 & 0.00 & 21.02 & 23.01 \\
\hline \multirow[t]{2}{*}{ GT } & 1 & -4.11 & 0.00 & -6.36 & -1.85 \\
\hline & $\begin{array}{l}2 \\
3\end{array}$ & -1.30 & 0.19 & -3.24 & 0.65 \\
\hline \multirow[t]{2}{*}{ S23 } & 1 & -2.23 & 0.02 & -4.10 & -0.36 \\
\hline & $\begin{array}{l}2 \\
3\end{array}$ & 0.65 & 0.28 & -0.53 & 1.84 \\
\hline \multirow[t]{2}{*}{ S45 } & 1 & -2.71 & 0.00 & -4.48 & -0.95 \\
\hline & $\begin{array}{l}2 \\
3\end{array}$ & -0.72 & 0.14 & -1.66 & 0.23 \\
\hline \multirow[t]{2}{*}{ ISP } & 1 & -4.71 & 0.00 & -6.48 & -2.93 \\
\hline & $\begin{array}{l}2 \\
3\end{array}$ & -1.70 & 0.03 & -3.24 & -0.17 \\
\hline \multirow[t]{6}{*}{ USA } & 0 & -7.25 & 0.00 & -8.96 & -5.55 \\
\hline & 1 & -5.53 & 0.00 & -6.87 & -4.19 \\
\hline & 2 & -4.71 & 0.00 & -7.52 & -1.90 \\
\hline & 3 & -4.00 & 0.01 & -6.83 & -1.18 \\
\hline & 4 & -3.61 & 0.00 & -5.29 & -1.93 \\
\hline & 5 & & & & \\
\hline \multicolumn{6}{|c|}{ 42]; Dependent variable: age } \\
\hline \multirow{2}{*}{\multicolumn{2}{|c|}{ Parameter }} & B & Siq. & $95 \%$ Confic & cee Interval \\
\hline & & & & Lower Bound & Upper Bound \\
\hline \multicolumn{2}{|l|}{ Intercept } & 19.26 & 0.00 & 14.51 & 24.01 \\
\hline \multirow[t]{2}{*}{ S12 } & 1 & 1.74 & 0.49 & -3.20 & 6.68 \\
\hline & $\begin{array}{l}2 \\
3\end{array}$ & 2.98 & 0.23 & -1.88 & 7.83 \\
\hline \multirow[t]{3}{*}{ S23 } & 1 & -1.67 & 0.08 & -3.56 & 0.22 \\
\hline & 2 & 1.43 & 0.02 & 0.21 & 2.65 \\
\hline & 3 & & & & \\
\hline \multirow[t]{2}{*}{ S45 } & 1 & -3.22 & 0.00 & -4.96 & -1.47 \\
\hline & $\begin{array}{l}2 \\
3\end{array}$ & -1.07 & 0.02 & -1.98 & -0.16 \\
\hline \multirow[t]{2}{*}{ ISP } & 1 & -6.80 & 0.00 & -8.18 & -5.42 \\
\hline & 2 & -2.33 & 0.00 & -3.68 & -0.98 \\
\hline \multirow[t]{3}{*}{ ICE } & 1 & -8.36 & 0.00 & -9.72 & -6.99 \\
\hline & 2 & -4.81 & 0.00 & -5.76 & -3.86 \\
\hline & 3 & & & & \\
\hline
\end{tabular}

${ }^{*}$ Model $=19.26+$ S12 + S23 + S45 + ISP + ICE [Error: 2.41]; Dependent variable: age

\begin{tabular}{|c|c|c|c|c|c|}
\hline \multirow{2}{*}{\multicolumn{2}{|c|}{ Parameter }} & \multirow{2}{*}{ B } & \multirow{2}{*}{ Sig. } & \multicolumn{2}{|c|}{ 95\% Confidence Interval } \\
\hline & & & & Lower Bound & Upper Bound \\
\hline \multicolumn{2}{|c|}{ Intercept } & 22.74 & 0.00 & 22.14 & 23.33 \\
\hline \multirow{2}{*}{$\mathrm{FH}$} & 1 & -1.71 & 0.25 & -4.60 & 1.18 \\
\hline & $\begin{array}{l}2 \\
3\end{array}$ & 1.02 & 0.39 & -1.34 & 3.38 \\
\hline \multirow[t]{2}{*}{ GT } & 1 & -3.76 & 0.02 & -6.95 & -0.56 \\
\hline & $\begin{array}{l}2 \\
3\end{array}$ & -1.75 & 0.20 & -4.42 & 0.92 \\
\hline \multirow[t]{2}{*}{ ISP } & 1 & -5.33 & 0.00 & -7.34 & -3.31 \\
\hline & $\begin{array}{l}2 \\
3\end{array}$ & -2.37 & 0.01 & -4.03 & -0.71 \\
\hline \multirow[t]{2}{*}{ ICE } & 1 & -7.90 & 0.00 & -9.65 & -6.16 \\
\hline & $\begin{array}{l}2 \\
3\end{array}$ & -4.68 & 0.00 & -5.63 & -3.73 \\
\hline
\end{tabular}

${ }^{*}$ Model $=22.74+$ FH + GT + ISP + ICE [Error: 2.58]; Dependent variable: age 
APPENDICES

\begin{tabular}{|c|c|c|c|c|c|}
\hline \multirow{2}{*}{\multicolumn{2}{|c|}{ Parameter }} & \multirow{2}{*}{ B } & \multirow{2}{*}{ Sig. } & \multicolumn{2}{|c|}{ 95\% Confidence Interval } \\
\hline & & & & Lower Bound & Upper Bound \\
\hline \multicolumn{2}{|c|}{ Intercept } & 19.26 & 0.00 & 14.57 & 23.95 \\
\hline \multirow[t]{2}{*}{ S12 } & 1 & 1.74 & 0.48 & -3.15 & 6.62 \\
\hline & $\begin{array}{l}2 \\
3\end{array}$ & 2.90 & 0.23 & -1.89 & 7.69 \\
\hline \multirow[t]{2}{*}{ S23 } & 1 & -1.73 & 0.07 & -3.60 & 0.14 \\
\hline & $\begin{array}{l}2 \\
3\end{array}$ & 1.38 & 0.03 & 0.17 & 2.60 \\
\hline \multirow[t]{2}{*}{ S45 } & 1 & -2.97 & 0.00 & -4.69 & -1.24 \\
\hline & $\begin{array}{l}2 \\
3\end{array}$ & -0.80 & 0.09 & -1.72 & 0.11 \\
\hline \multirow[t]{2}{*}{ ISP } & 1 & -6.66 & 0.00 & -8.02 & -5.29 \\
\hline & $\begin{array}{l}2 \\
3\end{array}$ & -2.05 & 0.00 & -3.40 & -0.71 \\
\hline \multirow[t]{6}{*}{ FRE } & 0 & -8.69 & 0.00 & -10.05 & -7.32 \\
\hline & 1 & -6.17 & 0.00 & -7.48 & -4.86 \\
\hline & 2 & -3.91 & 0.01 & -6.68 & -1.15 \\
\hline & 3 & -4.72 & 0.00 & -6.32 & -3.12 \\
\hline & 4 & -3.63 & 0.00 & -4.97 & -2.29 \\
\hline & 5 & & & & \\
\hline
\end{tabular}

${ }^{*}$ Model $=19.26+$ S12 + S23 + S45 + ISP + FRE [Error: 2.38]; Dependent variable: age

\begin{tabular}{|c|c|c|c|c|c|}
\hline \multirow{2}{*}{ Parameter } & & \multirow{2}{*}{ B } & \multirow{2}{*}{ Sig. } & \multicolumn{2}{|c|}{$95 \%$ Confidence Interval } \\
\hline & & & & Lower Bound & Upper Bound \\
\hline \multicolumn{2}{|l|}{ Intercept } & 19.26 & 0.00 & 14.33 & 24.19 \\
\hline \multirow{2}{*}{$\mathrm{S} 12$} & 1 & 1.72 & 0.51 & -3.41 & 6.85 \\
\hline & $\begin{array}{l}2 \\
3\end{array}$ & 2.89 & 0.26 & -2.15 & 7.93 \\
\hline \multirow[t]{2}{*}{$\mathrm{S} 23$} & 1 & -2.56 & 0.01 & -4.50 & -0.61 \\
\hline & $\begin{array}{l}2 \\
3\end{array}$ & 0.56 & 0.38 & -0.68 & 1.80 \\
\hline \multirow[t]{2}{*}{ S45 } & 1 & -2.94 & 0.00 & -4.77 & -1.12 \\
\hline & $\begin{array}{l}2 \\
3\end{array}$ & -0.78 & 0.11 & -1.76 & 0.19 \\
\hline \multirow[t]{2}{*}{ ISP } & 1 & -6.66 & 0.00 & -8.10 & -5.23 \\
\hline & $\begin{array}{l}2 \\
3\end{array}$ & -2.06 & 0.00 & -3.47 & -0.64 \\
\hline \multirow[t]{6}{*}{ USA } & 0 & -7.86 & 0.00 & -9.27 & -6.46 \\
\hline & 1 & -5.32 & 0.00 & -6.70 & -3.94 \\
\hline & 2 & -4.76 & 0.00 & -7.65 & -1.86 \\
\hline & 3 & -4.00 & 0.01 & -6.91 & -1.08 \\
\hline & 4 & -3.63 & 0.00 & -5.36 & -1.89 \\
\hline & 5 & & & & \\
\hline
\end{tabular}

${ }^{*}$ Model $=19.26+$ S12 + S23 + S45 + ISP + USA [Error: 2.50]; Dependent variable: age

\begin{tabular}{cccccc}
\hline Parameter & & B & Sig. & \multicolumn{2}{c}{ 95\% Confidence Interval } \\
Lower Bound & Upper Bound \\
\hline Intercept & & 22.74 & 0.00 & 22.09 & 23.38 \\
ISP & 1 & -8.79 & 0.00 & -10.23 & -7.36 \\
& 2 & -2.32 & 0.00 & -3.88 & -0.76 \\
FRE & 3 & & & & -7.25 \\
& 0 & -8.73 & 0.00 & -10.20 & -4.68 \\
& 1 & -6.12 & 0.00 & -7.56 & -0.58 \\
& 2 & -3.83 & 0.02 & -7.09 & -2.58 \\
& 3 & -4.45 & 0.00 & -6.31 & \\
\hline & 4 & -3.27 & 0.00 & -4.80 & \\
\hline
\end{tabular}

${ }^{*}$ Model $=22.74+$ ISP + FRE [Error: 2.81]; Dependent variable: age 


\section{APPENDICES}

\begin{tabular}{|c|c|c|c|c|c|}
\hline \multirow{2}{*}{\multicolumn{2}{|c|}{ Parameter }} & \multirow{2}{*}{ B } & \multirow{2}{*}{ Sig. } & \multicolumn{2}{|c|}{ 95\% Confidence Interval } \\
\hline & & & & Lower Bound & Upper Bound \\
\hline \multicolumn{2}{|c|}{ Intercept } & 22.74 & 0.00 & 22.15 & 23.32 \\
\hline \multirow[t]{2}{*}{$\mathrm{FH}$} & 1 & -1.87 & 0.20 & -4.71 & 0.98 \\
\hline & $\begin{array}{l}2 \\
3\end{array}$ & 0.85 & 0.47 & -1.47 & 3.18 \\
\hline \multirow[t]{2}{*}{ GT } & 1 & -3.91 & 0.01 & -7.06 & -0.77 \\
\hline & $\begin{array}{l}2 \\
3\end{array}$ & -1.89 & 0.16 & -4.52 & 0.74 \\
\hline \multirow[t]{2}{*}{ ISP } & 1 & -4.91 & 0.00 & -6.91 & -2.91 \\
\hline & $\begin{array}{l}2 \\
3\end{array}$ & -1.89 & 0.03 & -3.55 & -0.23 \\
\hline \multirow[t]{6}{*}{ FRE } & 0 & -8.00 & 0.00 & -9.72 & -6.28 \\
\hline & 1 & -6.19 & 0.00 & -7.50 & -4.87 \\
\hline & 2 & -3.83 & 0.01 & -6.78 & -0.89 \\
\hline & 3 & -4.45 & 0.00 & -6.13 & -2.76 \\
\hline & 4 & -3.27 & 0.00 & -4.65 & -1.89 \\
\hline & 5 & & & & \\
\hline
\end{tabular}

${ }^{\star}$ Model $=22.74+$ FH + GT + ISP + FRE [Error: 2.54]; Dependent variable: age

\begin{tabular}{|c|c|c|c|c|c|}
\hline \multirow{2}{*}{ Parameter } & & \multirow{2}{*}{ B } & \multirow{2}{*}{ Sig. } & \multicolumn{2}{|c|}{ 95\% Confidence Interval } \\
\hline & & & & Lower Bound & Upper Bound \\
\hline \multicolumn{2}{|l|}{ Intercept } & 22.19 & 0.00 & 21.63 & 22.74 \\
\hline \multirow[t]{2}{*}{$\mathrm{FH}$} & 1 & -1.87 & 0.21 & -4.82 & 1.08 \\
\hline & $\begin{array}{l}2 \\
3\end{array}$ & 0.85 & 0.49 & -1.56 & 3.26 \\
\hline \multirow[t]{2}{*}{ GT } & 1 & -3.92 & 0.02 & -7.18 & -0.65 \\
\hline & $\begin{array}{l}2 \\
3\end{array}$ & -1.89 & 0.17 & -4.62 & 0.83 \\
\hline \multirow[t]{2}{*}{ ISP } & 1 & -4.91 & 0.00 & -6.98 & -2.83 \\
\hline & $\begin{array}{l}2 \\
3\end{array}$ & -1.89 & 0.03 & -3.61 & -0.16 \\
\hline \multirow[t]{6}{*}{ USA } & 0 & -7.45 & 0.00 & -9.22 & -5.69 \\
\hline & 1 & -5.65 & 0.00 & -7.03 & -4.28 \\
\hline & 2 & -4.68 & 0.00 & -7.73 & -1.64 \\
\hline & 3 & -4.00 & 0.01 & -7.05 & -0.95 \\
\hline & 4 & -3.52 & 0.00 & -5.33 & -1.70 \\
\hline & 5 & & & & \\
\hline
\end{tabular}

${ }^{*}$ Model $=22.19+$ FH + GT + ISP + USA [Error: 2.63]; Dependent variable: age

\begin{tabular}{cccccc}
\hline Parameter & \multirow{2}{*}{ B } & Sig. & \multicolumn{2}{c}{ 95\% Confidence Interval } \\
Lower Bound & Upper Bound \\
\hline Intercept & & 19.26 & 0.00 & 13.40 & 25.12 \\
$\mathrm{FH}$ & 1 & -2.40 & 0.12 & -5.43 & 0.63 \\
& 2 & 0.80 & 0.57 & -1.94 & 3.54 \\
$\mathrm{LT}$ & 3 & & & & -7.05 \\
& 1 & -10.01 & 0.00 & -12.97 & -4.71 \\
$\mathrm{~S} 12$ & 2 & -6.90 & 0.00 & -9.09 & 7.04 \\
& 3 & & & & 8.73 \\
$\mathrm{~S} 23$ & 2 & 0.94 & 0.76 & -5.16 & -0.56 \\
& 3 & 2.74 & 0.37 & -3.25 & 1.20 \\
& 1 & -2.87 & 0.02 & -5.18 & -1.70 \\
$\mathrm{~S} 45$ & 3 & -0.26 & 0.73 & -1.71 & -1.37 \\
& 1 & -3.86 & 0.00 & -6.02 & \\
\hline
\end{tabular}

${ }^{*}$ Model $=19.26+\mathrm{FH}+\mathrm{LT}+\mathrm{S} 12+\mathrm{S} 23+\mathrm{S} 45$ [Error: 2.98]; Dependent variable: age 


\section{APPENDICES}

\begin{tabular}{cccccc}
\hline Parameter & \multirow{2}{*}{ B } & Sig. & \multicolumn{2}{c}{$95 \%$ Confidence Interval } \\
Lower Bound & Upper Bound \\
\hline Intercept & & 19.26 & 0.00 & 10.19 & 28.33 \\
S12 & 1 & -4.83 & 0.31 & -14.21 & 4.56 \\
& 2 & 3.23 & 0.49 & -6.04 & 12.50 \\
S23 & 3 & & & & -1.28 \\
& 1 & -4.83 & 0.01 & -8.38 & 1.12 \\
S45 & 2 & -1.13 & 0.32 & -3.37 & -5.54 \\
& 3 & & & & -4.63 \\
& 1 & -8.77 & 0.00 & -11.99 & \\
\hline
\end{tabular}

${ }^{\star}$ Model $=19.26+$ S12 + S23 + S45 [Error: 4.61]; Dependent variable: age

\begin{tabular}{cccccc}
\hline Parameter & B & Sig. & $\begin{array}{c}\text { 95\% Confidence Interval } \\
\text { Lower } \\
\text { Bound }\end{array}$ & $\begin{array}{c}\text { Upper } \\
\text { Bound }\end{array}$ \\
\hline Intercept & & 22.74 & 0.00 & 22.08 & 23.39 \\
ISP & 1 & -9.02 & 0.00 & -10.46 & -7.58 \\
& 2 & -2.66 & 0.00 & -4.22 & -1.10 \\
ICE & 3 & & & & -7.02 \\
& 1 & -8.50 & 0.00 & -9.99 & -3.61 \\
\hline
\end{tabular}

${ }^{*}$ Model $=22.74+$ ISP + ICE [Error: 2.84]; Dependent variable: age

\begin{tabular}{cccccc}
\hline Parameter & \multirow{2}{*}{ B } & Sig. & \multicolumn{2}{c}{ 95\% Confidence Interval } \\
Lower Bound & Upper Bound \\
\hline Intercept & & 22.19 & 0.00 & 21.58 & 22.79 \\
ISP & 1 & -8.79 & 0.00 & -10.27 & -7.31 \\
& 2 & -2.32 & 0.00 & -3.93 & -0.71 \\
USA & 3 & & & & -6.68 \\
& 0 & -8.18 & 0.00 & -9.68 & -4.08 \\
& 1 & -5.58 & 0.00 & -7.08 & -1.34 \\
& 2 & -4.68 & 0.01 & -8.03 & -0.66 \\
& 3 & -4.00 & 0.02 & -7.34 & -1.52 \\
\hline
\end{tabular}

${ }^{*}$ Model $=22.19+$ ISP + USA [Error: 2.89]; Dependent variable: age 


\section{APPENDICES}

\subsection{Appendix V - Transition analysis results for individual sexes (left side only)}

Table 8.3. Transition analysis of the fusion phase scores (right side) of the proximal femur, os coxa and iliac crest (individual and pooled sex).

\begin{tabular}{llllllll}
\hline \multicolumn{2}{l}{ Location \& } & Female & \multicolumn{3}{c}{ Male } & \multicolumn{2}{l}{ Combined } \\
Stage & & Age & SD & Age & SD & Age & SD \\
\hline FH & $1-2$ & 7.31 & 2.29 & 10.16 & 2.45 & 8.77 & 2.75 \\
& $2-3$ & 13.05 & 1.76 & 15.70 & 0.68 & 14.31 & 1.88 \\
GT & $1-2$ & 8.36 & 2.13 & 11.58 & 2.01 & 9.97 & 2.62 \\
& $2-3$ & 13.77 & 1.09 & 15.88 & 0.81 & 14.82 & 1.45 \\
LT & $1-2$ & 11.59 & 1.58 & 14.77 & 1.14 & 13.21 & 2.06 \\
& $2-3$ & 13.91 & 0.98 & 15.99 & 1.38 & 14.96 & 1.72 \\
ILIS & $1-2$ & 10.40 & 1.43 & 12.78 & 1.99 & 11.65 & 2.12 \\
& $2-3$ & 13.41 & 1.29 & 15.14 & 1.54 & 14.30 & 1.62 \\
ILP & $1-2$ & 10.49 & 1.46 & 13.01 & 1.82 & 11.79 & 2.07 \\
& $2-3$ & 13.42 & 1.29 & 15.65 & 0.94 & 14.53 & 1.58 \\
ISP & $1-2$ & 10.22 & 1.40 & 12.90 & 1.71 & 11.59 & 2.04 \\
& $2-3$ & 13.40 & 1.28 & 15.65 & 0.92 & 14.53 & 1.59 \\
AlIS & $1-2$ & 12.77 & 1.65 & 16.21 & 1.54 & 13.96 & 1.70 \\
& $2-3$ & 13.94 & 1.54 & 15.38 & 0.27 & 14.64 & 1.52 \\
ITE & $1-2$ & 13.19 & 1.30 & 15.42 & 0.60 & 14.27 & 1.47 \\
& $2-3$ & 15.13 & 1.41 & 16.19 & 1.00 & 15.66 & 1.38 \\
ICE & $1-2$ & 14.87 & 1.51 & 15.82 & 1.44 & 15.35 & 1.56 \\
& $2-3$ & 19.57 & 2.90 & 19.54 & 2.47 & 19.55 & 2.67 \\
FRE & $0-1$ & 14.88 & 1.50 & 15.79 & 1.41 & 15.33 & 1.56 \\
& $1-2$ & 16.66 & 1.80 & 16.86 & 1.58 & 16.77 & 1.76 \\
& $2-3$ & 16.79 & 2.65 & 17.66 & 2.08 & 17.31 & 2.35 \\
& $3-4$ & 18.02 & 2.77 & 18.71 & 2.70 & 18.40 & 2.72 \\
& $4-5$ & 19.54 & 2.97 & 19.63 & 2.25 & 19.57 & 2.58 \\
USA & $0-1$ & 14.88 & 1.51 & 15.80 & 1.41 & 15.34 & 1.55 \\
& $1-2$ & 16.55 & 1.77 & 16.80 & 1.46 & 16.67 & 1.65 \\
& $2-3$ & 16.76 & 2.23 & 17.45 & 2.17 & 17.10 & 2.25 \\
& $3-4$ & 17.04 & 2.58 & 17.77 & 2.23 & 17.43 & 2.43 \\
& $4-5$ & 18.02 & 2.79 & 18.69 & 2.70 & 18.37 & 2.76 \\
\hline & & & & & & & \\
& & & &
\end{tabular}

